US Army Corps

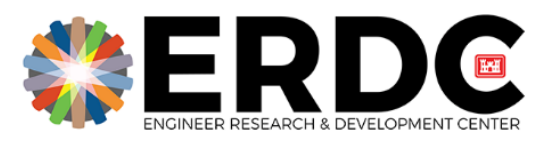
of Engineers ${ }_{\circledast}$

Engineer Research and

Development Center

\title{
Evaluation of Rapid-Setting Cementitious Materials and Testing Protocol for Airfield Spall Repair
}
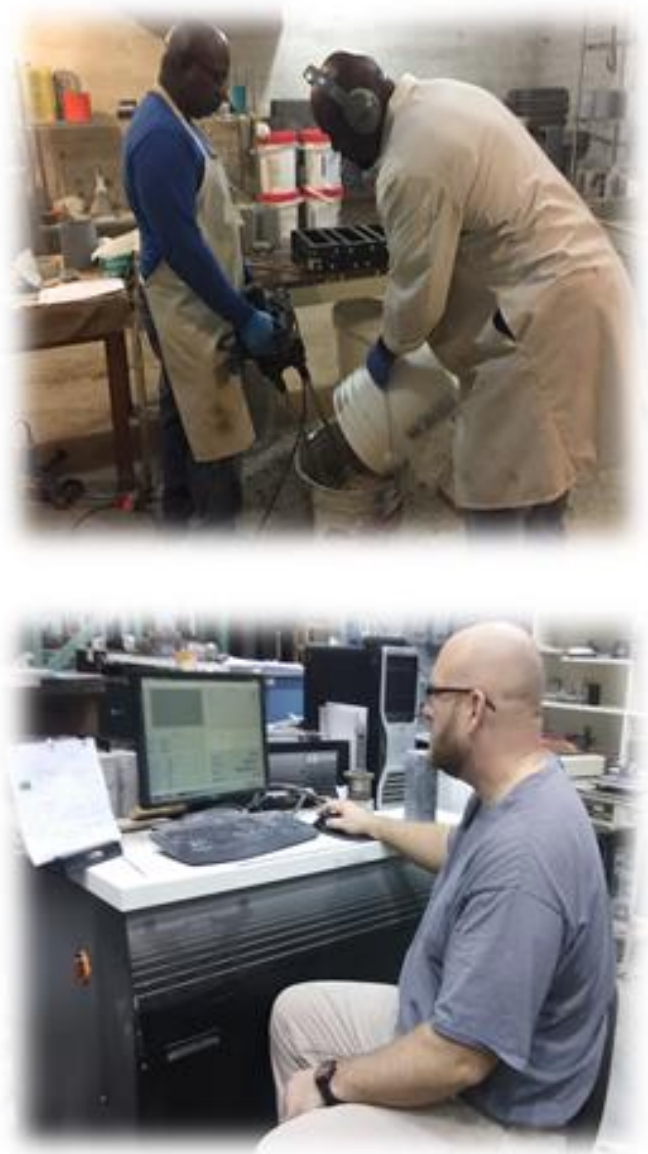
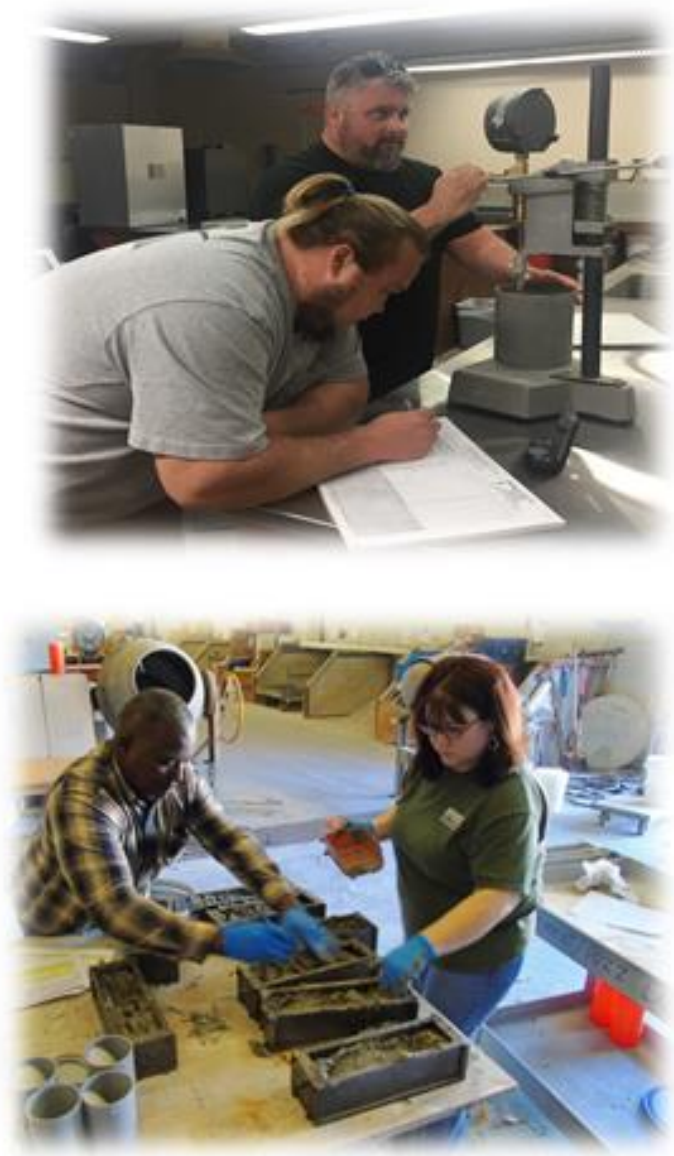
The U.S. Army Engineer Research and Development Center (ERDC) solves the nation's toughest engineering and environmental challenges. ERDC develops innovative solutions in civil and military engineering, geospatial sciences, water resources, and environmental sciences for the Army, the Department of Defense, civilian agencies, and our nation's public good. Find out more at www.erdc.usace.army.mil.

To search for other technical reports published by ERDC, visit the ERDC online library at http://acwc.sdp.sirsi.net/client/default. 


\title{
Evaluation of Rapid-Setting Cementitious
} Materials and Testing Protocol for Airfield Spall Repair

\author{
Monica A. Ramsey and Jeb S. Tingle \\ Geotechnical and Structures Laboratory \\ U.S. Army Engineer Research and Development Center \\ 3909 Halls Ferry Road \\ Vicksburg, MS 39180-6199 \\ Dr. Craig A. Rutland \\ Engineering Division \\ Civil Engineering Branch \\ Air Force Civil Engineering Center \\ 139 Barnes Drive, Suite 1 \\ Tyndall AFB, FL 32403
}

Final report

Approved for public release; distribution is unlimited.

\footnotetext{
Prepared for Headquarters, Air Force Civil Engineer Center 139 Barnes Avenue, Suite 1

Tyndall AFB, FL 32403-5319

Under MIPR\# F4ATA46021JW02
} 


\section{Abstract}

The rapid-setting cementitious material certification program is part of a research effort to assist the U.S. Air Force Civil Engineering Center in the execution of independent testing on select commercially available proprietary products to repair partial-depth spalls in airfield concrete pavements. The purpose of this research was to determine whether the existing requirements for evaluating rapid-repair products for spall repairs were sufficient or further refinement and modifications were needed. This protocol is intended to aid airfield managers and repair teams in the selection of optimal spall repair materials by maintaining a database of approved tested products.

This report presents the test methods and results of 26 cementitious rapid-setting repair products tested at the U.S. Army Engineer Research and Development Center in Vicksburg, MS, during 2013 to 2017. An evaluation of these test methods and results, along with the historic database of products tested, led to the development of an updated testing protocol for assessing a material's suitability for airfield spall repairs. Based on the revised criteria, 10 products were identified as most compatible for partial-depth airfield pavement concrete spall repairs.

DISCLAIMER: The contents of this report are not to be used for advertising, publication, or promotional purposes. Citation of trade names does not constitute an official endorsement or approval of the use of such commercial products. All product names and trademarks cited are the property of their respective owners. The findings of this report are not to be construed as an official Department of the Army position unless so designated by other authorized documents. 


\section{Contents}

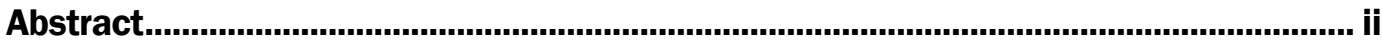

Figures and Tables..............................................................................................................

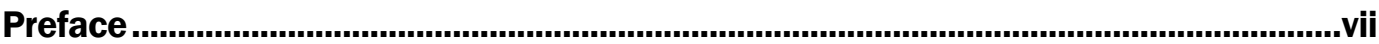

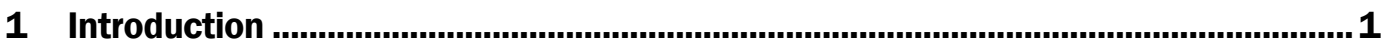

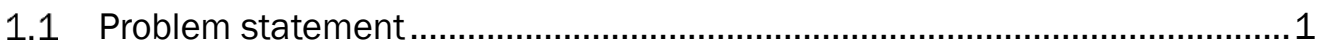

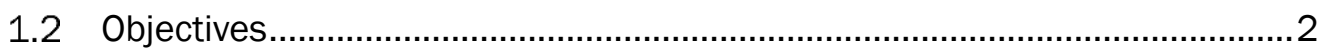

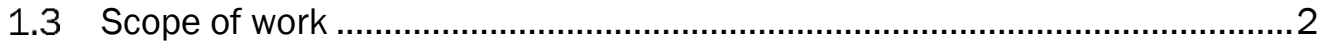

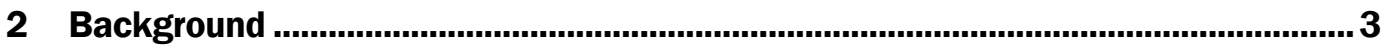

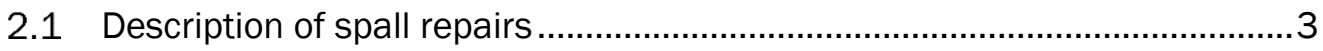

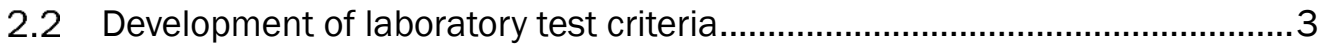

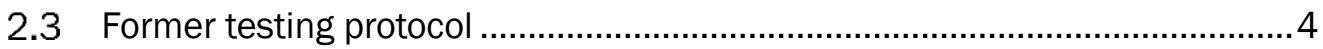

2.4 Historical database of approved/non-approved products .............................. 6

2.5 Continuation from previous research ....................................................... 8

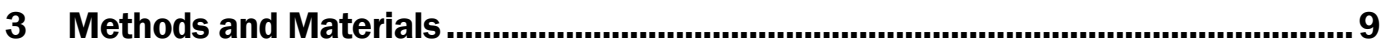

3.1 Methods for tier testing of cementitious materials .....................................

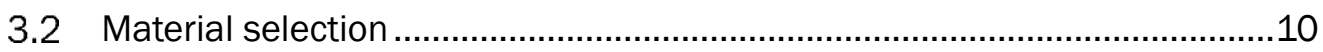

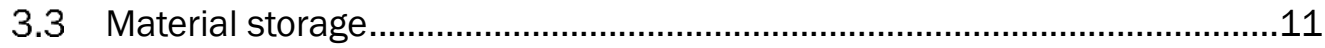

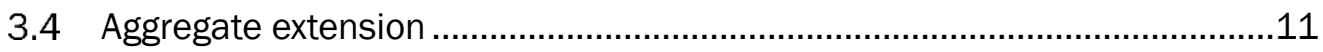

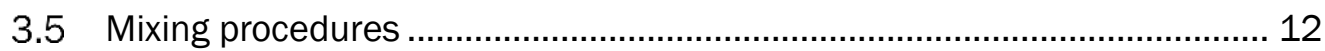

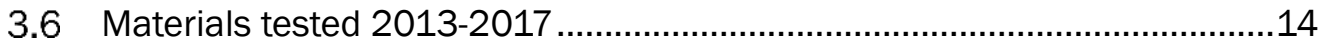

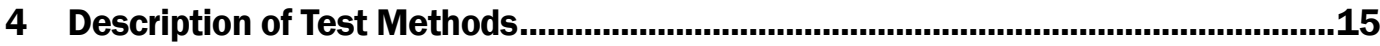

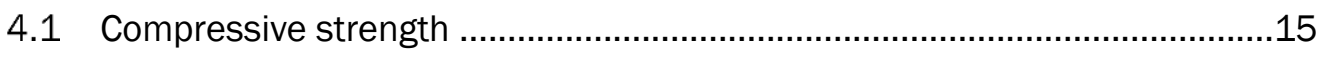

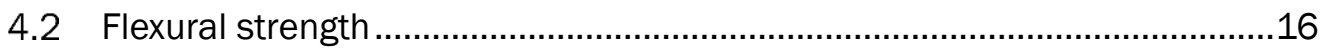

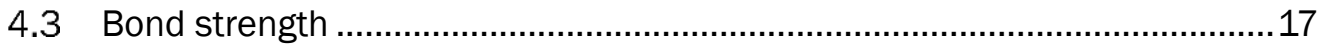

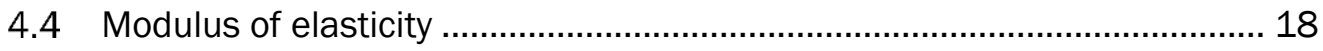

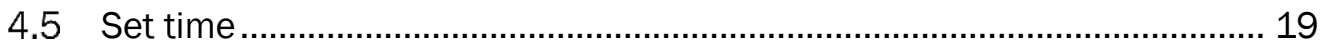

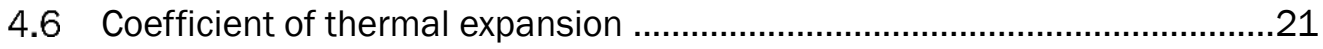

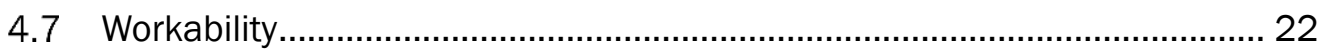

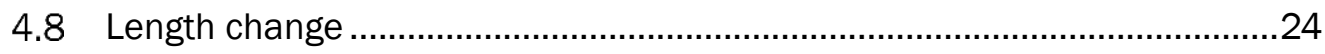

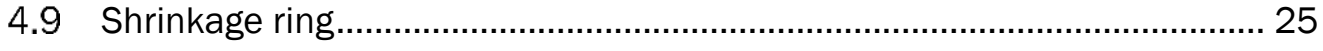

4.10 Freeze-thaw resistance ........................................................................... 26

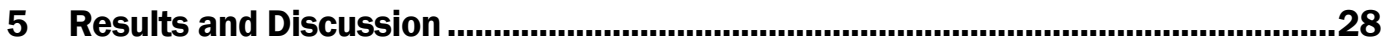

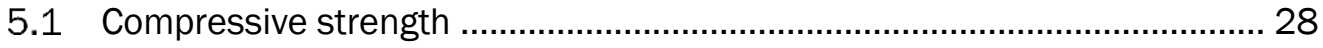

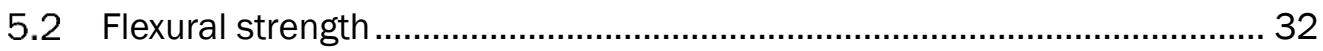

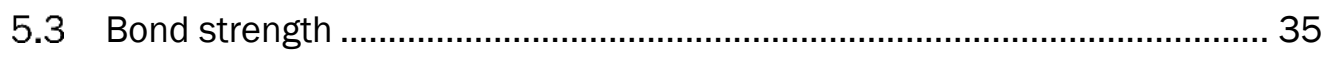




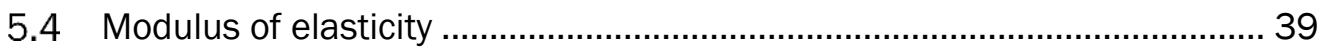

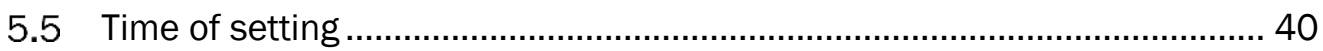

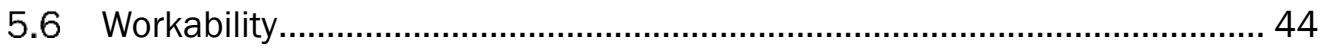

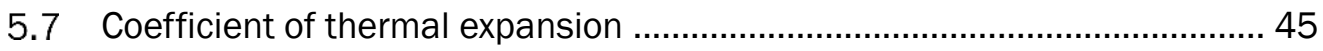

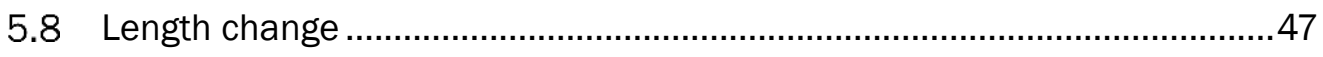

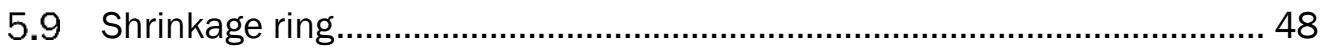

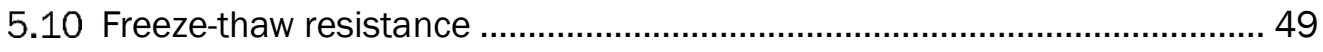

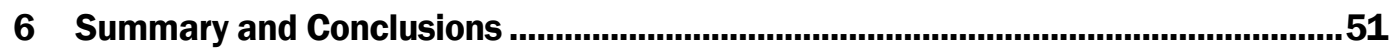

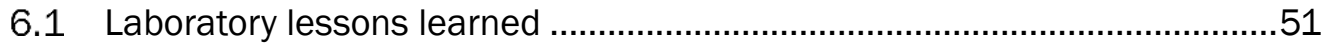

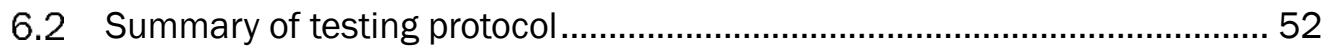

6.3 Summary of approved products ........................................................... 55

6.4 Other testing recommendations ........................................................... 55

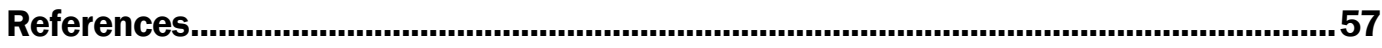

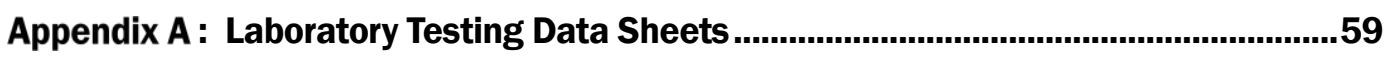

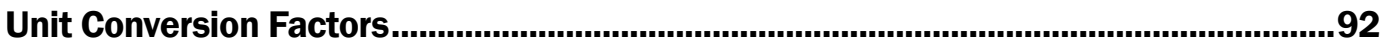

Report Documentation Page 


\section{Figures and Tables}

\section{Figures}

Figure 1. Properties of 3/8-in. pea gravel used to extend repair materials........................ 12

Figure 2. Laboratory mixing conducted by using Jiffy-type drill and paddle...................... 13

Figure 3. Laboratory mixing conducted by using small drum mixer. ................................ 13

Figure 4. Concrete cylinder undergoing compression strength test.................................. 16

Figure 5. Concrete beam undergoing flexural strength test............................................... 17

Figure 6. Composite bond strength and slant shear specimens...................................... 18

Figure 7. Concrete cylinder specimen undergoing modulus of elasticity test. ....................19

Figure 8. Set time demonstrated by penetrometer and Vicat methods. ...........................20

Figure 9. Coefficient of thermal expansion mortar bars specimens................................. 22

Figure 10. Workability demonstrated in accordance to (a) ASTM C143 and (b)

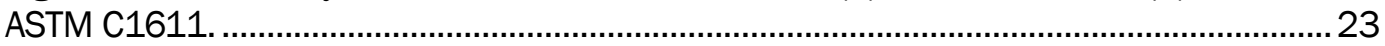

Figure 11. Length change specimen storage in air cure environment. ..............................25

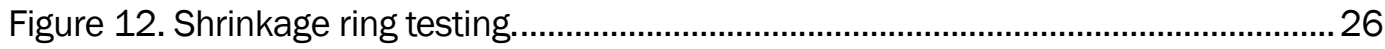

Figure 13. Freeze-thaw specimen undergoing testing for transverse frequency............... 27

Figure 14. Summary of compressive strength product comparison by age.......................30

Figure 15. Summary of flexural strength product comparison by age.................................34

Figure 16. Summary of bond strength product comparison by age................................... 37

Figure 17. Summary of time of setting product comparison based on ASTM C191.......... 42

Figure 18. Summary of time of setting product comparison based on ASTM

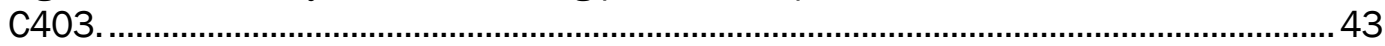

Figure 19. Flowchart of test requirements for workability................................................. 45

Figure 20. Comparison graph of CTE results and criteria limits......................................... 47

\section{Tables}

Table 1. Test requirements established in ETL 08-02 (AFCEC 2008).................................. 5

Table 2. Test requirements established in TR 11-13 (Priddy 2011)................................. 6

Table 3. Prior approved products based on tri-service website as of January 2017............ 7

Table 4. Prior non-approved products based on tri-service website as of January

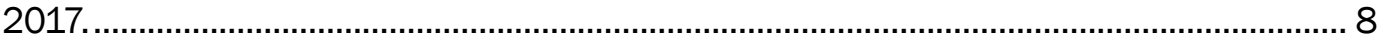

Table 5. Cementitious material tier testing approach........................................................ 9

Table 6. Summary of products tested in the laboratory during 2013-2017....................... 14

Table 7. Summary of compressive strength results..........................................................28

Table 8. Summary of flexural strength results.................................................................. 33

Table 9. Summary of bond strength results. …….......................................................... 36 
Table 10. Summary of modulus of elasticity results.......................................................... 39

Table 11. Summary of time of setting results........................................................................ 41

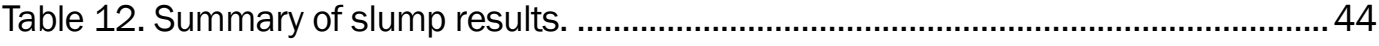

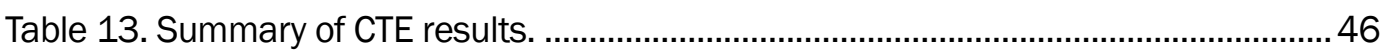

Table 14. Summary of length change results................................................................ 48

Table 15. Summary of shrinkage ring results................................................................. 49

Table 16. Summary of the freeze-thaw results.................................................................50

Table 17. Summary of updated test protocol for cementitious materials...........................53

Table 18. Comparison of former test criteria and new test criteria.....................................54

Table 19. Recommended approved products based on new test protocol.........................55

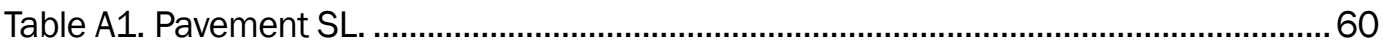

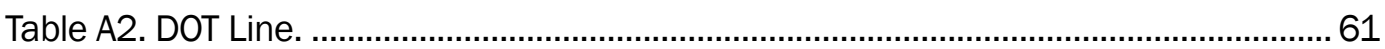

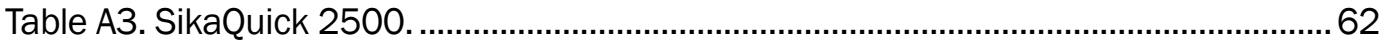

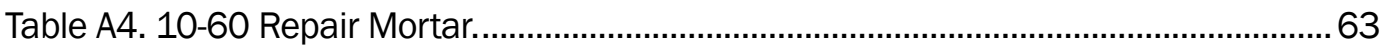

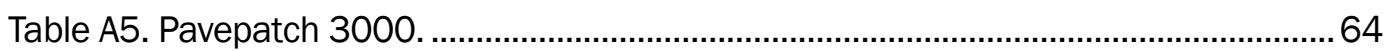

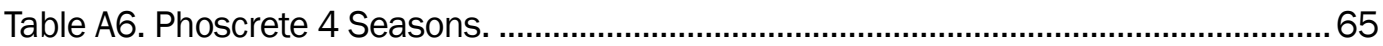

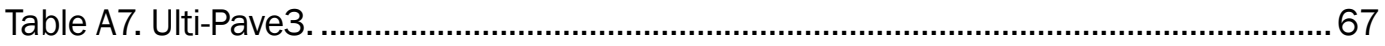

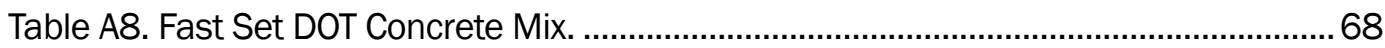

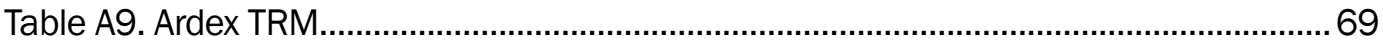

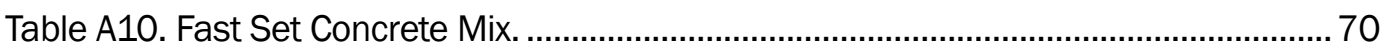

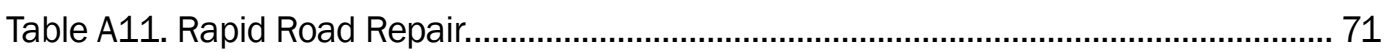

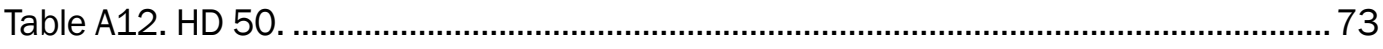

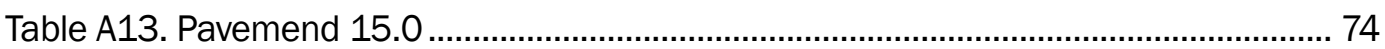

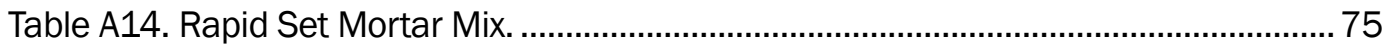

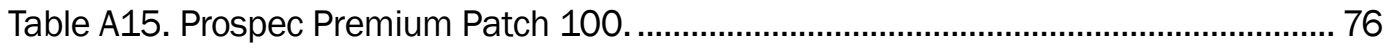

Table A16. Prospec Premium Patch 200 ...................................................................... 77

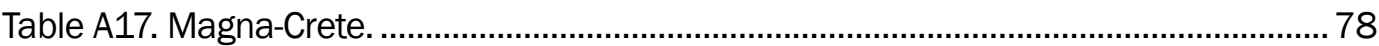

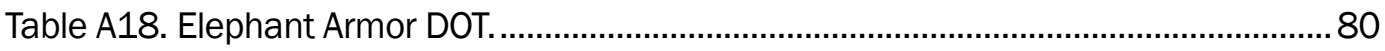

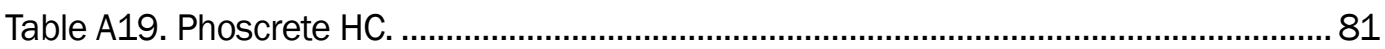

Table A20. FasTrac 246 Concrete.............................................................................. 82

Table A21. Magna-Crete............................................................................................. 83

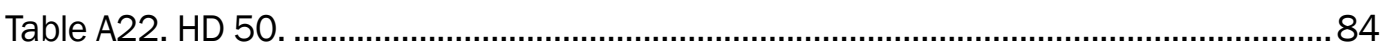

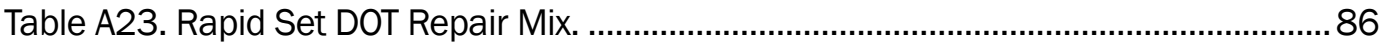

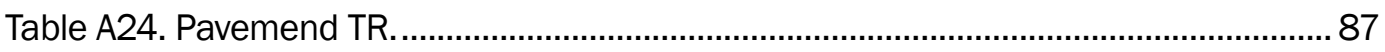

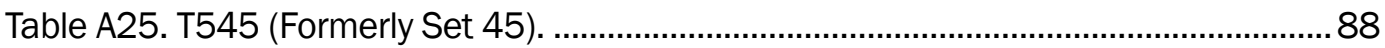

Table A26. T545T (Formerly Set 45HT) ......................................................................... 89

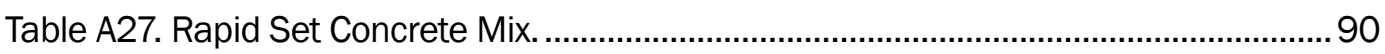

Table A28. T1061 (Formerly 10-61 Rapid Mix). ................................................................. 91 


\section{Preface}

This study was conducted using MIPR F4ATA46021JWo2 under the U.S. Air Force Civil Engineer Modernization Program sponsored by the Air Force Civil Engineer Center (AFCEC) located in Tyndall Air Force Base in Panama City, FL. The AFCEC technical manager was Dr. Craig A. Rutland.

The work was performed by the Airfields and Pavements Branch (GMA) and the Concrete and Materials Branch (GMC) of the Engineering Systems and Materials Division (GM), U.S. Army Engineer Research and Development Center, Geotechnical and Structures Laboratory (ERDCGSL). At the time of publication, Dr. Timothy W. Rushing was Chief, GMA; Mr. Christopher M. Moore was Chief, GMC; Mr. Justin S. Strickler was Chief, GM; and Mr. R. Nicholas Boone, GZT, was the Technical Director for Force Projection and Maneuver Support. The Deputy Director of the ERDC-GSL was Mr. Charles W. Ertle II, and the Director was Mr. Bartley P. Durst.

COL Teresa A. Schlosser was the Commander of ERDC, and Dr. David W. Pittman was the Director. 


\section{Introduction}

Selecting an optimal cementitious repair product to repair spalls rapidly in airfield concrete pavements can be difficult for military personnel, considering the number of available commercial proprietary products. Most are patented under trade names, making identification of the specific cementitious agent difficult to identify. In addition, proprietary products often evolve over time with reformulations and brand name changes. Material safety data sheets and product data results available from the manufacturer often offer limited information, focused only on the product's favorable properties and neglecting its less-favorable properties.

The testing protocol presented herein is necessary for DoD organizations to eliminate materials that have a low probability of success in the field. The field success of materials that pass this testing protocol cannot be guaranteed, but such materials could be considered to be worthy of field testing. The purpose of this report is to document the results of the products tested and to make recommendations concerning improvements that can be made in the test protocol for cementitious rapid-repair materials.

\subsection{Problem statement}

Rapid-repair technologies for airfield pavements have become critical to pavement repair and rehabilitation because of the demand to minimize the time in which the pavement is out of service. Rapid-repair products provide short setting times, high early-age strengths, and durability to withstand heavy loads. Due to this combination of advantageous characteristics, these materials exhibit great potential to meet the challenges of spall repairs in concrete pavements.

One potential issue with using rapid-repair products is that they can become brittle and prone to cracking, causing potential foreign object debris (FOD) damage to aircraft if a non-compatible product is used to repair the existing concrete pavement. The use of unproven products may not meet operational or mission requirements or may lead to economic losses by the government from repetitive or unscheduled repairs and application of materials that repair teams cannot effectively use. Proven products are also subject to the same risks from manufacturers' habitually repackaging or reformulating products. Unless the material has undergone 
recent testing to verify its properties, engineering personnel tasked to perform or monitor repair work cannot be confident that commercially available materials will meet performance expectations.

\subsection{Objectives}

The primary objective of this study was to conduct independent laboratory testing on the mechanical properties (compressive strength, flexural strength, bond strength, elastic modulus, and set time) and volumetric properties (length change, restrained shrinkage, and coefficient of thermal expansion) of a variety of rapid-setting cementitious materials in an effort to determine products most compatible for DoD airfield pavement spall repairs. Results of the products tested were then to be documented on summary data sheets and published on the tri-service transportation website, which DoD users can access at https://transportation.erdc.dren.mil/cacsites/TriService/pavement repair.aspx.

The secondary objective of this study was to further develop and refine the laboratory testing material protocol for identifying properties most important for material selection of cementitious rapid-repair materials. This was accomplished by fully assessing and comparing the test results for all methods used to test the rapid-setting repair materials.

\subsection{Scope of work}

The test protocol presented in this report is applicable only to the selection of products suitable for partial depth concrete spall repairs, defined further in the next chapter. Products are limited to only cementitious rapid-repair materials with a maximum aggregate size of $0.75 \mathrm{in}$. and do not include other rapid-repair families, such as polymeric or asphaltic products, due to the extensive differences in material properties. In addition, this protocol does not apply to larger repairs, such as crater or slab replacements, and does not address any field placement or construction methods. Users are encouraged to practice strict adherence to manufacturers' guidance. 


\section{Background}

The following section provides a background of the rapid-setting material testing program. Clarifying definitions are first provided, followed by the development of the laboratory test criteria section reprinted from ERDC TR 11-13 (Priddy 2011). Finally, the methodology for the evolution of the test protocol to identify properties of ideal rapid-repair materials is discussed.

\subsection{Description of spall repairs}

Spalls are described as concrete surface damage such as cracking, breaking, chipping, or fraying of the pavement that does not penetrate through the surface to the underlying layers or cause damage by upheaval of the surrounding pavement. A spall may be caused by a number of influencing factors including, but not limited to, fatigue due to impact of the aircraft, corrosion of metal joint inserts, aged joint sealant, incompressibles in the joint, misaligned dowel bars, reinforcing steel placed too near the surface, D-cracking, freeze-thaw damage, alkali-silica reaction (ASR), lack of consolidation of concrete near the joints, corrosion of reinforcing steel, or damage from munitions.

Spalls may be up to $5 \mathrm{ft}$. in diameter and typically require less than $1 \mathrm{ft}^{3}$ of repair material. Spalls may be either partial or full depth. Partial-depth repairs require restoration to areas usually within the upper one-third of the concrete slab depth. Full-depth spall repairs are more severe, sometimes requiring complete slab replacement. Depending on critical timing and service life requirement, a spall repair may be either temporary or permanent. Expedient spall repairs are made when a return to service is critical or resources are not available to perform a permanent repair. Typically these repairs are not properly saw cut to create a rectangular shape with clean edges, as with a permanent repair described in HQ Army, Navy, Air Force (2018). The durability and long-term performance may suffer with these expedient repairs. The scope of this report is intended to treat partial-depth spalls for permanent repairs.

\subsection{Development of laboratory test criteria}

In order to compare repair materials and evaluate the materials for use in airfield pavement repairs, laboratory testing was necessary to determine 
the basic material properties of each candidate material. Previous studies have identified numerous tests applicable for repair materials.

In 1991, the Federal Highway Administration (FHWA) identified compressive strength, flexural strength, modulus of elasticity, Poisson's ratio, bond strength, thermal compatibility, length change, resistance to freezing and thawing, and resistance to abrasion and scaling as important performance characteristics for repair materials (Wilson et al. 1999). Another study recommended testing compressive and flexural strength, set time, and shear bond (Beer et al. 1984) to evaluate material performance.

In 1992, the Waterways Experiment Station (WES) evaluated 12 cementitious and polymeric materials under the Repair, Evaluation, Maintenance, and Rehabilitation (REMR) Program to identify applicable laboratory tests and minimum test results for use in selecting repair materials (WES 1992). Testing performed under this program identified compressive strength, modulus of elasticity, shrinkage, creep, thermal compatibility, and flexural strength as applicable tests for repair materials. Out of these tests, required values were recommended for compressive strength, tensile strength, and drying shrinkage (Vaysburd et al. 1999).

In 2006, the U.S. Air Force released a draft engineering technical letter (ETL) identifying compressive strength, bond strength, thermal compatibility, shrinkage potential, and freeze-thaw resistance as the most important characteristics to evaluate in comparing cementitious, rapidsetting materials for spall repairs. The requirements set forth in GSL TR11-13 (Priddy 2011) were based on laboratory and field testing conducted during 2005 and 2006 by personnel at ERDC. Results from the tests were compared to requirements produced under the REMR Program (WES 1992; Vaysburd et al. 1999).

\subsection{Former testing protocol}

The purpose of this research was to determine whether the existing requirements set forth in the ETL 08-02 (AFCEC 2008) or adapted from TR-11-13 (Priddy 2011), shown in Table 1 and Table 2, respectively, were sufficient or modifications were needed. 
Table 1. Test requirements established in ETL 08-02 (AFCEC 2008).

\begin{tabular}{|c|c|c|}
\hline Property & ASTM & Requirement \\
\hline Compressive Strength & C39 & $\begin{array}{l}\geq 3,000 \text { psi } \\
\text { Test at age of } 2 \text { hours } \\
\geq 5,000 \text { psi } \\
\text { Test at age of } 1 \text { day }\end{array}$ \\
\hline Flexural Strength & $\mathrm{C} 78$ & $\begin{array}{l}\geq 350 \text { psi } \\
\text { Test at ages of } 2 \text { hours and } 1 \text { day }\end{array}$ \\
\hline Bond Strength & C882 & $\begin{array}{l}\geq 850 \text { psi (repair bonding to OPC mortar) } \\
\geq 1,000 \text { psi (repair material bonding to repair material) } \\
\text { Test at age of } 1 \text { day }\end{array}$ \\
\hline Modulus of Elasticity & C469 & $\begin{array}{l}\leq 3 \times 10^{6} \mathrm{psi} \\
\text { Test at age of } 2 \text { hours } \\
\leq 4 \times 10^{6} \mathrm{psi} \\
\text { Test at age of } 3 \text { days }\end{array}$ \\
\hline & C531 & $\begin{array}{l}\leq 7 \times 10^{-6} \mathrm{in} / \mathrm{in} /{ }^{\circ} \mathrm{F} \\
\text { Test begins at age of } 3 \text { days }\end{array}$ \\
\hline & C157 & $\begin{array}{l}<0.03 \% \\
\text { Test begins at age of } 4 \text { days }\end{array}$ \\
\hline Shrinkage Potential & C1581 & $\begin{array}{l}\leq 40 \text { microstrain at } 14 \text { days and no cracking at } 28 \text { days } \\
\text { Test begins at time of casting }\end{array}$ \\
\hline $\begin{array}{l}\text { Freeze-Thaw } \\
\text { Resistance }\end{array}$ & C666 & $\begin{array}{l}\text { No requirement at this time }{ }^{1} \\
\text { Test begins at age of } 3 \text { days }\end{array}$ \\
\hline Time of Setting & C191 & $\begin{array}{l}\text { No requirement at this time }{ }^{2} \\
\text { Test begins immediately }\end{array}$ \\
\hline \multicolumn{3}{|c|}{$\begin{array}{l}1 \text { Depending on results that are gathered for the database, a possible requirement designed to } \\
\text { eliminate materials that are extremely susceptible to freeze-thaw damage would be }<=50 \% \text { loss in } \\
\text { relative dynamic modulus of elasticity after } 50 \text { cycles. } \\
{ }^{2} \text { Report initial and final set times in minutes. } \\
\text { Note: Some requirements were adapted from those produced by research conducted under the } \\
\text { Repair, Evaluation, Maintenance, and Rehabilitation Research Program. Reference: Vaysbur, A.M., } \\
\text { Emmons, P.H., McDonald, J.E., Poston, R.W., and Kesner, K.E. (1999). Performance Criteria for } \\
\text { Concrete Repair Materials, Phase II Summary Report, Technical Report REMR-CS-62, U.S. Army } \\
\text { Waterways Experiment Station, Vicksburg, MS. }\end{array}$} \\
\hline
\end{tabular}


Table 2. Test requirements established in TR 11-13 (Priddy 2011).

\begin{tabular}{|c|c|c|c|c|c|}
\hline \multirow[b]{2}{*}{ Property } & \multirow[b]{2}{*}{ ASTM } & \multicolumn{2}{|c|}{ Temporary Repairs } & \multicolumn{2}{|c|}{ Permanent Airfield Repairs } \\
\hline & & Crater Repair & Expeditionary Spall Repair & Primary Runways and Taxiways & $\begin{array}{l}\text { Secondary Runways, Secondary } \\
\text { Taxiways, } \\
\text { and Parking Aprons }\end{array}$ \\
\hline $\begin{array}{l}\text { Compressive } \\
\text { strength }\end{array}$ & C 39 & $\begin{array}{l}\geq 3,000 \mathrm{psi} \text { at age of } 2 \mathrm{hra} \\
\geq 5,000 \mathrm{psi} \text { at age of } 1 \text { day }\end{array}$ & $\begin{array}{l}\text { No laboratory requirement at } \\
\text { this time. Requires field testing } \\
\text { prior to approval. }\end{array}$ & $\begin{array}{l}\geq 3,000 \mathrm{psi} \text { at } 2 \mathrm{hr} \text { or at age } \\
\text { of opening } \\
\geq 5,000 \mathrm{psi} \text { at age of } 1 \text { day }\end{array}$ & $\begin{array}{l}\geq 3,000 \text { psi at specified age of } \\
\text { opening } \\
\geq 5,000 \text { psi at age of } 7 \text { days and } 28 \\
\text { days }\end{array}$ \\
\hline Flexural strength & C 78 & Not required & Not required & $\begin{array}{l}\geq 350 \mathrm{psi} \text { at age of } 2 \mathrm{hr} \\
\geq 600 \mathrm{psi} \text { at age of } 7 \text { days and } \\
28 \text { days } \\
\text { Full-slab replacement only }\end{array}$ & $\begin{array}{l}\geq 350 \text { psi at specified age of opening } \\
\geq 600 \text { psi at age of } 7 \text { days and } 28 \\
\text { days } \\
\text { Full-slab replacement only }\end{array}$ \\
\hline Bond strength & C 882 & $\begin{array}{l}\geq 1,000 \mathrm{psi} \text { (repair bonding to } \\
\text { OPC mortar) } \\
\geq 1,000 \mathrm{psi} \text { (repair material } \\
\text { bonding to repair material) } \\
\text { Test at age of } 1 \text { day. }\end{array}$ & $\begin{array}{l}\geq 1,000 \text { psi (repair bonding to } \\
\text { OPC mortar) } \\
\geq 1,000 \text { psi (repair material } \\
\text { bonding to repair material) } \\
\text { Test at age of } 1 \text { day. }\end{array}$ & $\begin{array}{l}\geq 1,000 \text { psi (repair bonding to } \\
\text { OPC mortar) } \\
\geq 1,000 \text { psi (repair material } \\
\text { bonding to repair material) } \\
\text { Test at age of } 1 \text { day. }\end{array}$ & $\begin{array}{l}\geq 1,000 \mathrm{psi} \text { (repair bonding to OPC } \\
\text { mortar) } \\
\geq 1,000 \text { psi (repair material bonding to } \\
\text { repair material) } \\
\text { Test at age of } 1 \text { day. }\end{array}$ \\
\hline $\begin{array}{l}\text { Modulus of } \\
\text { elasticity }\end{array}$ & C 469 & $\begin{array}{l}2 \times 10^{6} \text { to } 6 \times 10^{6} \mathrm{psi} \\
\text { Test at age } 2 \mathrm{hr} \text { and } 28 \text { days. }\end{array}$ & $\begin{array}{l}2 \times 10^{6} \text { to } 6 \times 10^{6} \mathrm{psi} \\
\text { Test at age } 2 \mathrm{hr} \text { and } 28 \text { days. }\end{array}$ & $\begin{array}{l}2 \times 10^{6} \text { to } 6 \times 10^{6} \mathrm{psi} \\
\text { Test at age } 2 \mathrm{hr} \text { and } 28 \text { days. }\end{array}$ & $\begin{array}{l}2 \times 10^{6} \text { to } 6 \times 10^{6} \mathrm{psi} \\
\text { Test at age } 2 \mathrm{hr} \text { and } 28 \text { days. }\end{array}$ \\
\hline \multirow[t]{2}{*}{$\begin{array}{l}\text { Volumetric } \\
\text { expansion }\end{array}$} & C 531 & $\begin{array}{l}\leq 12 \times 10^{-6} \mathrm{in} . / \mathrm{in} . /{ }^{\circ} \mathrm{F} \\
\text { Test begins at age of } 7 \text { days. }\end{array}$ & $\begin{array}{l}\leq 12 \times 10^{-6} \mathrm{in} . / \mathrm{in} . /{ }^{\circ} \mathrm{F} \\
\text { Test begins at age of } 7 \text { days. }\end{array}$ & $\begin{array}{l}\leq 12 \times 10^{-6} \mathrm{in} . / \mathrm{in} . /{ }^{\circ} \mathrm{F} \\
\text { Test begins at age of } 7 \text { days. }\end{array}$ & $\begin{array}{l}\leq 12 \times 10^{-6} \mathrm{in} . / \mathrm{in} . /{ }^{\circ} \mathrm{F} \\
\text { Test begins at age of } 7 \text { days. }\end{array}$ \\
\hline & C 157 & $\begin{array}{l}<+0.03 \% \text { expansion or } \\
<-0.04 \% \text { shrinkage @ } 28 \text { days }\end{array}$ & $\begin{array}{l}<+0.03 \% \text { expansion or } \\
<-0.04 \% \text { shrinkage @ } 28 \text { days }\end{array}$ & $\begin{array}{l}<+0.03 \% \text { expansion or } \\
<-0.04 \% \text { shrinkage @ } 28 \text { days }\end{array}$ & $\begin{array}{l}<+0.03 \% \text { expansion or }<-0.04 \% \\
\text { shrinkage @ } 28 \text { days }\end{array}$ \\
\hline Shrinkage potential & C 1581 & $\begin{array}{l}\leq 40 \text { microstrain at } 14 \text { days } \\
\text { and no cracking at } 28 \text { days } \\
\text { Test begins at time of casting. }\end{array}$ & $\begin{array}{l}\leq 40 \text { microstrain at } 14 \text { days and } \\
\text { no cracking at } 28 \text { days } \\
\text { Test begins at time of casting. }\end{array}$ & $\begin{array}{l}\leq 40 \text { microstrain at } 14 \text { days and } \\
\text { no cracking at } 28 \text { days } \\
\text { Test begins at time of casting. }\end{array}$ & $\begin{array}{l}\leq 40 \text { microstrain at } 14 \text { days and no } \\
\text { cracking at } 28 \text { days } \\
\text { Test begins at time of casting. }\end{array}$ \\
\hline $\begin{array}{l}\text { Freeze-thaw } \\
\text { resistance }\end{array}$ & C 666 & Not required & Not required & No requirement at this time & No requirement at this time \\
\hline Time of settingb & C 191 & $\begin{array}{l}15 \text { min initial set } \\
25 \text { to } 35 \text { min final set }\end{array}$ & Not required & $\begin{array}{l}15 \text { min initial set } \\
25 \text { to } 35 \text { min final set }\end{array}$ & $\begin{array}{l}15 \text { min initial set } \\
25 \text { to } 35 \text { min final set }\end{array}$ \\
\hline slump & C143 & Record slump & Record slump & Record slump & Record slump \\
\hline \multicolumn{6}{|c|}{$\begin{array}{l}1 \text { Field verification of material performance can be used in lieu of achievement of the test requirements. Consult } \\
\text { https://transportation.wes.army.mil/triservice/pavement repair.aspx. for a list of approved products. }\end{array}$} \\
\hline
\end{tabular}

It is important to note the products tested and reported in TR-11-13 (Priddy 2011) were conducted for a variety of permanent and temporary repairs including spalls, small patches, large patches, and slab replacement. In addition, special testing was conducted specifically for expeditionary spall repairs. As mentioned previously, this study identified products most suitable for only permanent spall repairs. Temporary repairs and larger placements for craters were outside the scope of work for this investigation.

\subsection{Historical database of approved/non-approved products}

The first approach to reviewing the criteria of the existing protocol was to compile historic data for the products tested. As of January 2017, the triservice database had published 23 approved cementitious products and 16 non-approved products as listed in Table 3 and Table 4, respectively. Upon review of summary datasheets, several of the approved products did not meet the limits of some of the existing protocol's passing criteria, and 
many products had limited test data. The previous approvals of many products were based on good field performance.

Table 3. Prior approved products based on tri-service website as of January 2017.

\begin{tabular}{|c|c|c|c|}
\hline No. & Product & Manufacturer & Year Tested \\
\hline 1 & MasterEmaco T1060 & BASF & 2007 \\
\hline 2 & Rapid Set DOT Repair Mix & CTS Cement Corp. & 2007 \\
\hline 3 & MasterEmaco T545HT & BASF & 2007 \\
\hline 4 & MasterEmaco T545 & BASF & 2007 \\
\hline 5 & MasterEmaco T1061 & BASF & 2007 \\
\hline 6 & Pavepatch 3000 & Dayton Superior Corp. & 2008 \\
\hline 7 & Pavemend SLQ & CeraTech Inc. & 2008 \\
\hline 8 & SikaQuick 2500 & Sika Corp. & 2008 \\
\hline 9 & Pavemend TR & CeraTech Inc. & 2008 \\
\hline 10 & Versapeed & Euclid Chemical Co. & 2008 \\
\hline 11 & Ultimax Concrete Mix & Ultimax Cement & 2008 \\
\hline 12 & Great White & CeraTech Inc. & 2009 \\
\hline 13 & Fast Set DOT Concrete Mix & Quickcrete Companies & 2010 \\
\hline 14 & Rapid Set Concrete Mix & CTS Cement Corp. & 2010 \\
\hline 15 & DOTLine & Cera Tech, Inc. & 2013 \\
\hline 16 & Pavepatch 3000 & Dayton Superior Corp. & 2013 \\
\hline 17 & MasterEmaco T1060 & BASF & 2013 \\
\hline 18 & Ulti-Pave3 & Buzzi-Unicem USA Inc. & 2014 \\
\hline 19 & HD 50 & Dayton Superior Corp. & 2015 \\
\hline 20 & ProSpec Premium Patch 200 & H.B. Fuller Construction Products Inc. & 2015 \\
\hline 21 & Rapid Set Mortar Mix & CTS Cement Corp. & 2015 \\
\hline 22 & $\begin{array}{c}\text { Elephant Armor DOT } \\
\text { Industrial Grade Mortar }\end{array}$ & GST International & 2016 \\
\hline 23 & FasTrac 246 Concrete & Western Material and Design LLC & 2016 \\
\hline
\end{tabular}


Table 4. Prior non-approved products based on tri-service website as of January 2017.

\begin{tabular}{|c|c|c|c|}
\hline No. & Product & Manufacturer & Year Tested \\
\hline 1 & Pavemend EX-H & CeraTech, Inc. & 2007 \\
\hline 2 & Futura 15 & W.R. Meadows & 2008 \\
\hline 3 & Pavemend VR & CeraTech, Inc. & 2008 \\
\hline 4 & Mainline & CeraTech, Inc. & 2009 \\
\hline 5 & FasTrac & Western Material and Design, LLC & 2010 \\
\hline 6 & Speedcrete 2028 & Euclid Chemical Co. & 2010 \\
\hline 7 & Veraspeed LS & Euclid Chemical Co. & 2012 \\
\hline 8 & Pavemend SL & Cera Tech, Inc. & 2013 \\
\hline 9 & Phoscrete 4 Seasons & Phoscrete Corp. & 2013 \\
\hline 10 & Ardex TRM & Ardex Americas & 2014 \\
\hline 11 & Fast Set Concrete Mix & Quikcrete Companies & 2014 \\
\hline 12 & Rapid Road Repair & Quikcrete Companies & 2014 \\
\hline 13 & Magna-Crete & Henkel Americas & 2015 \\
\hline 14 & Pavemend 15 & Cera Tech, Inc. & 2015 \\
\hline 15 & Prospec Premium Patch 100 & H.B. Fuller Construction Products & 2015 \\
\hline 16 & Express Repair & Euclid Chemical Co. & NA \\
\hline
\end{tabular}

\subsection{Continuation from previous research}

It was expected that the testing protocol would evolve over time as it was put into use and data for test materials accumulated. The present study is a continuation of previous research to further improve the methods for assessing suitable materials for airfield spall repair. Some of the test methods and/or test ages have been changed or modified due to the nature of the rapid-repair materials. Any differences are noted in Chapter 4, "Description of Test Methods" and further detailed in Chapter 5, "Results and Discussion." As a result of this continued research, an updated test protocol has emerged for cementitious rapid-setting repair materials. The products evaluated in the ERDC testing laboratory from 2013-2017 were published as summary data sheets to the tri-service pavement website upon completion and documented in Appendix A of this report. 


\section{Methods and Materials}

Since the development of the laboratory testing criteria for evaluating cementitious, rapid-setting pavement repair materials, the majority of the laboratory testing has been conducted in accordance to the protocol requirements established in ETL-o8-02 (AFCEC 2008) and as reported in GSL TR-11-13 (Priddy 2011).

The methods for the majority of the laboratory tests conducted from 2013 to 2017 were based on a three-tier sequence of selected tests described in this chapter. The details of the material selection, storage, and mixing procedures are also presented in this chapter. The manufacturer's technical specification sheet of each material was strictly followed for the mixture proportioning, necessary equipment, proper substrate preparation, and curing of the test specimens. Finally, a summary of the materials tested from 2013 to 2017 is provided.

\subsection{Methods for tier testing of cementitious materials}

Due to the cost and time requirements of the numerous tests described in the following table, a three-tiered system was used to best balance the requirements to obtain results on the maximum number of products. Table 5 details the breakdown of the cementitious material tier testing approach.

Table 5. Cementitious material tier testing approach.

\begin{tabular}{|c|c|c|}
\hline \multicolumn{3}{|c|}{ Tier 1 Tests } \\
\hline Test Name & Measured Property & Specification \\
\hline Compressive Strength & Operational, Mechanical & ASTM C39 \\
\hline Flexural Strength & Operational, Mechanical & ASTM C78 \\
\hline Bond Strength & Mechanical & ASTM C882 \\
\hline Elastic Modulus & Mechanical & ASTM C469 \\
\hline Set Time & Workability & ASTM C191 \\
\hline Slump & Workability & ASTM C143 \\
\hline \multicolumn{2}{|c|}{ Tier 2 Tests } & Specification \\
\hline Test Name & Measured Property & ASTM C531 \\
\hline
\end{tabular}




\begin{tabular}{|c|c|c|}
\hline Length Change & Durability, Operational & ASTM C157 \\
\hline Restrained Shrinkage & Durability & ASTM C1581 \\
\hline \multicolumn{2}{|c|}{ Recommended } \\
\hline Test Name & Measured Property & Specification \\
\hline Freeze-Thaw & Durability & ASTM C666 \\
\hline Scaling & Durability & ASTM C672 \\
\hline $\begin{array}{c}\text { Variations in Environmental } \\
\text { Temperature }\end{array}$ & $\begin{array}{c}\text { Production, Operational, } \\
\text { Workability }\end{array}$ & - \\
\hline Variation in Batch Water & $\begin{array}{c}\text { Production, Operational, } \\
\text { Workability, Mechanical }\end{array}$ & - \\
\hline
\end{tabular}

This three-tiered procedure was used as a performance checkpoint, where the most economical performance measures were tested first, followed by the more extensive and time-consuming laboratory testing. A product was considered for further testing if it passed tier 1 tests. The goal of the tiered procedure was to efficiently gather pertinent material performance information and filter out poorly performing materials along the course of the evaluation.

In the first tier, the repair materials' individual properties of compressive strength, flexural strength, bond strength, modulus of elasticity, time, and workability were determined by using standard ASTM test procedures. In the second tier, volumetric properties of length change, shrinkage resistance, and coefficient of thermal expansion were determined also by using standard ASTM test procedures. The third tier of testing was recommended durability tests of freeze-thaw resistance and scaling and sensitivity to temperature and water variations. Of the recommended tests, only the freeze-thaw test was performed on some of the products in this report.

\subsection{Material selection}

The material selection process is a collaborative effort between the ERDC and the AFCEC to review candidate proprietary products to determine their feasibility as a successful repair material. Previously tested products requiring recertification are considered for renewed testing every five years. The final number of products selected for testing each year is at the discretion of the AFCEC. Typically, three to six products are tested each year. 


\subsection{Material storage}

Once candidate materials are selected, the products for testing ordered directly either from the manufacturer or through local construction material suppliers. Materials packaged in sealed buckets will be requested when purchased to allow for longer term storage and maximum shelf life. Many of the proprietary materials are sold only in 50-lb bags. For these products, upon arrival the testing laboratory placed the bagged product into reusable, airtight 5- to 7-gal plastic buckets for maximum humidity protection. The sealed buckets were then stored in a temperaturecontrolled room of $72 \pm 4^{\circ} \mathrm{F}$.

\subsection{Aggregate extension}

All products were tested as extended with aggregate if allowed by the manufacturer. The quantity of extension used was the maximum of either 50 percent (by volume of product per unit) or the maximum allowed by the manufacturer if less than 50 percent. Products sold as extended products (with coarse aggregate) were tested as produced without additional aggregate added by the testing laboratory. The coarse aggregate used for extending the paste or mortar product was an ASTM C33 (2016b)-compliant \#8 pea gravel local to Vicksburg, MS. The aggregate's physical properties are shown in Figure 1. 
Figure 1. Properties of 3/8-in. pea gravel used to extend repair materials.

\begin{tabular}{|c|c|c|c|c|c|c|}
\hline \multicolumn{7}{|c|}{ ASTM C 136: Sieve Analys is: } \\
\hline \multicolumn{7}{|c|}{ Cumulative Percent } \\
\hline Sieve Size & Mass Ret., $g$ & \% Ret. & Ret. & Pass & & Avg \\
\hline 3-in. & 0.0 & $0.00 \%$ & $0.00 \%$ & $100.00 \%$ & & $100 \%$ \\
\hline 1-іп. & 0.0 & $0.00 \%$ & $0.00 \%$ & $100.00 \%$ & & $100 \%$ \\
\hline 3/4-in. & 0.0 & $0.00 \%$ & $0.00 \%$ & $100.00 \%$ & & $100 \%$ \\
\hline $1 / 2$-in. & 30.9 & $0.61 \%$ & $0.61 \%$ & $99.39 \%$ & & $99 \%$ \\
\hline $3 / 8$-in. & $1,208.4$ & $23.78 \%$ & $24.37 \%$ & $75.63 \%$ & & $76 \%$ \\
\hline No. 4 & $3,649.5$ & $71.77 \%$ & $98.14 \%$ & $3.86 \%$ & & $4 \%$ \\
\hline No. 8 & 165.1 & $3.25 \%$ & $99.39 \%$ & $0.61 \%$ & & $1 \%$ \\
\hline No. 18 & 3.2 & $0.08 \%$ & $99.45 \%$ & $0.55 \%$ & & $1 \%$ \\
\hline No. 30 & 0.9 & $0.02 \%$ & $99.47 \%$ & $0.53 \%$ & & $1 \%$ \\
\hline No. 50 & 4.0 & $0.08 \%$ & $99.55 \%$ & $0.45 \%$ & & $0 \%$ \\
\hline Pan & 23.0 & $0.45 \%$ & $100.00 \%$ & & & \\
\hline Total & $5,085.0$ & $100.00 \%$ & & & & \\
\hline \multicolumn{3}{|c|}{ Fineness Modulus: } & 6.184 & & & 6.18 \\
\hline \multicolumn{7}{|c|}{ ASTM C 127: Bulk Specific Gravity \& Abs orption: } \\
\hline \multicolumn{4}{|c|}{ SSD Mass in Air, $g$} & \multicolumn{3}{|c|}{$3,933.8$} \\
\hline \multicolumn{4}{|c|}{ SSD Mass in W ater, $g$} & \multicolumn{3}{|c|}{$2,368.1$} \\
\hline \multicolumn{4}{|c|}{ Dis placed W ater, $g$} & \multicolumn{3}{|c|}{$1,587.7$} \\
\hline \multicolumn{4}{|c|}{ Water Temp C } & \multicolumn{3}{|c|}{22.8} \\
\hline \multicolumn{4}{|c|}{ Relative Density (Bulk Specific Gravity)(SSD) } & \multicolumn{2}{|r|}{2.5} & 2.51 \\
\hline \multicolumn{4}{|c|}{ Oven Dry Mas s, g } & \multicolumn{3}{|c|}{$3,810.3$} \\
\hline \multicolumn{4}{|c|}{ Mois ture Loss , $g$} & \multicolumn{3}{|c|}{123.5} \\
\hline \multicolumn{4}{|c|}{ Absorption } & & $3.24 \%$ & $3.2 \%$ \\
\hline
\end{tabular}

\subsection{Mixing procedures}

The mixture proportioning, mixing procedure, and mixing time were different for each repair material. Manufacturers' guidelines for producing their products at specified test temperatures and water contents were applied. However, this did not interfere with the requirements stated in ASTM C192 (2016e) used to control the production of all materials made for comparisons. All components, including mixing water, used to batch the repair material were temperature stabilized at $72 \pm 4^{\circ} \mathrm{F}$ before being added to the mixing unit to generate an accurate strength history of the products tested.

The water content of each mixture was as prescribed by the manufacturer. Potable tap water was used as the mixing water in all of the mixtures. The mixing water was adjusted to account for the absorption of the aggregate and the moisture content of the aggregate on the day of production. The proprietary products were typically mixed one bag at a time with a drill and paddle, as shown in Figure 2, or with a small drum mixer, as shown in Figure 3 . 
Figure 2. Laboratory mixing conducted by using Jiffy-type drill and paddle.

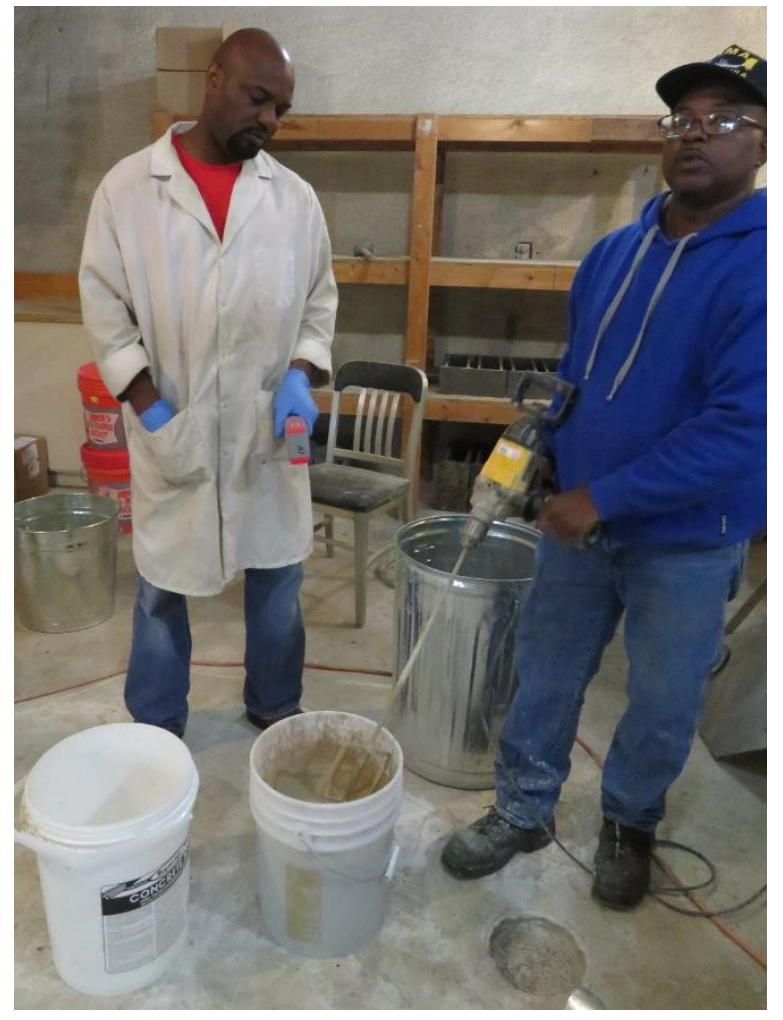

Figure 3. Laboratory mixing conducted by using small drum mixer.

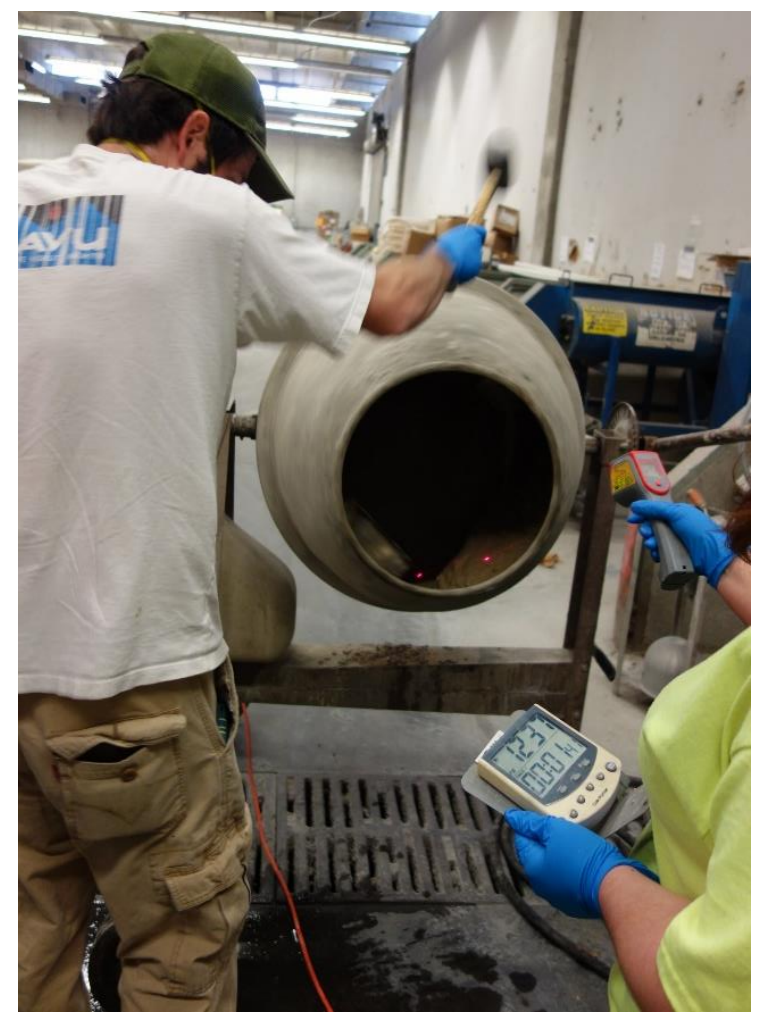




\subsection{Materials tested 2013-2017}

A total of 28 cementitious rapid-repair products listed in Table 6 were tested during 2013-2017. Datasheets containing the complete set of test results for each product are provided in Appendix A.

Table 6. Summary of products tested in the laboratory during 2013-2017.

\begin{tabular}{|c|c|c|c|}
\hline Product Name & Manufacturer & $\begin{array}{l}\text { Year } \\
\text { Tested }\end{array}$ & $\begin{array}{c}\text { Testing Tier } \\
\text { (Tier 1/Tier 2) }\end{array}$ \\
\hline Pavemend SL & Cera Tech, Inc. & 2013 & Tier $1 /$ Tier 2 \\
\hline DOT Line & Cera Tech, Inc. & 2013 & Tier $1 /$ Tier 2 \\
\hline SikaQuick 2500 & Sika Corp & 2013 & Tier $1 /$ Tier 2 \\
\hline 10-60 Repair Mortar & BASF & 2013 & Tier $1 /$ Tier 2 \\
\hline Pavepatch 3000 & Dayton Superior Corp. & 2013 & Tier $1 /$ Tier 2 \\
\hline Phoscrete 4 Seasons & Phoscrete Corp. & 2013 & Tier $1 /$ Tier 2 \\
\hline Ulti-Pave3 & Buzzi-Unicem USA, Inc. & 2014 & Tier $1 /$ Tier 2 \\
\hline Fast Set DOT Concrete Mix & Quikrete Companies & 2014 & Tier $1 /$ Tier 2 \\
\hline Ardex TRM & Ardex Americans & 2014 & Tier 1 \\
\hline Fast Set Concrete Mix & Quikrete Companies & 2014 & Tier $1 /$ Tier 2 \\
\hline Rapid Road Repair & Quikrete Companies & 2014 & Tier $1 /$ Tier 2 \\
\hline HD 50 & Dayton Superior Corp. & 2015 & Tier 1 \\
\hline Pavemend 15.0 & Cera Tech, Inc. & 2015 & Tier 1 \\
\hline Rapid Set Mortar Mix & CTS Cement Corp & 2015 & Tier 1/Tier 2 \\
\hline Prospec Premium Patch 100 & H.B. Fuller Construction & 2015 & Tier 1/Tier 2 \\
\hline Prospec Premium Patch 200 & H.B. Fuller Construction & 2015 & Tier 1/Tier 2 \\
\hline Magna-Crete & Henkel Americas & 2015 & Tier 1 \\
\hline Elephant Armor DOT & GST International & 2016 & Tier 1 \\
\hline Phoscrete $\mathrm{HC}$ & Phoscrete Corporation & 2016 & Tier 1 \\
\hline FasTrac 246 Concrete & Western Material \& Design, LLC & 2016 & Tier 1 \\
\hline Magna-Crete & Henkel Americas & 2016 & Tier 2 \\
\hline HD 50 & Dayton Superior Corp. & 2016 & Tier 2 \\
\hline Rapid Set DOT Repair & CTS Cement Corp. & 2017 & Tier 1 \\
\hline Pavemend TR & Cera Tech, Inc. & 2017 & Tier 1 \\
\hline T545 (Formerly Set 45) & BASF & 2017 & Tier 1 \\
\hline T545HT (Formerly Set 45HT) & BASF & 2017 & Tier 1 \\
\hline Rapid Set Concrete & CTS Cement Corp. & 2017 & Tier 1 \\
\hline T1061 & BASF & 2017 & Tier 1 \\
\hline
\end{tabular}




\section{Description of Test Methods}

This section summarizes the test methods employed to measure the merit of each cementitious, rapid-setting repair material addressed in this study. Any significant changes from the former test protocol are also noted.

\subsection{Compressive strength}

Compressive strength is important for ensuring that the repair material will not prematurely fail under wheel loads or under stresses caused by environmentally induced pavement movements. It is generally accepted that the repair material should have a compressive strength similar to that of the existing concrete substrate.

Compressive strength specimens were fabricated in accordance with ASTM C192 (2016e) and tested in accordance with ASTM C39 (2015a procedures, using 4-in. $\times$ 8-in. cylinders. Compression testing using larger 6-in. $\times 12$-in. cylinders or smaller 3 -in. $\times 6$-in. cylinders (Figure 4 ) is acceptable, but compression testing with 2-in. cube specimens in accordance to ASTM C109 (2016a) is not acceptable. Cube testing is intended for mortars only and often gives inflated strength values related to cylinders. The smaller 3 -in. $x$ 6-in. cylinders were often used due to the limited volume of material mixed for each product and the rapid setting time.

Timing of the strength testing was critical due to the rapid hardening of these repair materials. The cylinders were tested at different ages of 2, 3, and $24 \mathrm{hr}$ and 7 and 28 days. The early 2- and 3-hr strength measurements do not have specified testing time tolerances in ASTM C39. Therefore, a tolerance of $\pm 15 \mathrm{~min}$. was applied to this testing age to ensure true measures of strength at the specified times were collected, while balancing the laboratory's ability to collect the information in a timely manner. Triplicate cylinders were tested at each age at a loading rate of 35 $\mathrm{psi} / \mathrm{sec}$ until failure. Results were reported as maximum compressive stress (psi), which equals the maximum applied load divided by the specimen's initial, unloaded cross-sectional area. 
Figure 4. Concrete cylinder undergoing compression strength test.

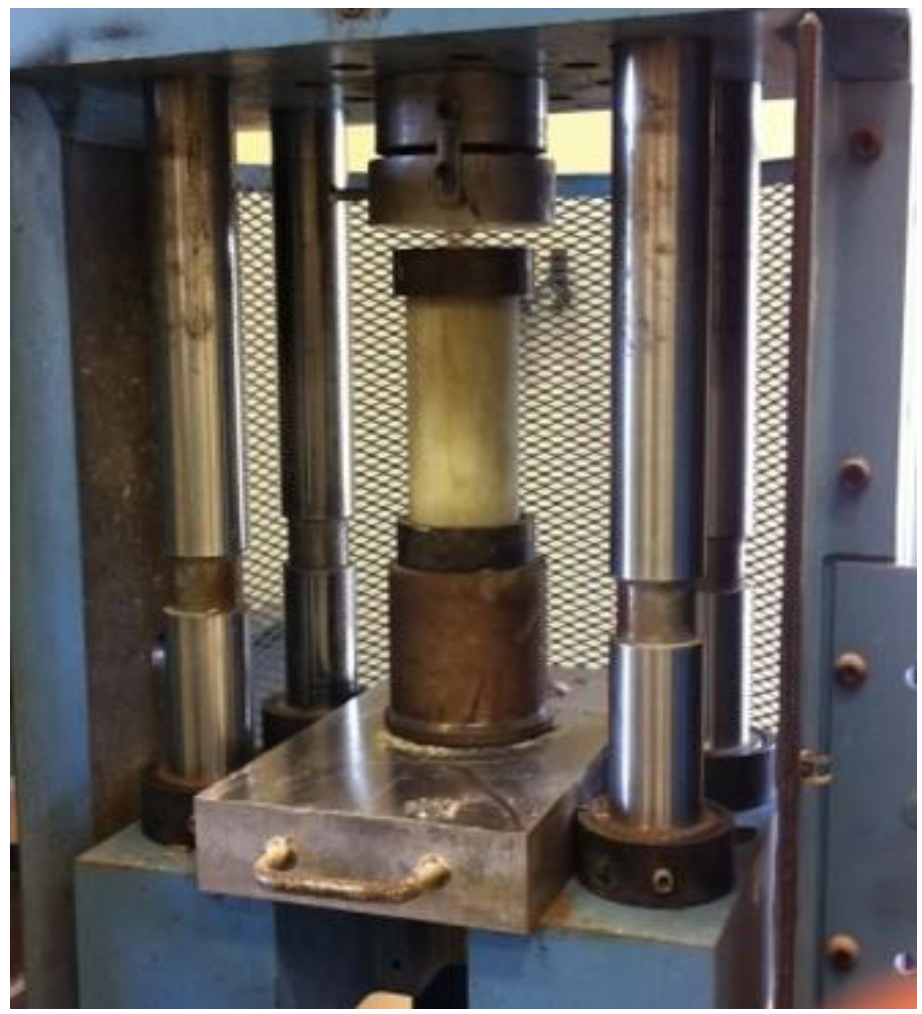

\subsection{Flexural strength}

Flexural strength is important to determine the stress of the material just before it yields. Most materials fail under tensile stress before they fail under compressive stress, so the maximum tensile stress value that can be sustained before the beam fails is its flexural strength. Flexural strength specimens were fabricated and tested in accordance with ASTM $\mathrm{C}_{7} 8$ (2016d) procedures (Figure 5).

The test specimens were rectangular beams with dimensions of 3 in. $\times 3$ in. $\times 12$ in. with loading applied at third-points of the span. The beams were tested at $2 \mathrm{hr} ., 7$ days, and 28 days. Triplicate beams at each test age were loaded at a specific rate to increase a stress of $150 \mathrm{psi} / \mathrm{min}$ in the bottom fiber (maximum tension) of the beam. Results were reported as the ultimate tensile stress achieved before failure, also known as the modulus of rupture. 
Figure 5. Concrete beam undergoing flexural strength test.

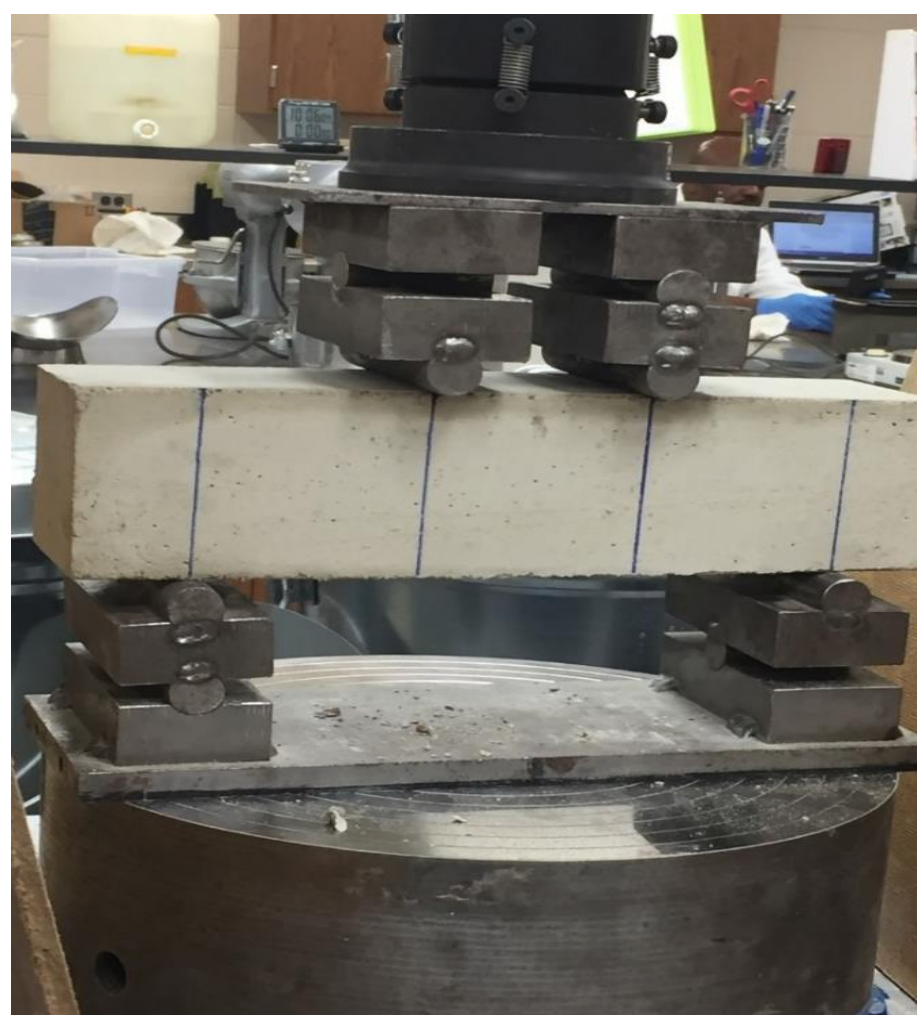

Larger 6-in. $\times$ 6-in $\times$ 21-in. beams may be used as specified in former test protocols. However, since this repair specification limits the maximum aggregate size of extended aggregate to $1 \mathrm{in}$. and the beams are unreinforced, the 6-in.-square cross section is not necessary for testing. The smaller 3 -in. $\times 3$-in. $\times 12$-in. beams can achieve similar results and reduce the cost of the testing by reducing the volume of material required while still abiding by the smallest 3 times the maximum nominal aggregate size rule of thumb used for slab depth flexural strength testing.

\subsection{Bond strength}

Bond strength is important for ensuring the material used for the spall repair will adhere to the existing concrete substrate to ensure adequate stress transfer during loading, expansion, and contraction. Bond strength specimens were fabricated and tested in accordance with ASTM C882 (2013a) procedures. This slant shear test involved the preparation of specimens in 3-in. $\times 6$-in. cylinder molds. A bond line was produced at approximately 30 degrees from the vertical angle by first casting wedgeshaped dummy sections of either portland cement concrete (PCC) or the repair material itself. 
The diagonally cast bonding area of each half-cylinder dummy sample was lightly sandblasted and submerged in water $24 \mathrm{hr}$ before placement in a new 3 -in. $\times 6$-in. mold and casting to the repair material. After curing, the composite cylinder was tested in compression. The bond strength was calculated by dividing the load carried by the specimen at failure by the area of the elliptical bonding surface. Figure 6 shows an example of the PCC slant shear half-cylinder before and after bonding to a repair material.

Figure 6. Composite bond strength and slant shear specimens.

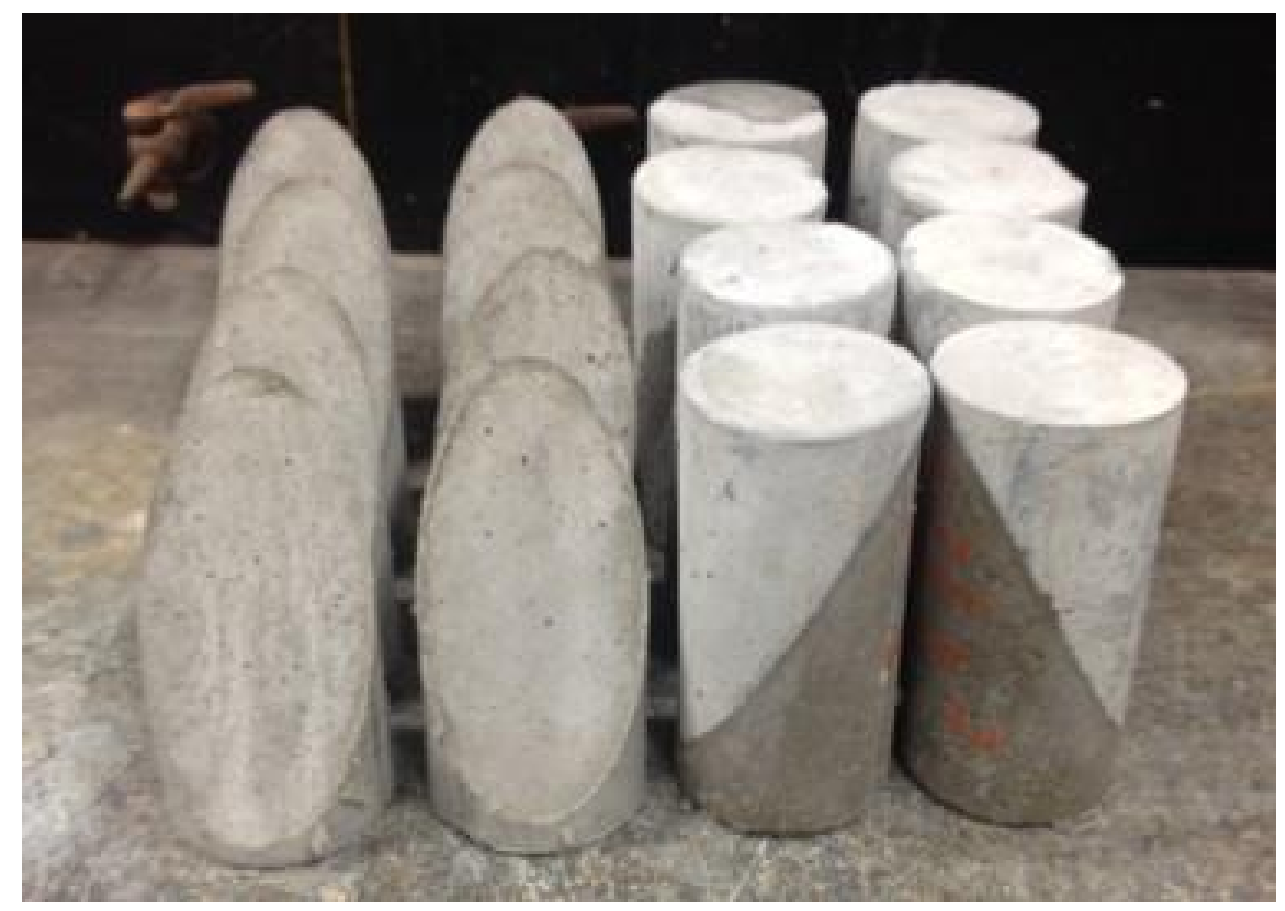

\subsection{Modulus of elasticity}

Modulus of elasticity is important because a spall repair material should not have stiffness significantly different from that of the parent material onto which it is applied in order to achieve a uniform load transfer across the repair section. With a higher stiffness, the repair material will assume higher stresses under wheel loading and pavement movement. If the repair material has a lower stiffness than the parent material, it will exhibit lower internal stresses; thus, the potential for cracking and delamination of the repair is reduced.

Modulus of elasticity testing was accomplished in accordance with ASTM C469 (2014c) procedures. Test specimens were either 3 -in. $\times$ 6-in. or 4-in. $\times 8$-in. cylinders instrumented with an unbounded sensing device attached to the cylinders at mid-height for the purpose of measuring vertical 
deformation. The cylinders were tested at $2 \mathrm{hr}$ and at 28 days. The modulus of elasticity (in psi) was calculated as change in stress divided by change in strain, where strain is calculated as vertical deformation divided by gauge length. Figure 7 shows a cylinder undergoing the modulus of elasticity test.

Figure 7. Concrete cylinder specimen undergoing modulus of elasticity test.

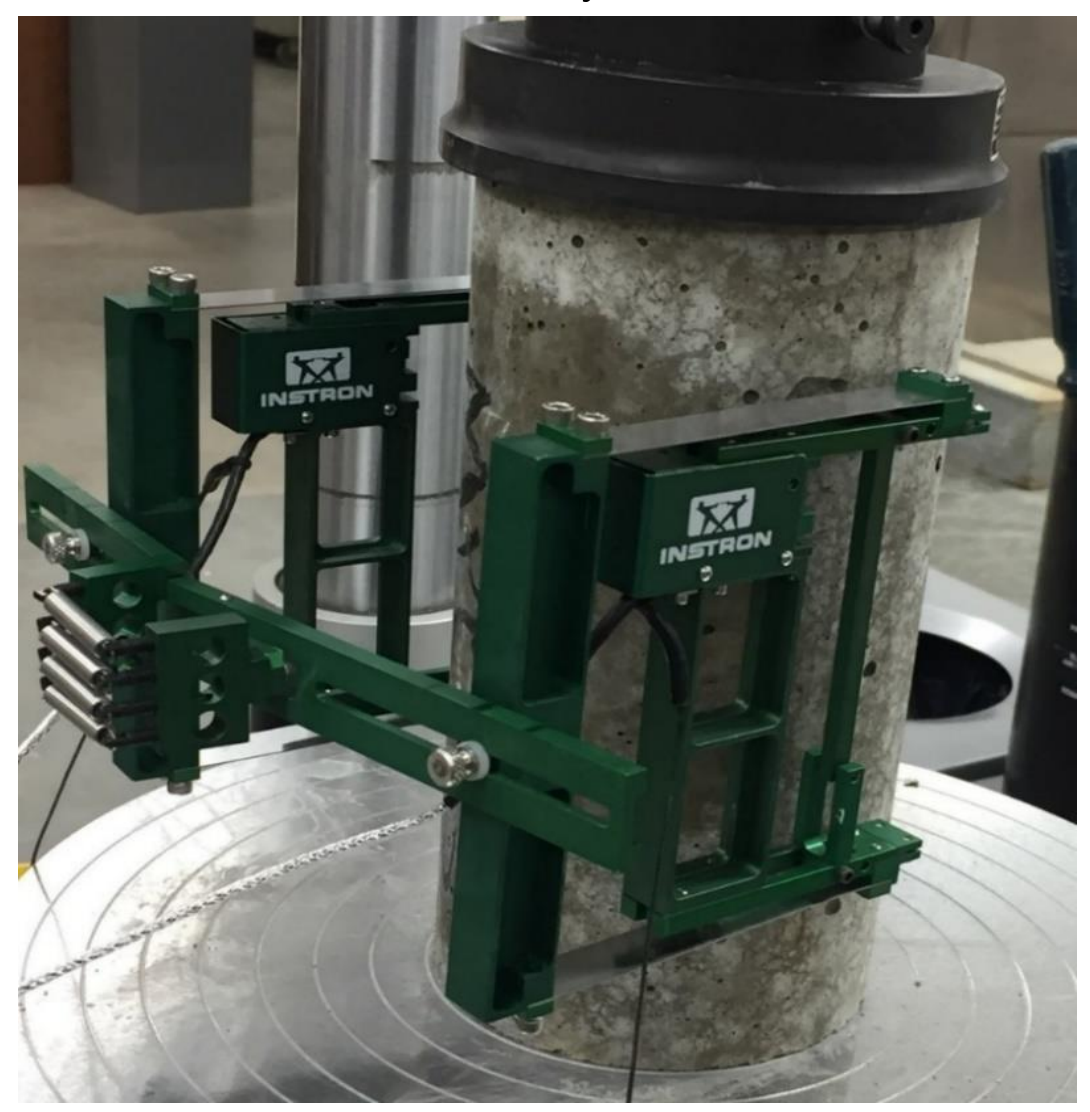

\subsection{Set time}

Set time is important because it strongly influences the workability, finishing, and load-carrying capacity of fresh concrete. Previous protocols required ASTM C191 (2013c) as the set time test method. This is a standard method for time of setting by Vicat needle based on a normal consistency of the cement paste, and many of the rapid-repair materials either contain aggregate within the proprietary product or can be extended.

The ASTM C191 method was modified to accommodate the many rapidrepair materials by wet sieving the mixed product over a \#4 sieve before allowing it to form in the mold for testing to remove any aggregate that 
would interfere with the 1-mm needle penetration. However, using this modified method for testing may not represent the actual performance of the product. Therefore, the time of setting was performed in accordance to ASTM C403 (2016f) which is better suited for concrete materials.

For the ASTM C403 method, periodic penetration tests were performed by using a penetrometer with an analog gauge by inserting a standardized needle of known surface area into the fresh concrete material and recording the resistance force. The penetration resistance (in psi) was calculated by dividing the recorded force (in pounds) by the bearing area of the needle (in square inches). The initial set time was the time elapsed between the initial contact of cement and water and the time when the penetration resistance equaled 500 psi. The final set time was the time elapsed between initial contact of the cement and water and the time when the penetration resistance equaled 4,000 psi. Figure 8 demonstrates both methods during testing.

Figure 8 . Set time demonstrated by penetrometer and Vicat methods.

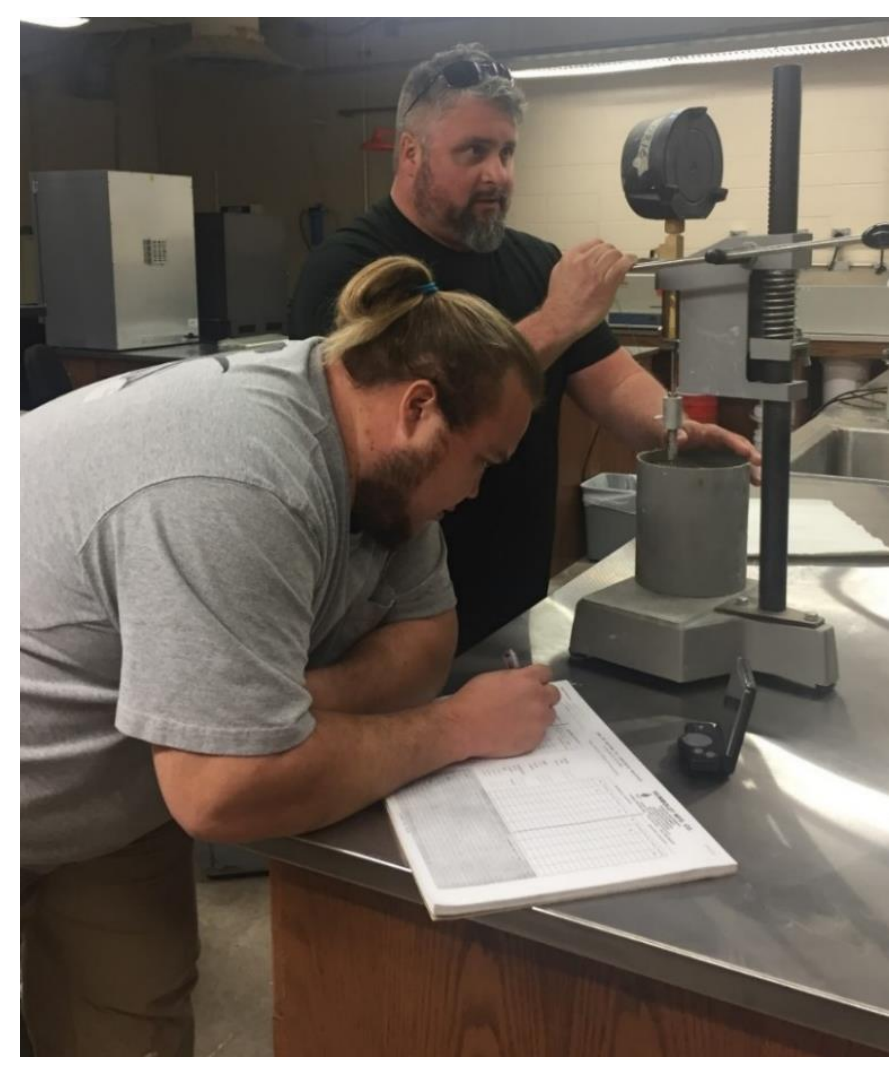

(a) Set time performed by the penetrometer method, ASTM C403. 


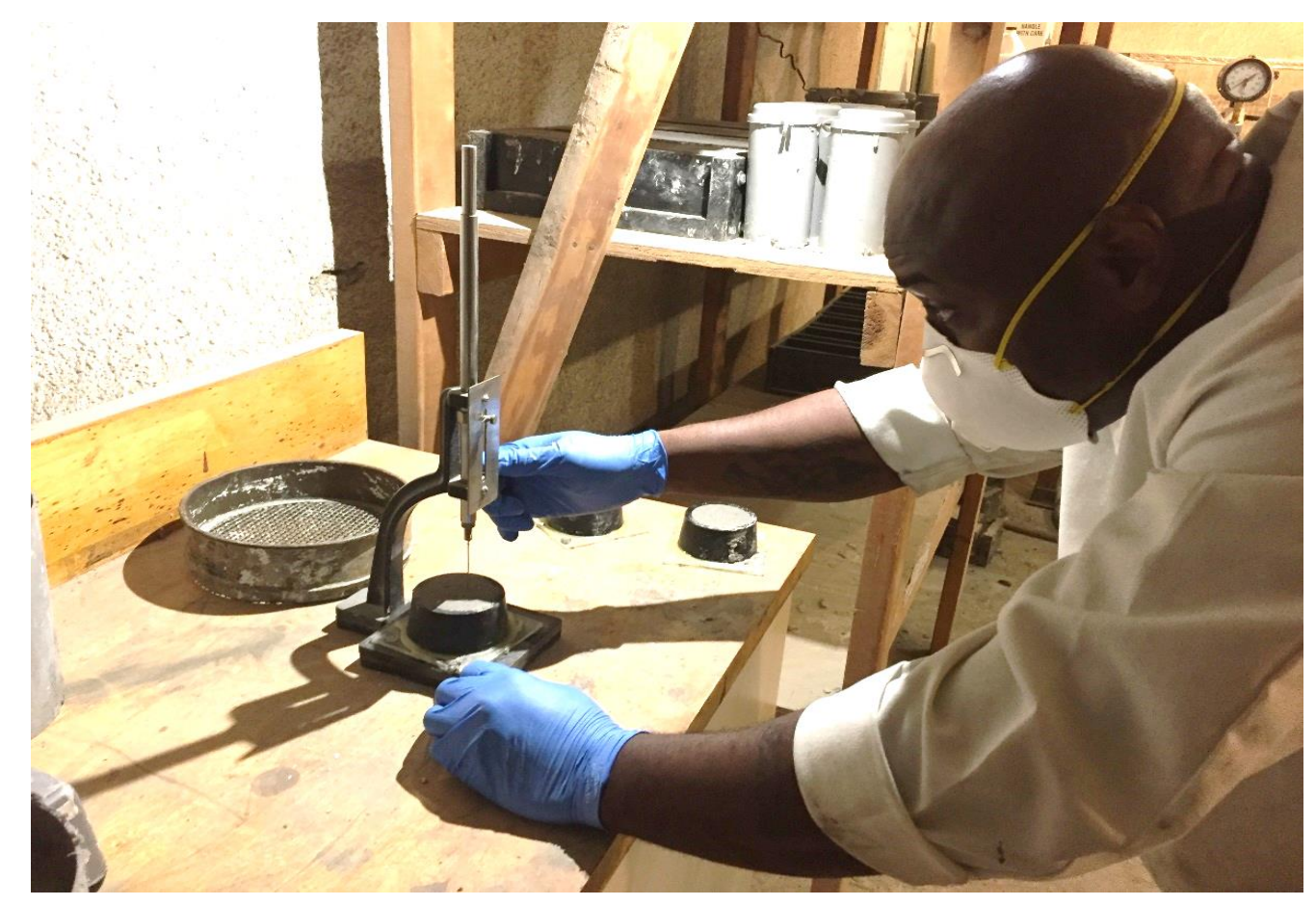

(b) Set time performed by the Vicat method, ASTM C191.

\subsection{Coefficient of thermal expansion}

The coefficient of thermal expansion (CTE) of a spall repair material is important to ensure that the expansion and contraction of the repair material with changes in temperature are compatible with the parent material. If the CTE of a repair material is higher than that of the existing material, it will experience greater volume changes with changes in temperature (volumetric expansion due to externally applied forces). The difference in movements for the repair versus the parent material tends to deteriorate their bond.

CTE testing was accomplished in accordance with ASTM C531 (2012a) procedures. Test bar specimens with dimensions of 1 in. $\times 1$ in. $\times 11.25$ in. with embedded gauge studs were fabricated from the repair material. Due to the size of the test specimen, any extended product must be sieved to meet the maximum aggregate size requirement. An initial gauge length of the bars was measured at $24 \mathrm{hr}$ then daily for two weeks to determine linear shrinkage. The specimens were maintained at an ambient laboratory temperature of $73^{\circ} \mathrm{F}$ during the first 2 weeks. The test specimens were then exposed to environmental conditions of $210^{\circ} \mathrm{F}$ for 3 days, and the gauge lengths were immediately recorded. The specimens were then cooled in a dedicator box at $73^{\circ} \mathrm{F}$ for $24 \mathrm{hr}$ and once again the 
gauge length was recorded. This heating/cooling cycle of a 3-day exposure at $210^{\circ} \mathrm{F}$ then cooling to $73^{\circ} \mathrm{F}$ continued until a constant CTE was determined (Figure 9). The CTE was reported as strain per degree F, with units of in./in. $/{ }^{\circ} \mathrm{F}$. The procedure differed from the previous protocol ETL 08-02 requirement for the test to begin at an age of 3 days and eliminated the procedure for linear shrinkage. The current method follows the ASTM C531 with no modifications.

Figure 9. Coefficient of thermal expansion mortar bars specimens.

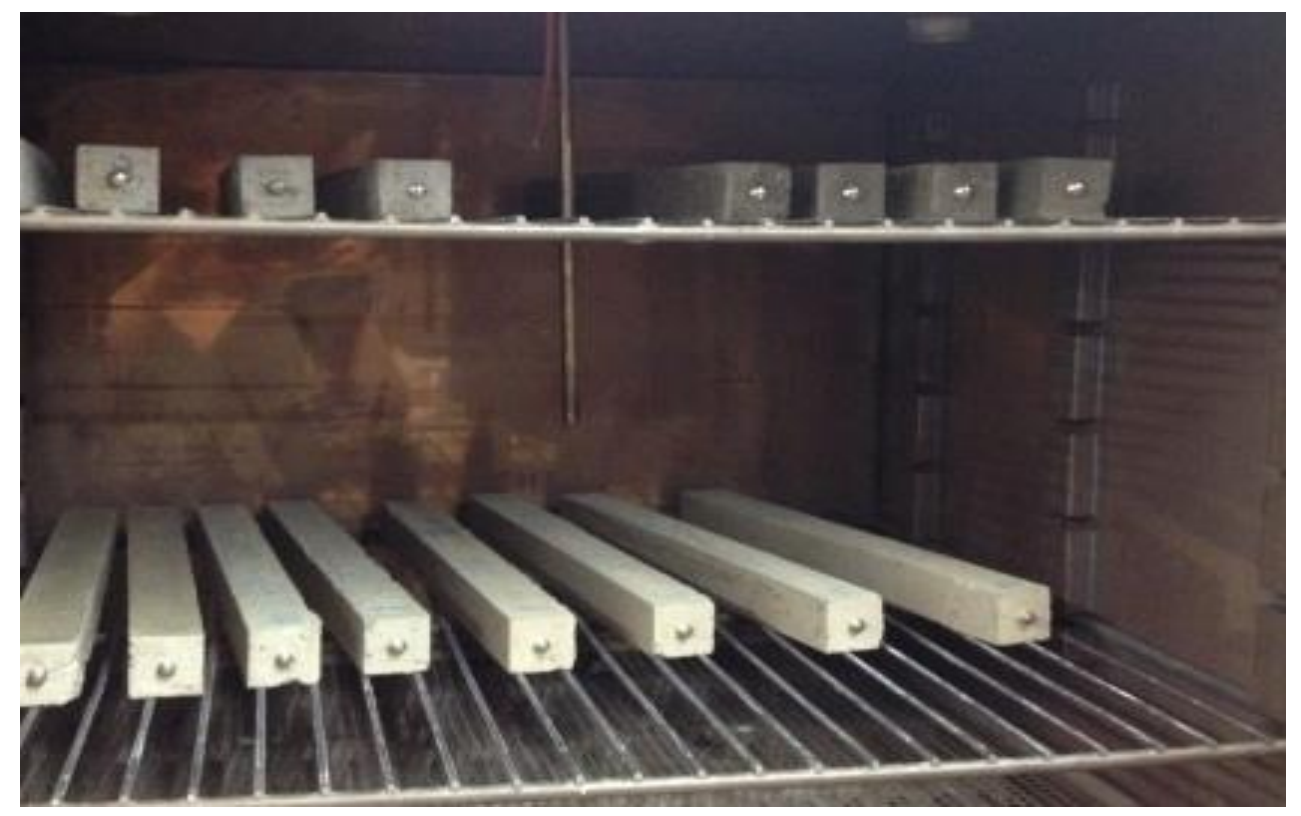

\subsection{Workability}

The workability is an important fresh property of concrete that is indicated by the amount of useful internal work required to fully compact the concrete without bleeding or segregation in the finished product. For most of the concretes tested, the workability was demonstrated by performing the ASTM C143 (2015d) slump test, which is the most generally accepted test to determine the consistency and workability of concrete. However, this method cautions that concretes having slumps greater than about 9 in. may not be adequately cohesive for this test to have significance. Therefore, if the slump was over 9 in., as indicated by the standard slump test, the ASTM D1611 (2014b) flow consistency test was performed. 
To perform the flow consistency test, the material was placed into a cylinder with openings on both ends; the material was struck off, then the cylinder was lifted to allow the material to spread onto a non-porous surface. The diameter of the spread was immediately measured in two perpendicular directions. The slump flow consistency, like the standard slump test, is reported as the average of the diameter. Figure 10 demonstrates both methods during testing.

Figure 10. Workability demonstrated in accordance to (a) ASTM C143 and (b) ASTM C1611.

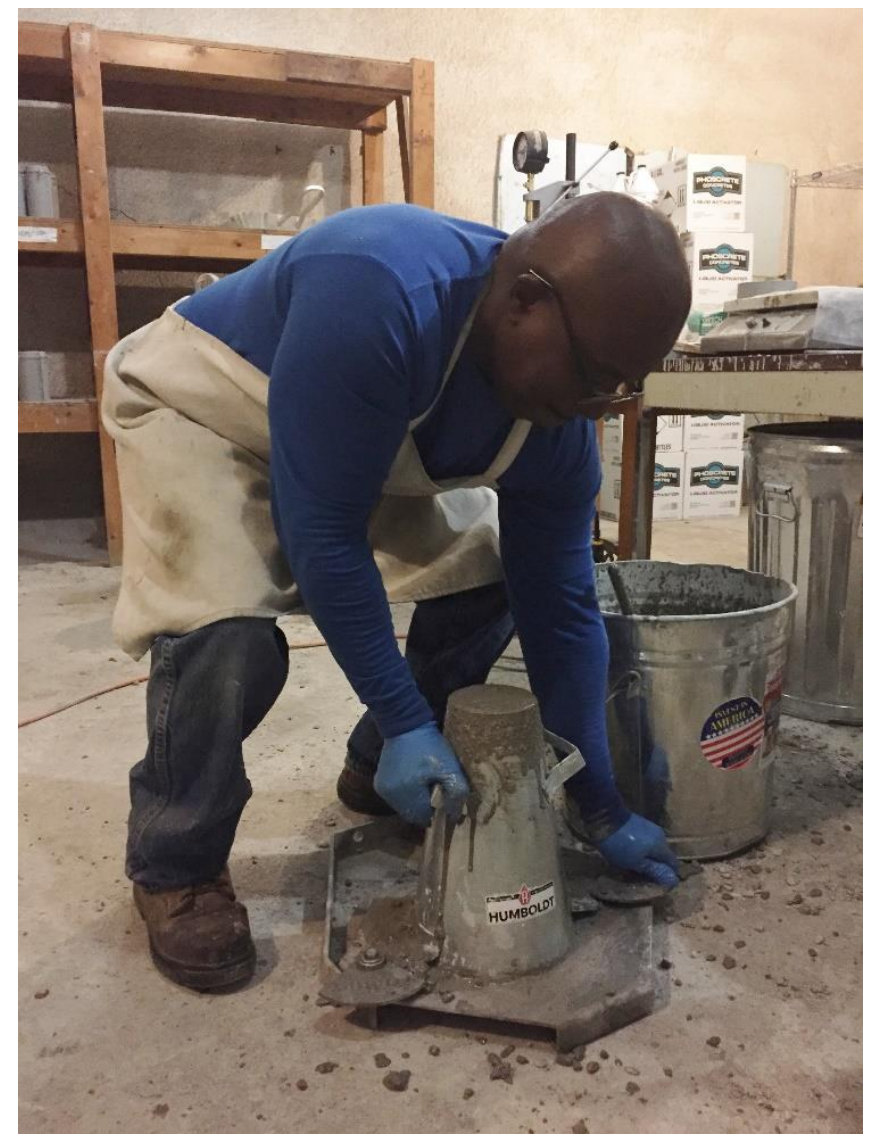

(a) Slump performed in accordance to ASTM C143. 


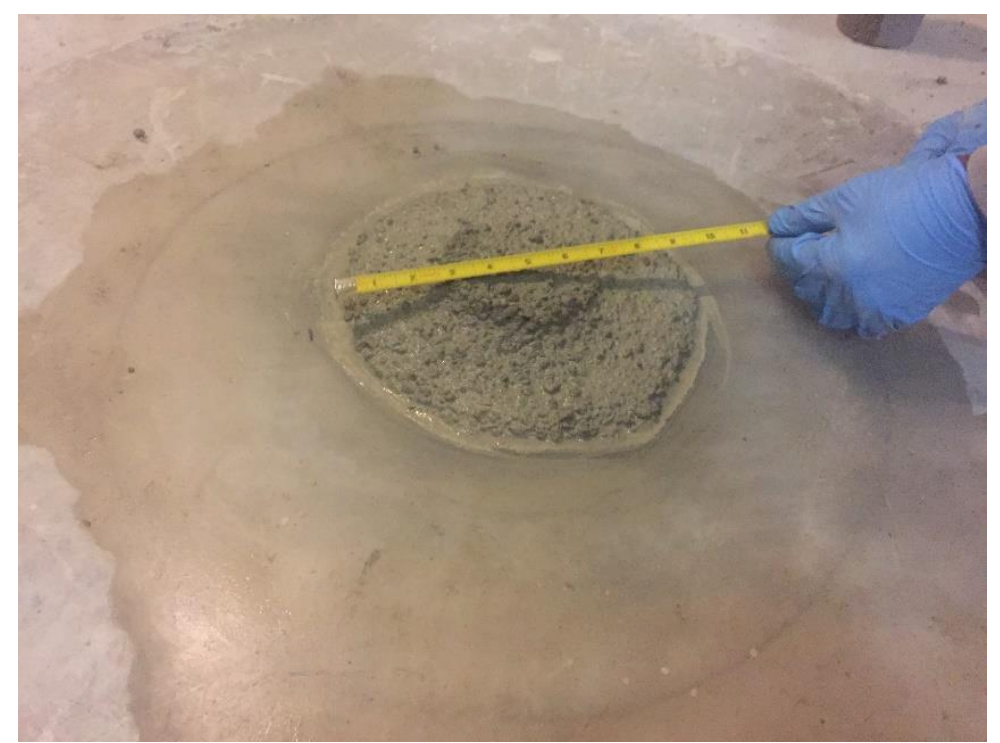

(b) Slump flow measured in accordance to ASTM C1611.

\subsection{Length change}

Length change is important because excessive expansion or contraction of a spall repair will result in a loss of bond to the parent material. Additionally, if the spall repair is large, excessive expansion can result in the deterioration of the surrounding pavements. Length change testing was accomplished in accordance with ASTM C157 (2014a) procedures with both air and water storage curing. Test prismatic specimens with dimensions of 3 in. $\times 3$ in. $\times 11.25$ in. with embedded gauge studs were fabricated from the repair material with a maximum aggregate size of 0.75 in. Readings were taken during the air and water curing periods after 4, 7, 14, and 28 days and after $8,16,32$, and 64 weeks. The length change at each age was reported as a percentage (change in length/original length $\times$ 100 percent). Figure 11 shows the storage conditions for length change specimens in the air cure environment. 
Figure 11. Length change specimen storage in air cure environment.

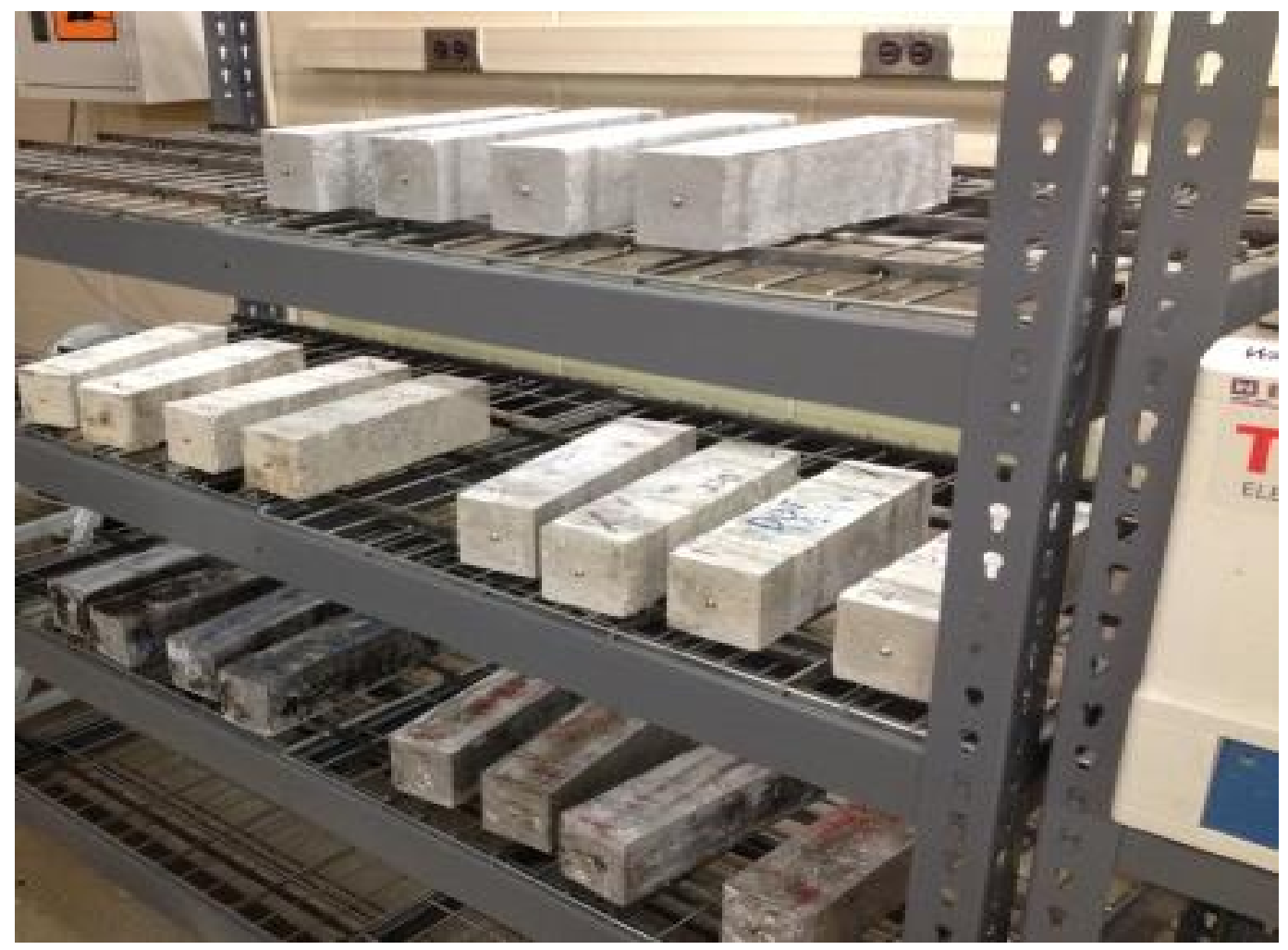

\subsection{Shrinkage ring}

Shrinkage potential is important because repair materials that shrink excessively are more prone to bonding problems and cracking. Shrinkage was measured by using a restraining ring device in accordance with ASTM $\mathrm{C} 1581$ (2016c). During this test, the ring of the repair material attempted to shrink, but the steel ring prevented its movements, resulting in the development of circumferential stresses that could lead to cracking. The maximum tensile stress was measured by strain gauges that measured cracking potential where visual cracking might not be observed. The restraining ring was constructed of structural steel pipe with a wall thickness of 0.5 in., an outside diameter of 13 in., and a height of 6 in. The repair material was cast on the outside of the restraining ring in a manner that produced a repair material ring with a height of 6 in. and a wall thickness of $1.5 \mathrm{in}$. The outer form that was used to shape the repair ring was removed after curing $24 \mathrm{hr}$ while the restraining ring stayed in place throughout testing. The repair rings were cured in an environment with 50 percent relative humidity and a temperature of $73^{\circ} \mathrm{F}$. A data logger recorded the microstrain for the instrumented shrinkage rings. The ring 
strain at 14 days was reported and, if any cracking occurred, at 28 days. Figure 12 shows products undergoing the shrinkage ring test.

Figure 12. Shrinkage ring testing.

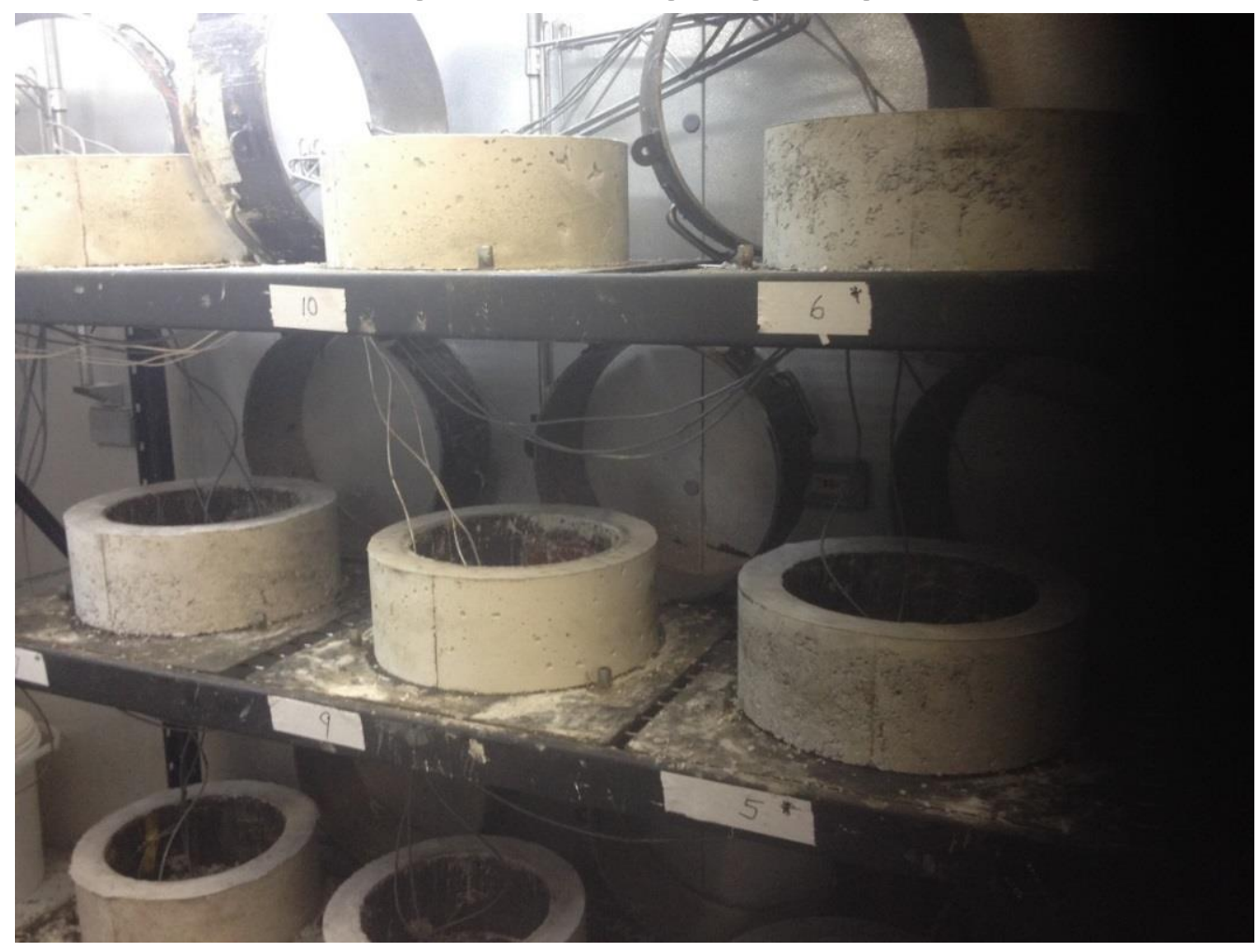

\subsection{Freeze-thaw resistance}

Resistance to damage during freezing and thawing is important to ensure the repair material can be used in cold climates that may subject the repaired surface to these environmental conditions. Freeze-thaw resistance testing was accomplished in accordance with ASTM C666, Procedure A (2015b). Test prisms with dimensions of 3 in. $\times 4$ in. $\times 16$ in. were moist cured for 14 days before being subjected to freeze-thaw cycles until failure (6o percent loss in dynamic modulus) or at a maximum of 300 cycles. During testing, specimens were weighed and their fundamental transverse frequency measured approximately every 36 cycles (Figure 13). Results were reported as the durability factor, which is a function of the number of cycles survived by the specimens and the relative dynamic modulus of elasticity at the time the test is terminated. 
Figure 13. Freeze-thaw specimen undergoing testing for transverse frequency.

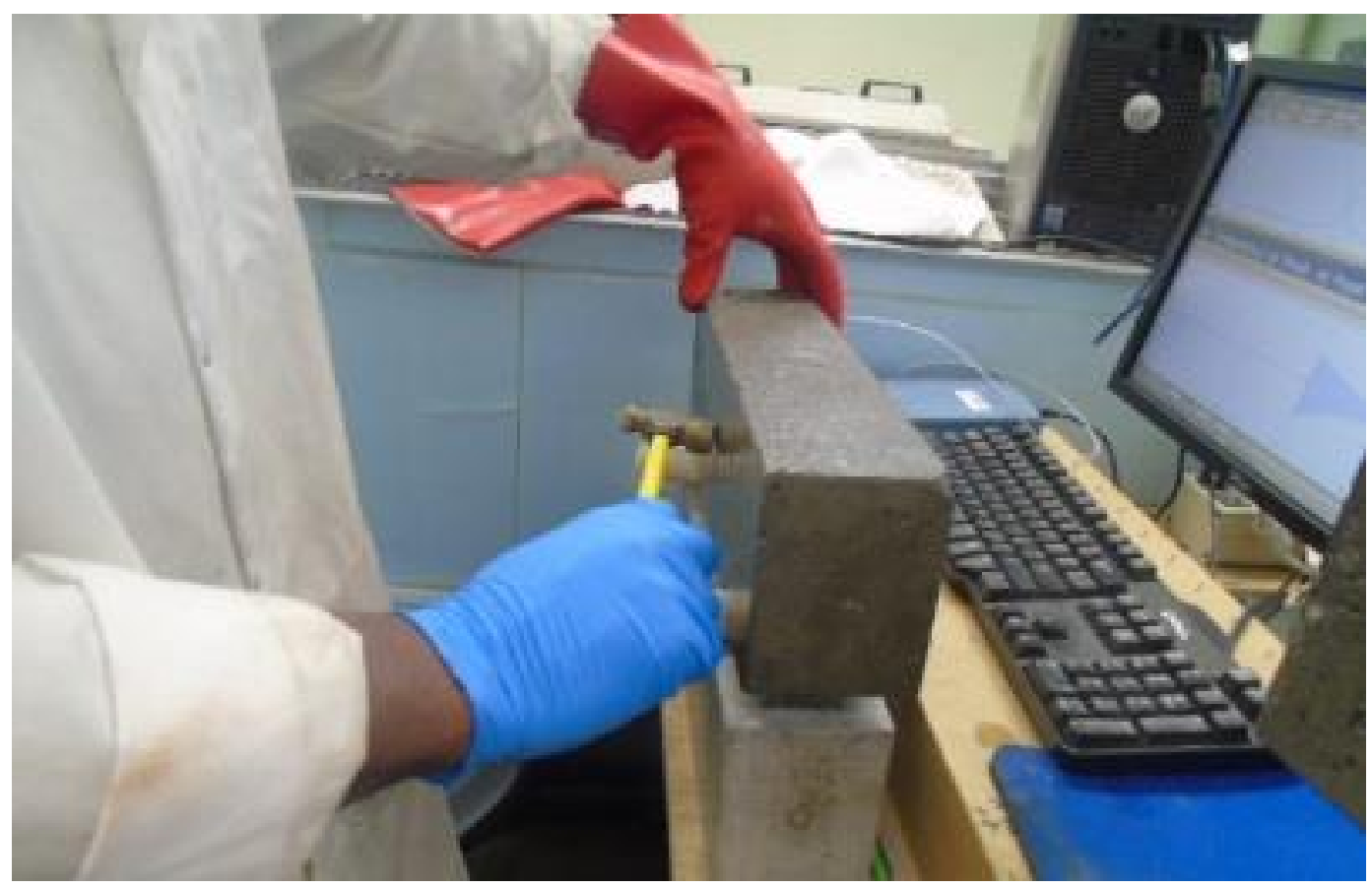




\section{Results and Discussion}

The following section provides a comparison of the laboratory test results from not only the laboratory tests conducted from 2013 to 2017, but also historical data extracted from datasheets from historical testing described in earlier sections published on the tri-service website. The recommendations for the new test protocol and approved products are based solely on the laboratory test results.

\subsection{Compressive strength}

Comparisons of the compressive strengths are detailed in Table 7 and illustrated in Figure 14. Based on these results, the following modifications for compressive strength testing are recommended.

- Reduce the 2-hr pass criterion from 3,000 psi to 2,500 psi. This is based on the observation that many products do not reach 3,000 psi until $3 \mathrm{hr}$.

- No requirement was established for the 3 -hr testing in previous protocols. It is recommended that products gain 3,000 psi for the 3 -hr pass criterion. This is based on observations in both the test results and the 3-hr performance requirement established in ASTM C928 (2013b) for an $\mathrm{R} 3$ concrete.

- Reduce the 1-day requirement from 5,000 psi to 4,000 psi. This is based on the fact that the ultimate strength is 5,000 psi and most products do not reach the maximum strength requirement at $24 \mathrm{hr}$. A more appropriate strength would be 4,000 psi at this early age.

- No changes are recommended for the 7-day and 28-day pass criteria of 5,000 psi.

Table 7. Summary of compressive strength results.

\begin{tabular}{|c|c|c|c|c|c|c|c|}
\hline \multirow[b]{2}{*}{ Product Name } & \multirow[b]{2}{*}{ Manufacturer } & \multirow{2}{*}{$\begin{array}{c}\text { Year } \\
\text { Tested }\end{array}$} & \multicolumn{5}{|c|}{ Compressive Strength (psi) } \\
\hline & & & $2 \mathrm{hrs}$ & $3 \mathrm{hrs}$ & 1 day & 7 days & 28 days \\
\hline Rapid Set DOT Repair Mix & CTS Cement Corp. & 2007 & 4,500 & - & 8,550 & - & - \\
\hline MasterEmaco T545HT & BASF & 2007 & 2,820 & - & 4,430 & - & - \\
\hline Pavemend EX-H & Cera Tech, Inc. & 2007 & - & 2,580 & - & - & - \\
\hline Pavemend SLQ & CeraTech, Inc. & 2008 & 1,230 & - & 2,530 & - & - \\
\hline Ultimax Concrete Mix & Ultimax Cement & 2008 & 4,000 & - & 6,390 & - & - \\
\hline Futura 15 & W.R. Meadows & 2008 & 1,960 & - & 4,680 & - & - \\
\hline
\end{tabular}




\begin{tabular}{|c|c|c|c|c|c|c|c|}
\hline Pavemend VR & Cera Tech, Inc. & 2008 & 405 & 3,160 & - & - & - \\
\hline Great White & Cera Tech, Inc. & 2009 & 2,340 & & 4,195 & - & - \\
\hline Mainline & Cera Tech, Inc. & 2009 & 2,223 & 5,074 & - & - & - \\
\hline Fast Set DOT Concrete Mix & Quickcrete Companies & 2010 & 3,340 & 3,970 & 6,050 & 5,190 & 5,460 \\
\hline Rapid Set Concrete Mix & CTS Cement Corp. & 2010 & 3,404 & & 4,512 & - & - \\
\hline FasTrac & Western Material \& Design & 2010 & 1,117 & - & 4,364 & - & - \\
\hline Speed-crete 2028 & Euclid Chemical Co. & 2010 & 1,930 & - & - & - & - \\
\hline DOTLine & Cera Tech, Inc. & 2013 & 3,920 & 5,080 & 6,420 & 8,290 & 10,170 \\
\hline Pavepatch 3000 & Dayton Superior Corp. & 2013 & 3,170 & 3,905 & 5,190 & 6,290 & 7,100 \\
\hline SikaQuick 2500 & Sika Corp. & 2013 & 3,660 & 3,960 & 5,280 & 7,230 & 8,090 \\
\hline MasterEmaco T1060 & BASF & 2013 & 2,950 & 3,520 & 4,590 & 6,170 & 6,290 \\
\hline Pavemend SL & Cera Tech, Inc. & 2013 & 4,740 & 5,070 & 6,800 & 9,970 & 10,590 \\
\hline Phoscrete 4-Seasons & Phoscrete Corp. & 2013 & 4,210 & 5,080 & 5,030 & 5,690 & 5,700 \\
\hline Ulti-Pave3 & Buzzi-Unicem USA, Inc. & 2014 & 4,630 & 5,530 & 7,880 & 8,740 & 9,490 \\
\hline Ardex TRM & Ardex Americas & 2014 & 550 & 1,570 & 2,640 & 3,560 & 3,820 \\
\hline Fast Set Concrete Mix & Quikcrete Companies & 2014 & 2,020 & 2,490 & 3,150 & 3,760 & 5,360 \\
\hline Rapid Road Repair & Quikcrete Companies & 2014 & 2,140 & 2,240 & 4,570 & 6,050 & 7,980 \\
\hline HD 50 & Dayton Superior Corp. & 2015 & 4,080 & 4,200 & 4,700 & 6,370 & 6,980 \\
\hline Prospec Premium Patch 100 & H.B. Fuller Construction & 2015 & 2,460 & 3,220 & 3,620 & 5,400 & 6,550 \\
\hline ProSpec Premium Patch 200 & H.B. Fuller Construction & 2015 & 3,210 & 3,630 & 4,320 & 5,570 & 6,890 \\
\hline Rapid Set Mortar Mix & CTS Cement Corp. & 2015 & 4,150 & 4,610 & 5,730 & 6,580 & 7,270 \\
\hline Magna-Crete & Henkel Americas & 2015 & 3,510 & 3,620 & 3,870 & 4,440 & 7,270 \\
\hline Pavemend 15 & Cera Tech, Inc. & 2015 & 1,210 & 3,170 & 3,730 & 3,970 & 5,060 \\
\hline Phoscrete HC & Phoscrete Corp. & 2016 & 5,140 & 5,350 & 6,030 & 7,580 & 7,730 \\
\hline Elephant Armor DOT & GST International & 2016 & 3,020 & 3,030 & 3,270 & 4,150 & 4,520 \\
\hline FasTrac 246 Concrete & Western Material \& Design & 2016 & 2,620 & 4,340 & 6,070 & 7,290 & 8,160 \\
\hline Rapid Set DOT Repair & CTS Cement Corp. & 2017 & 5,120 & 5,720 & 6,690 & 7,290 & 8,900 \\
\hline Pavemend TR & Cera Tech, Inc. & 2017 & 1,480 & 1,750 & 3,610 & 3,950 & 4,650 \\
\hline T545 (Formerly Set 45) & BASF & 2017 & 2,510 & 3,090 & 4,110 & 5,090 & 5,310 \\
\hline T545HT (Formerly Set 45HT) & BASF & 2017 & 2,640 & 3,170 & 4,110 & 5,240 & 6,250 \\
\hline Rapid Set Concrete & CTS Cement Corp. & 2017 & 3,630 & 4,080 & 4,530 & 5,040 & 5,710 \\
\hline T1061 & BASF & 2017 & 1,270 & 2,720 & 5,690 & 6,280 & 7,770 \\
\hline
\end{tabular}


Figure 14. Summary of compressive strength product comparison by age.

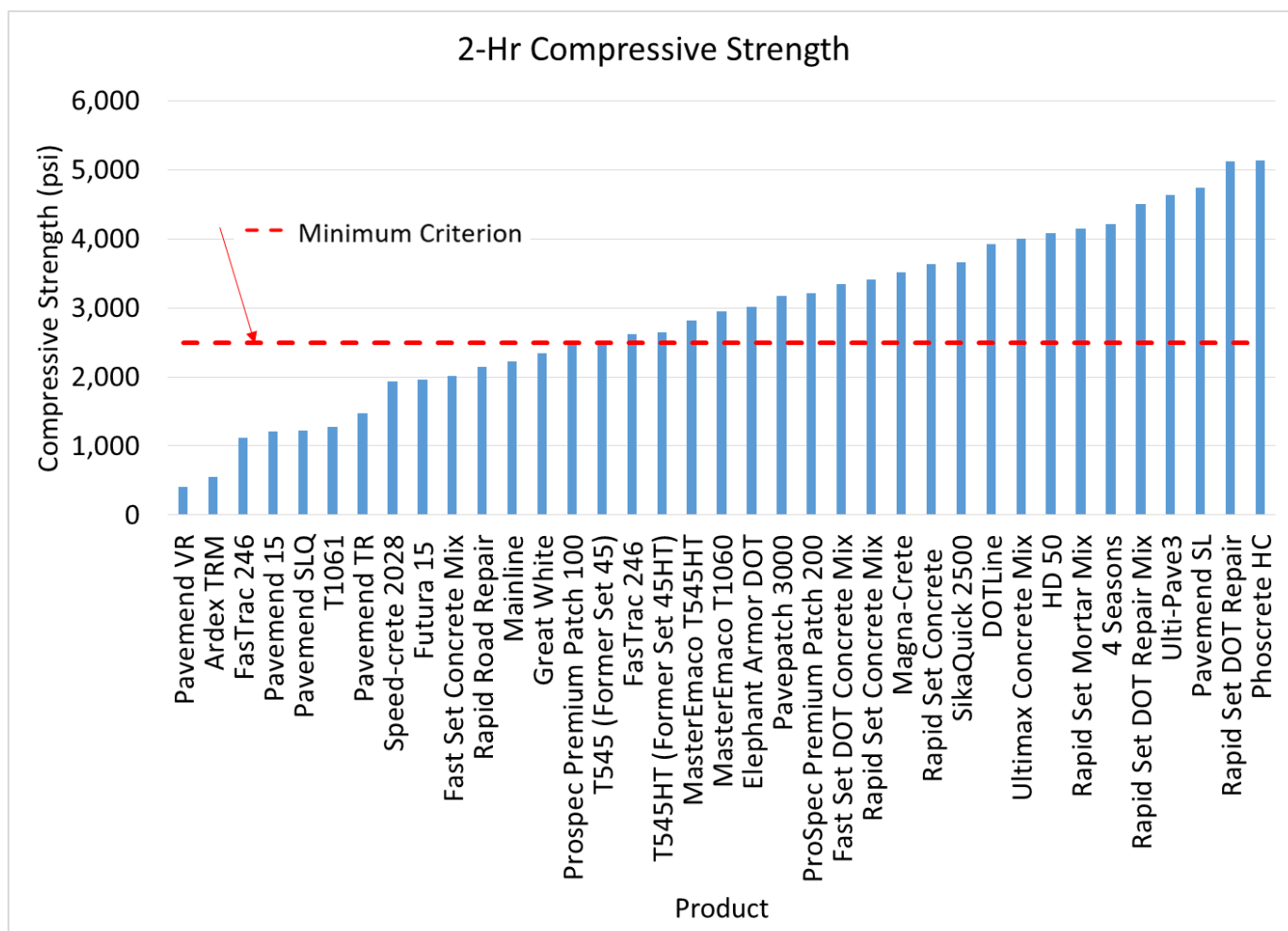

(a) Product comparison at 2-hr compressive strength.

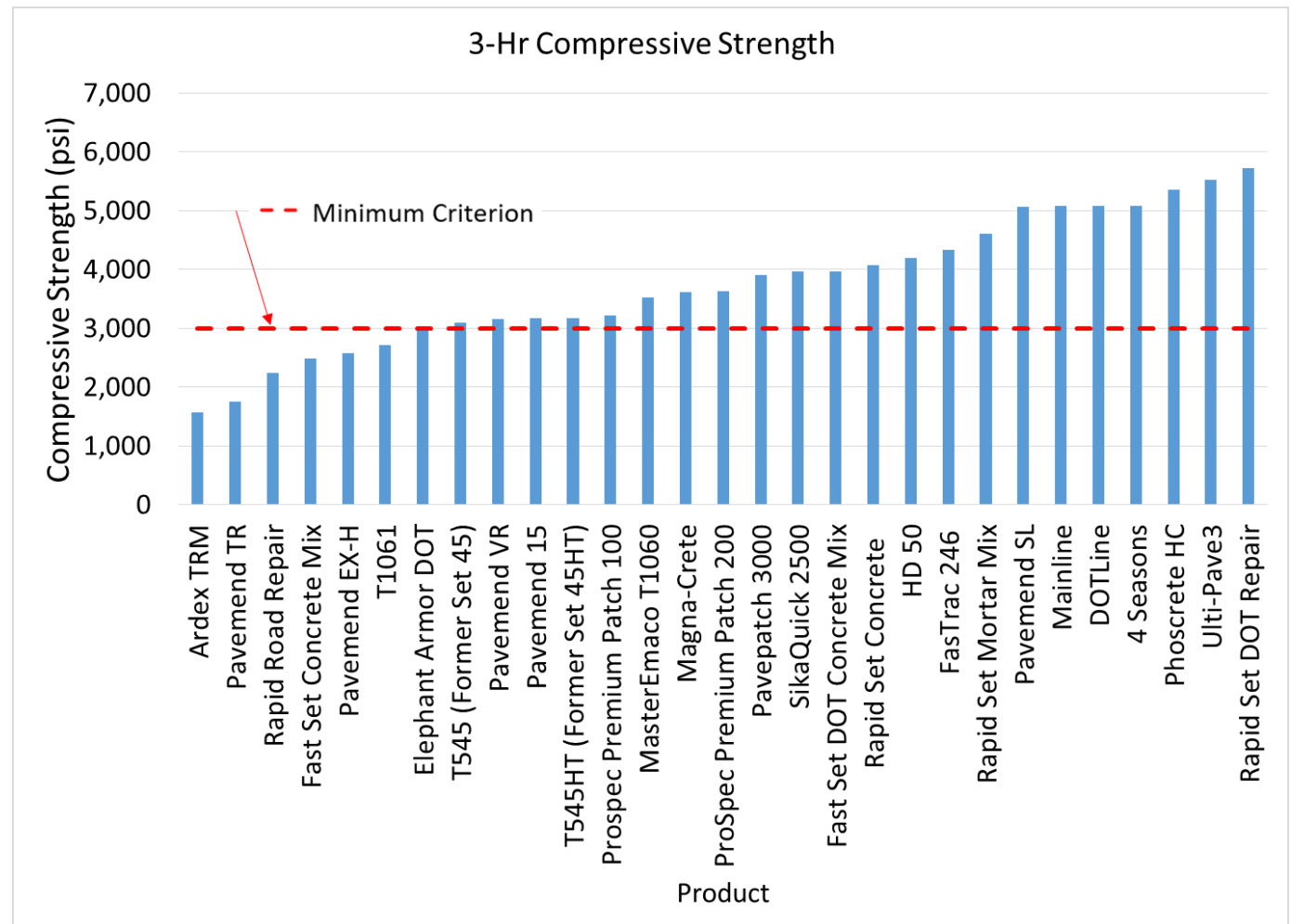

(b) Product comparison at 3-hr compressive strength. 


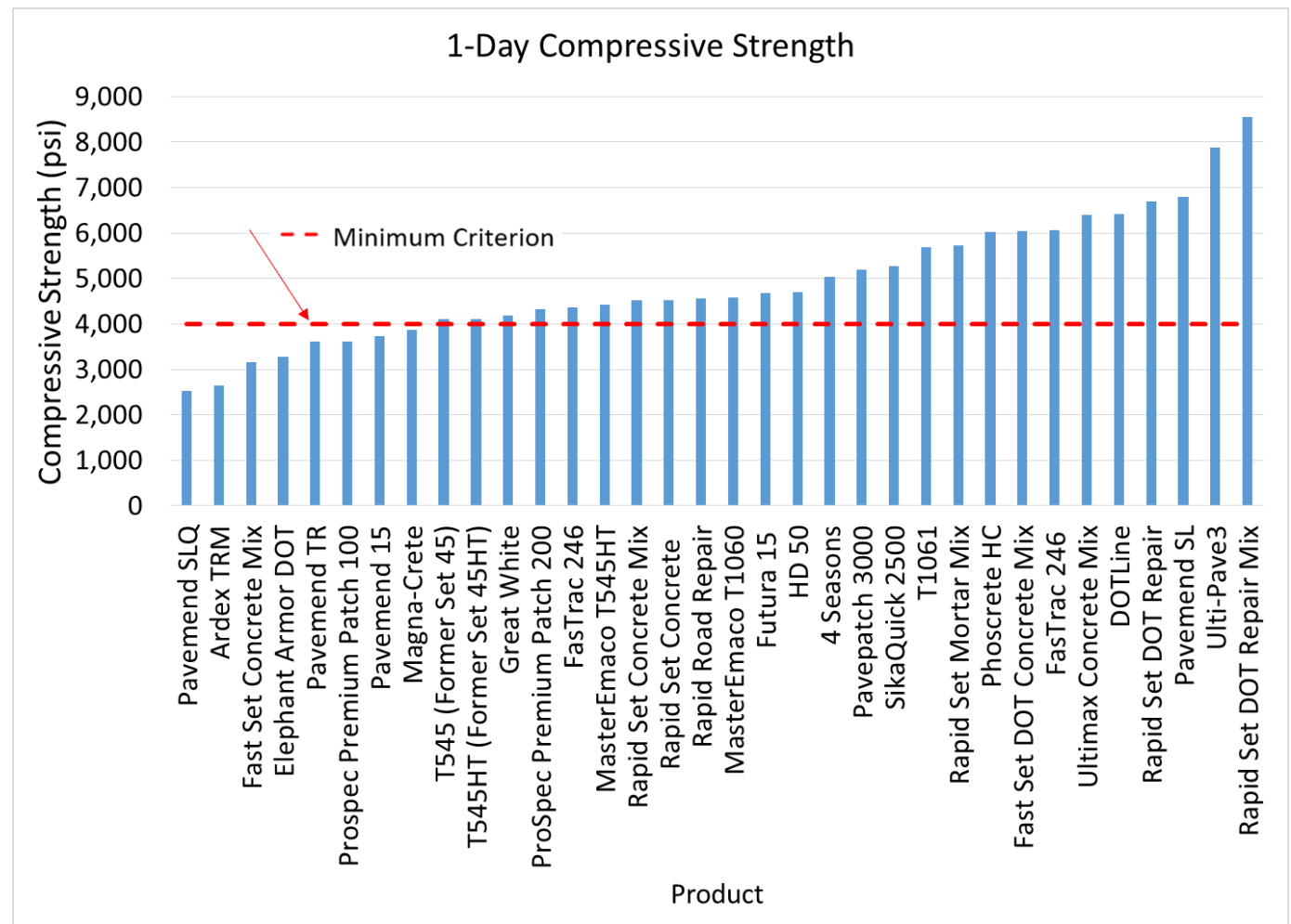

(c) Product comparison at 1 day compressive strength.

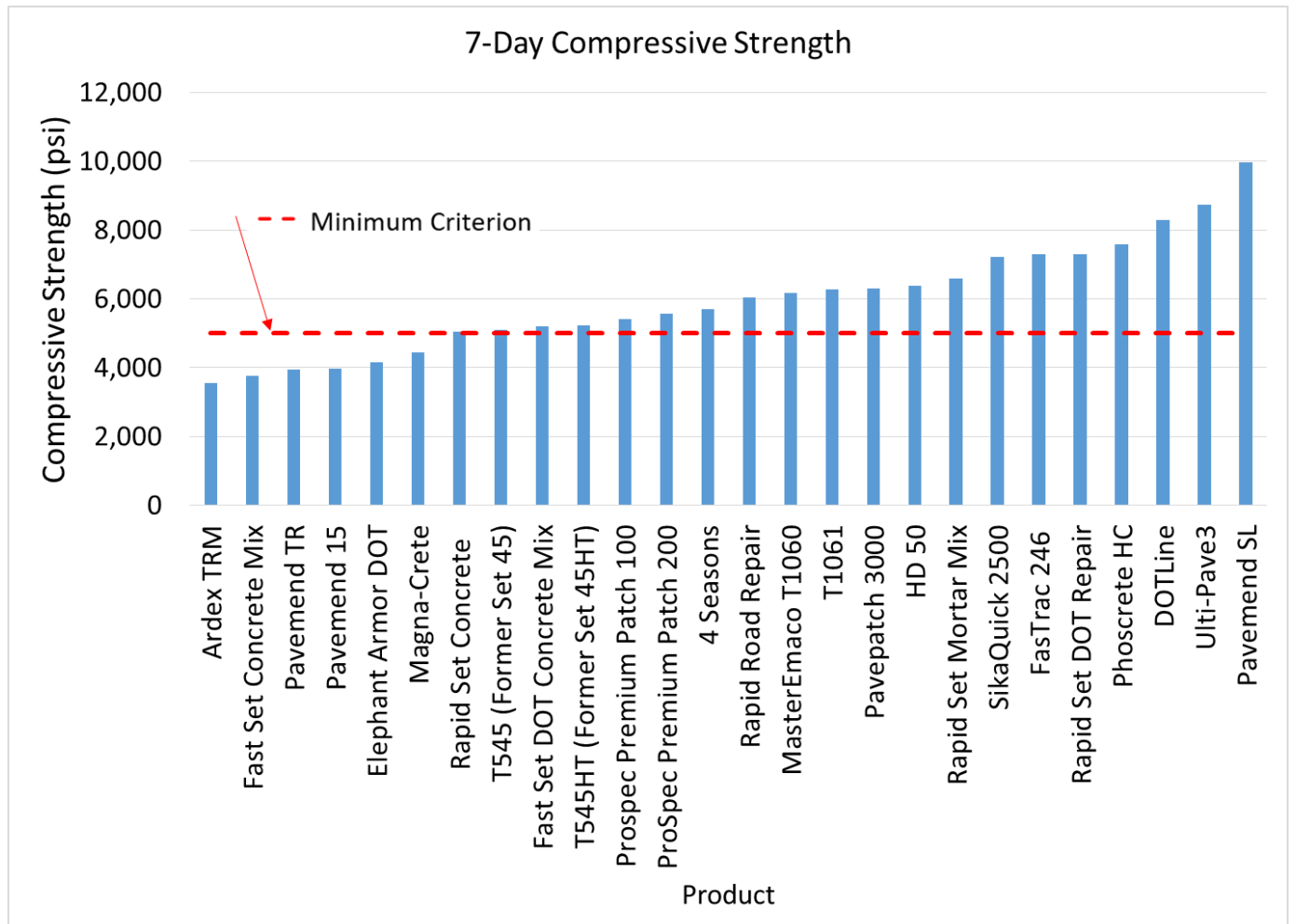

(d) Product comparison at 7-day compressive strength. 


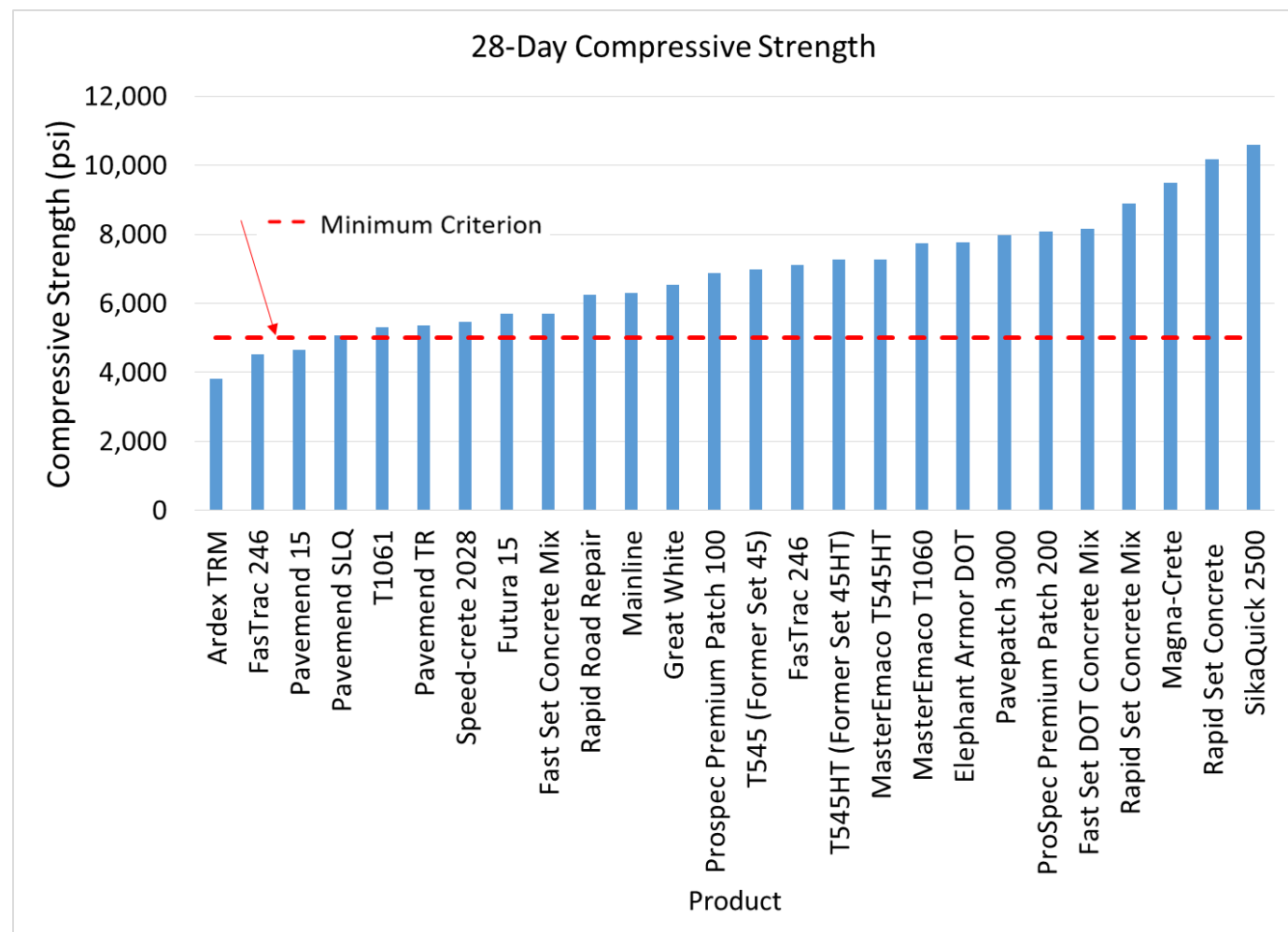

(e) Product comparison at 28-day compressive strength.

\subsection{Flexural strength}

Comparisons of the flexural strengths are detailed in Table 8 and illustrated in Figure 15. Based on these results, the following modifications are recommended.

- The rate of flexural strength development was similar to the rate of strength development shown by compressive strengths.

- No changes are recommended for the current 2-hr pass criteria of 350 psi.

- It is recommended that the 7-day strength requirement decrease from $600 \mathrm{psi}$ to $500 \mathrm{psi}$. This is based on the test results showing a more appropriate trend. 
Table 8. Summary of flexural strength results.

\begin{tabular}{|c|c|c|c|c|c|}
\hline \multirow[b]{2}{*}{ Product Name } & \multirow[b]{2}{*}{ Manufacturer } & \multirow{2}{*}{$\begin{array}{l}\text { Year } \\
\text { Tested }\end{array}$} & \multicolumn{3}{|c|}{ Flexural Strength (psi) } \\
\hline & & & $2 \mathrm{hrs}$ & 7 days & 28 days \\
\hline Pavemend SLQ & Cera Tech, Inc. & 2008 & - & 305 & - \\
\hline Ultimax Concrete Mix & Ultimax Cement & 2008 & 385 & - & - \\
\hline Futura 15 & W.R. Meadows & 2008 & 475 & - & - \\
\hline Pavemend VR & Cera Tech, Inc. & 2008 & 310 & - & - \\
\hline Great White & Cera Tech, Inc. & 2009 & 355 & - & - \\
\hline Mainline & Cera Tech, Inc. & 2009 & 320 & 430 & - \\
\hline Fast Set DOT Concrete Mix & Quickcrete Companies & 2010 & 560 & 805 & 840 \\
\hline Rapid Set Concrete Mix & CTS Cement Corp. & 2010 & 390 & - & 580 \\
\hline FasTrac & Western Material \& Design & 2010 & 385 & - & - \\
\hline Speedcrete 2028 & Euclid Chemical Co. & 2010 & 353 & - & - \\
\hline DOT Line & CeraTech, Inc. & 2013 & 620 & 985 & 1,095 \\
\hline Pavepatch 3000 & Dayton Superior Corp. & 2013 & 490 & 530 & 790 \\
\hline SikaQuick 2500 & Sika Corp. & 2013 & 610 & 680 & 1,250 \\
\hline MasterEmaco T1060 & BASF & 2013 & 470 & 710 & 690 \\
\hline Pavemend SL & Cera Tech, Inc. & 2013 & 645 & 790 & 2,340 \\
\hline Phoscrete 4 Seasons & Phoscrete Corp. & 2013 & 495 & 560 & 545 \\
\hline Ulti-Pave3 & Buzzi-Unicem USA, Inc. & 2014 & 465 & 790 & 875 \\
\hline Ardex TRM & Ardex Americas & 2014 & 235 & 490 & 505 \\
\hline Fast Set Concrete Mix & Quikcrete Companies & 2014 & 370 & 425 & 450 \\
\hline Rapid Road Repair & Quikcrete Companies & 2014 & 380 & 840 & 1,045 \\
\hline HD 50 & Dayton Superior Corp. & 2015 & 625 & 710 & 770 \\
\hline Rapid Set Mortar Mix & CTS Cement Corp. & 2015 & 425 & 560 & 820 \\
\hline Magna-Crete & Henkel Americas & 2015 & 515 & 610 & 730 \\
\hline Pavemend 15 & Cera Tech, Inc. & 2015 & 275 & 460 & 445 \\
\hline Prospec Premium Patch 100 & H.B. Fuller Construction & 2015 & 430 & 585 & 685 \\
\hline ProSpec Premium Patch 200 & H.B. Fuller Construction & 2015 & 515 & 750 & 815 \\
\hline Phoscrete HC & Phoscrete Corp. & 2016 & 565 & 685 & 880 \\
\hline Elephant Armor DOT & GST International & 2016 & 1,260 & 1,350 & 1,355 \\
\hline FasTrac 246 Concrete & Western Material \& Design & 2016 & 360 & 915 & 1,210 \\
\hline Rapid Set DOT Repair & CTS Cement Corp. & 2017 & 800 & 985 & 875 \\
\hline Pavemend TR & Cera Tech, Inc. & 2017 & 190 & 490 & 475 \\
\hline T545 (Formerly Set 45) & BASF & 2017 & 355 & 520 & 610 \\
\hline T545HT (Formerly Set 45HT) & BASF & 2017 & 355 & 520 & 615 \\
\hline Rapid Set Concrete & CTS Cement Corp. & 2017 & 460 & 540 & 605 \\
\hline T1061 & BASF & 2017 & 150 & 840 & 860 \\
\hline
\end{tabular}


Figure 15. Summary of flexural strength product comparison by age.

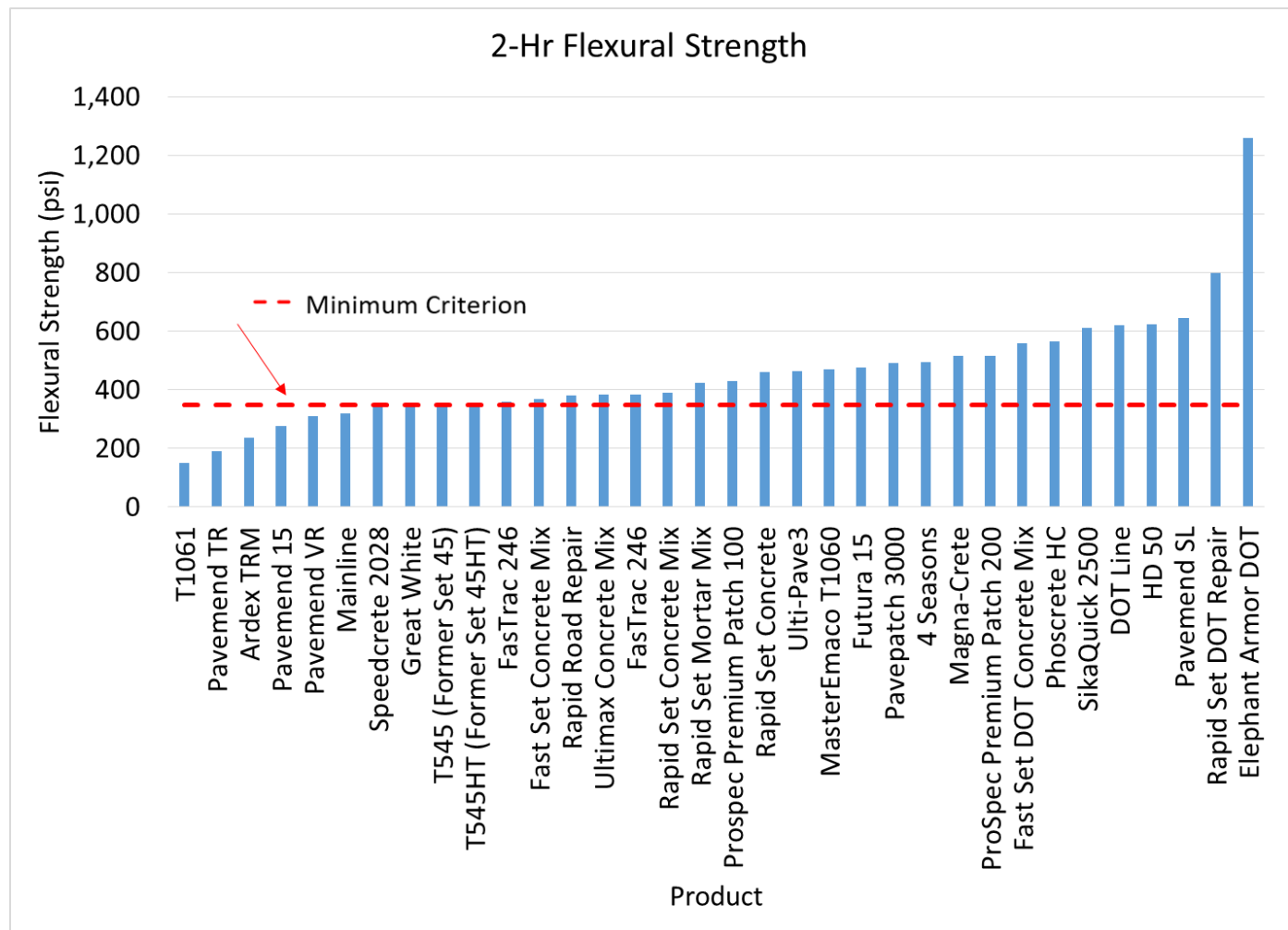

(a) Product comparison at 2-hr flexural strength.

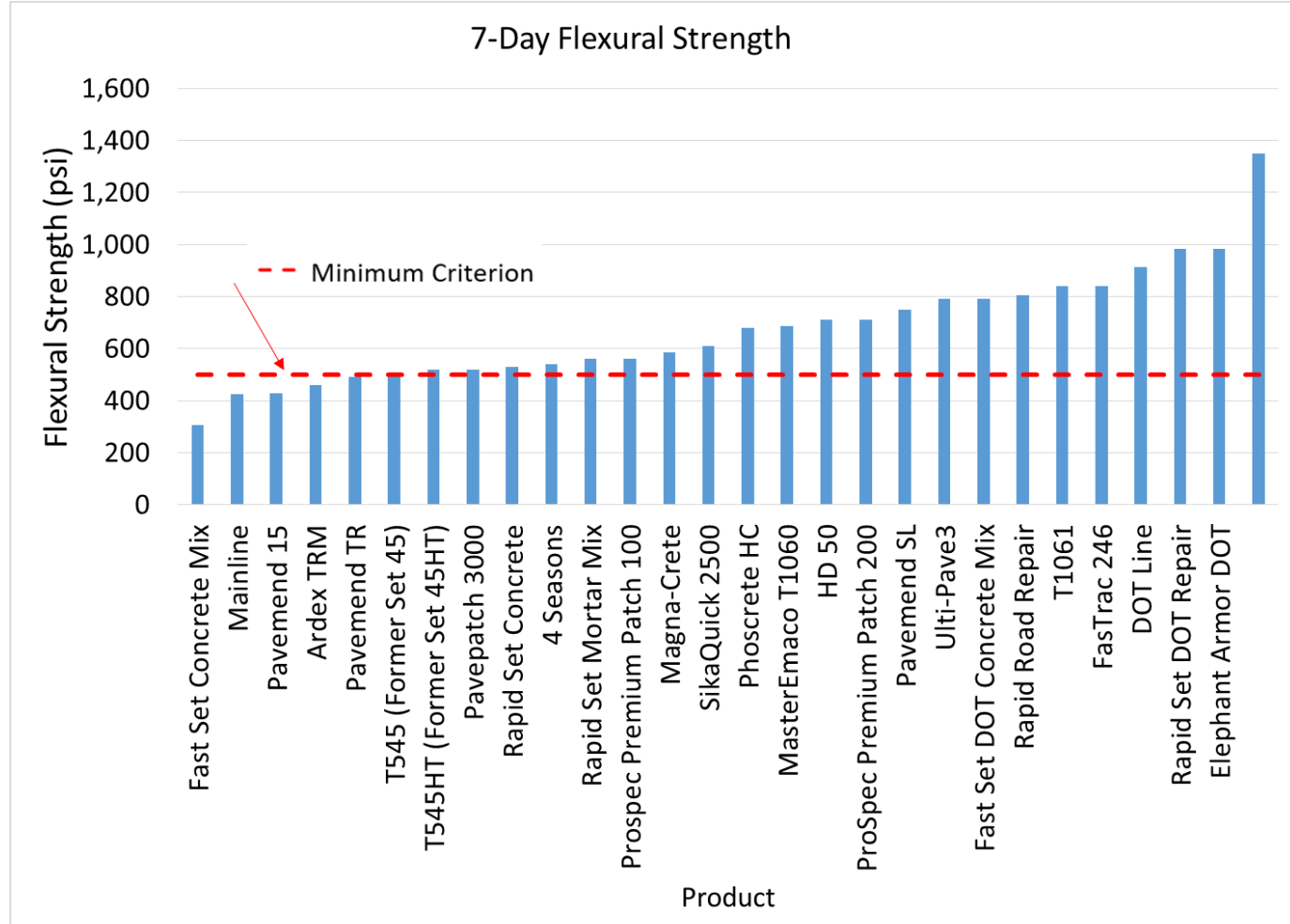

(b) Product comparison at 7-day flexural strength. 


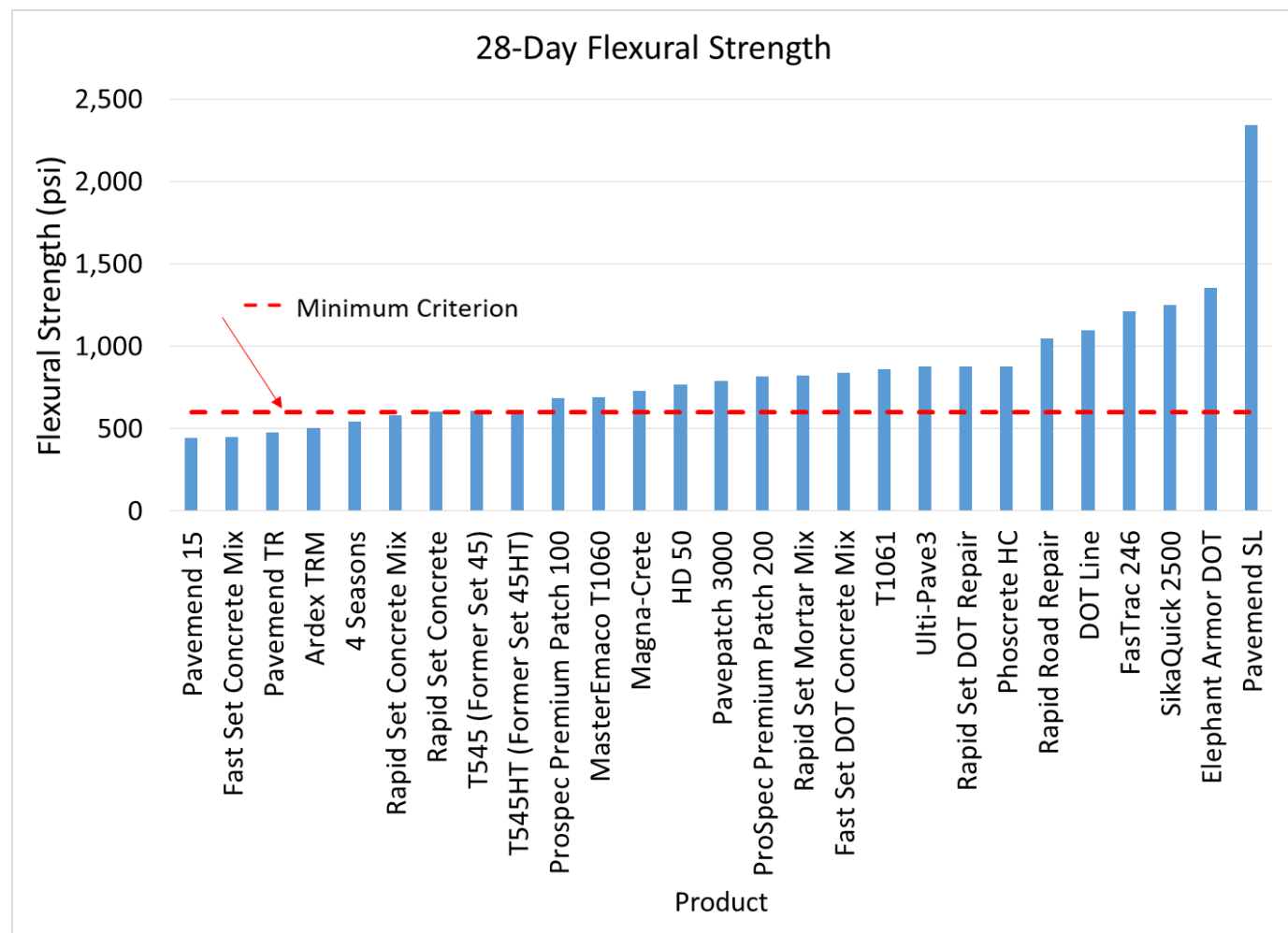

(c) Product comparison at 28-day flexural strength.

\subsection{Bond strength}

The ASTM C928 (2013b) provides a minimum performance requirement for this test of 1,000 psi at 1 day and 1,500 psi at 7 days for the rapidsetting material bonded to rapid-setting material (RS/RS). No criterion is provided in this standard for rapid-setting material bonded to portland cement concrete (PCC) material (RS/PCC). The current protocol requires a minimum of 1,000 psi for both RS/RS and RS/PCC at 1 day but no requirement at 7 days. Comparisons of the bond strengths are detailed in Table 9 and illustrated in Figure 16. Based on these results, the following modifications are recommended:

- No changes are recommended for the 1-day pass criterion of 1,00o psi on both the RS/RS and RS/PCC specimens. The majority of products meet or exceed this minimum value.

- Establish the 7-day pass criteria of 1,250 psi for the RS/ PCC specimens and 1,500 psi for RS/RS specimens. 
Table 9. Summary of bond strength results.

\begin{tabular}{|c|c|c|c|c|c|c|}
\hline \multirow[b]{2}{*}{ Product Name } & \multirow[b]{2}{*}{ Manufacturer } & \multirow[b]{2}{*}{ Year Tested } & \multicolumn{2}{|c|}{ RS/RS (psi) } & \multicolumn{2}{|c|}{ RS/PCC (psi) } \\
\hline & & & 1 day & 7 days & 1 day & 7 days \\
\hline Rapid Set DOT Repair Mix & CTS Cement Corp & 2007 & - & - & 1,470 & - \\
\hline MasterEmaco T545HT & BASF & 2007 & - & - & 1,240 & - \\
\hline Pavemend SLQ & Cera Tech, Inc. & 2008 & - & - & 910 & - \\
\hline Ultimax Concrete Mix & Ultimax Cement & 2008 & - & - & 1,930 & - \\
\hline Versapeed & Euclid Chemical Co. & 2008 & - & - & 1,290 & - \\
\hline Futura 15 & W.R. Meadows & 2008 & - & - & 325 & - \\
\hline Pavemend VR & Cera Tech, Inc. & 2008 & 595 & - & - & - \\
\hline Great White & CeraTech, Inc. & 2009 & - & - & 891 & - \\
\hline Mainline & Cera Tech, Inc. & 2009 & - & - & 1,672 & - \\
\hline Fast Set DOT Concrete Mix & Quickcrete Companies & 2010 & 1,430 & 2,133 & 1,600 & 2,380 \\
\hline Rapid Set Concrete Mix & CTS Cement Corp & 2010 & - & - & 850 & - \\
\hline FasTrac & Western Material & 2010 & - & - & 2,737 & - \\
\hline DOTLine & CeraTech, Inc. & 2013 & 2,220 & 3,030 & 2,030 & 2,420 \\
\hline Pavepatch 3000 & Dayton Superior Corp & 2013 & 1,260 & 1,900 & 1,030 & 1,470 \\
\hline SikaQuick 2500 & Sika Corp & 2013 & 1,250 & 1,840 & 1,170 & 1,410 \\
\hline MasterEmaco T1060 & BASF & 2013 & 1,530 & 1,960 & 1,350 & 1,930 \\
\hline Pavemend SL & Cera Tech, Inc. & 2013 & 1,610 & 2,400 & 1,600 & 1,990 \\
\hline 4 Seasons & Phoscrete Corp. & 2013 & 2,350 & 2,570 & 1,080 & 1,160 \\
\hline Ulti-Pave3 & Buzzi-Unicem USA Inc. & 2014 & 1,720 & 2,360 & 1,390 & 1,740 \\
\hline Ardex TRM & Ardex Americas & 2014 & 1,600 & 2,120 & 1,240 & 1,450 \\
\hline Fast Set Concrete Mix & Quikcrete Companies & 2014 & 1,080 & 1,470 & 1,320 & 1,580 \\
\hline Rapid Road Repair & Quikcrete Companies & 2014 & 1,950 & 2,970 & 1,350 & 1,520 \\
\hline HD 50 & Dayton Superior Corp & 2015 & 1,820 & 2,960 & 1,550 & 2,390 \\
\hline Prospec Premium Patch 100 & H.B. Fuller Construction & 2015 & 1,200 & 1,690 & 1,040 & 1,550 \\
\hline ProSpec Premium Patch 200 & H.B. Fuller Construction & 2015 & 1,780 & 2,350 & 1,820 & 2,150 \\
\hline Rapid Set Mortar Mix & CTS Cement Corp & 2015 & 1,480 & 2,100 & 1,300 & 1,910 \\
\hline Magna-Crete & Henkel Americas & 2015 & 2,250 & 2,430 & 1,790 & 2,430 \\
\hline Pavemend 15 & Cera Tech, Inc. & 2015 & 1,130 & 1,790 & 820 & 1,010 \\
\hline Phoscrete HC & Phoscrete Corp. & 2016 & 2,040 & 2,330 & 1,590 & 1,720 \\
\hline Elephant Armor DOT & GST International & 2016 & 1,490 & 1,910 & 690 & 770 \\
\hline FasTrac 246 Concrete & Western Material \& Design & 2016 & 1,920 & 2,290 & 1,870 & 1,945 \\
\hline Rapid Set DOT Repair & CTS Cement Corp. & 2017 & 2,370 & 2,440 & 2,430 & 2,540 \\
\hline Pavemend TR & CeraTech & 2017 & 1,790 & 1,920 & 1,560 & 1,770 \\
\hline T545 (Formerly Set 45) & BASF & 2017 & 1,600 & 1,780 & 1,050 & 1,340 \\
\hline T545HT (Formerly Set 45HT) & BASF & 2017 & 1,580 & 1,780 & 1,130 & 1,530 \\
\hline Rapid Set Concrete & CTS Cement Corp. & 2017 & 2,200 & 2,620 & 1,800 & 2,130 \\
\hline T1061 & BASF & 2017 & 1,970 & 2,710 & 1,880 & 2,360 \\
\hline
\end{tabular}


Figure 16. Summary of bond strength product comparison by age.

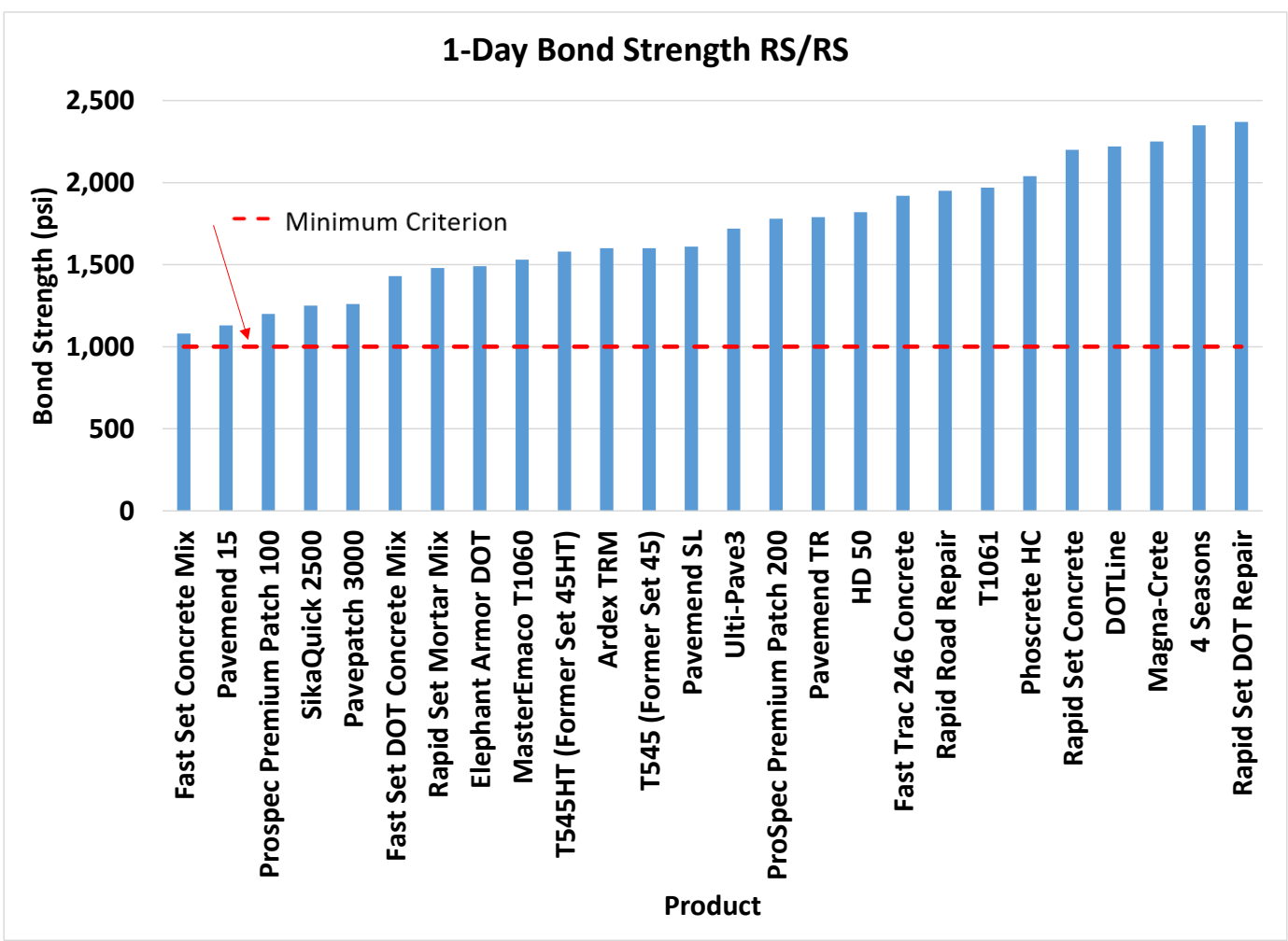

(a) Product comparison at 1-day bond strength RS/RS.

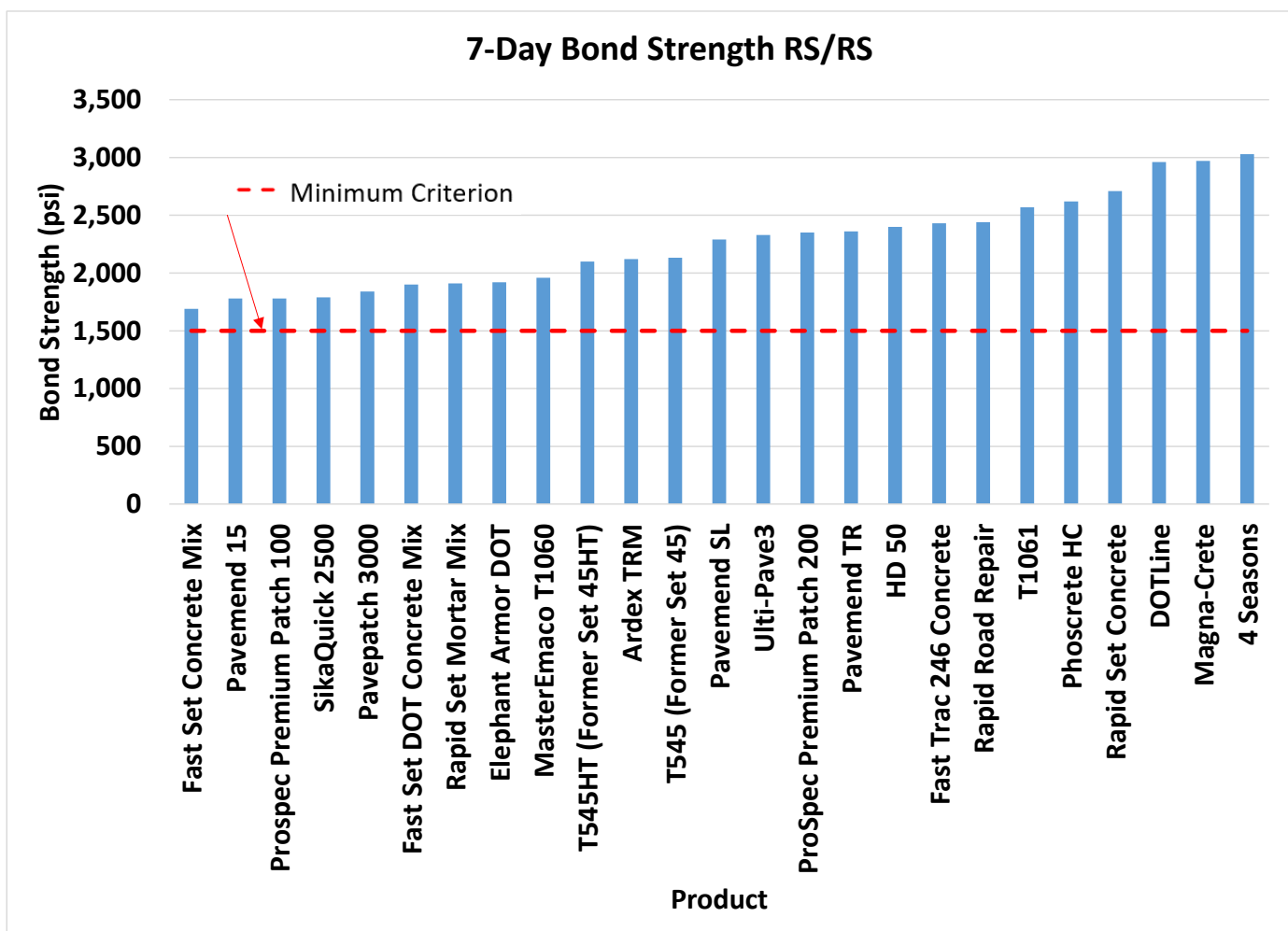

(b) Product comparison at 7-day bond strength RS/RS. 


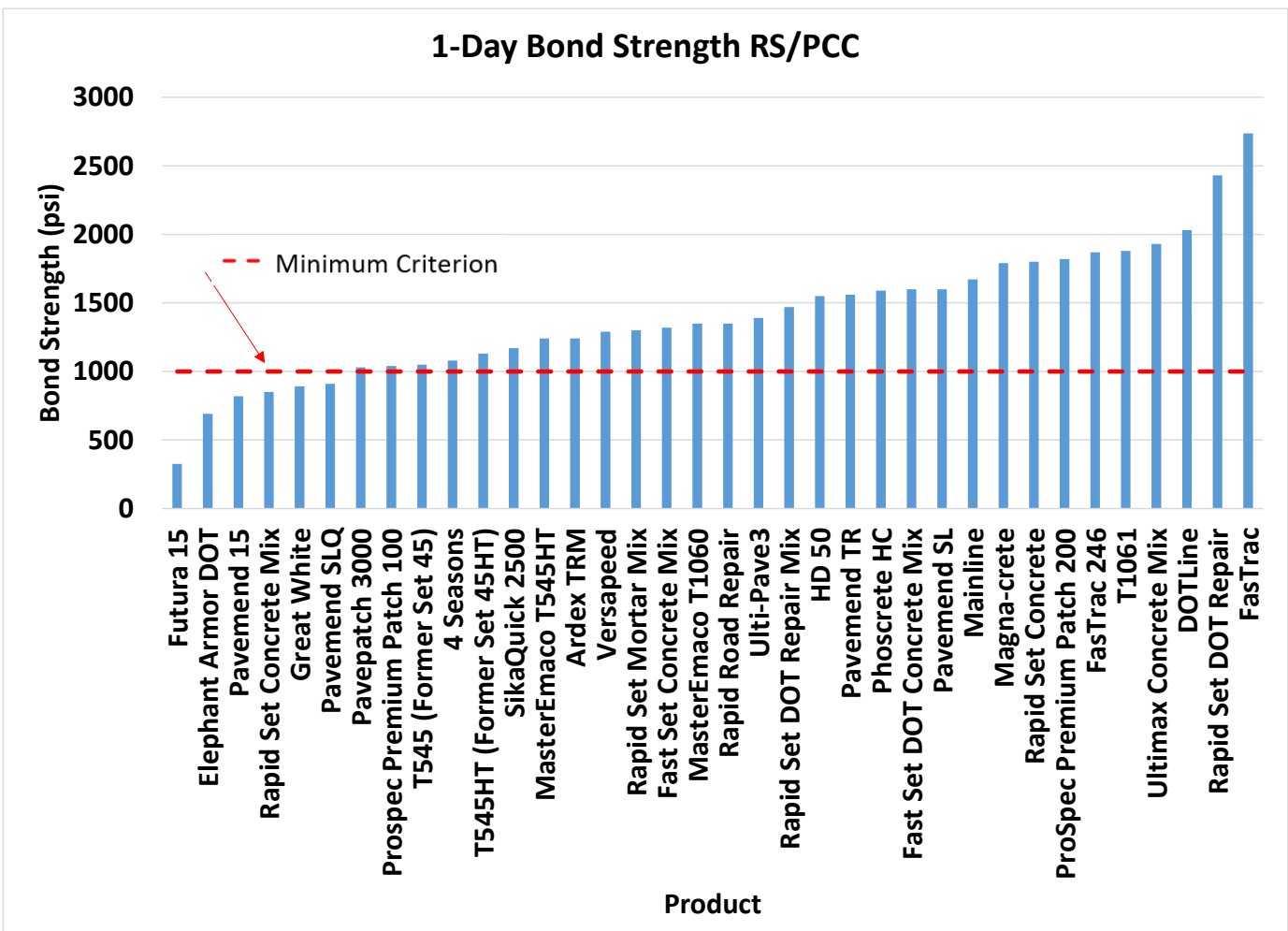

(c) Product comparison at 1-day bond strength RS/PCC.

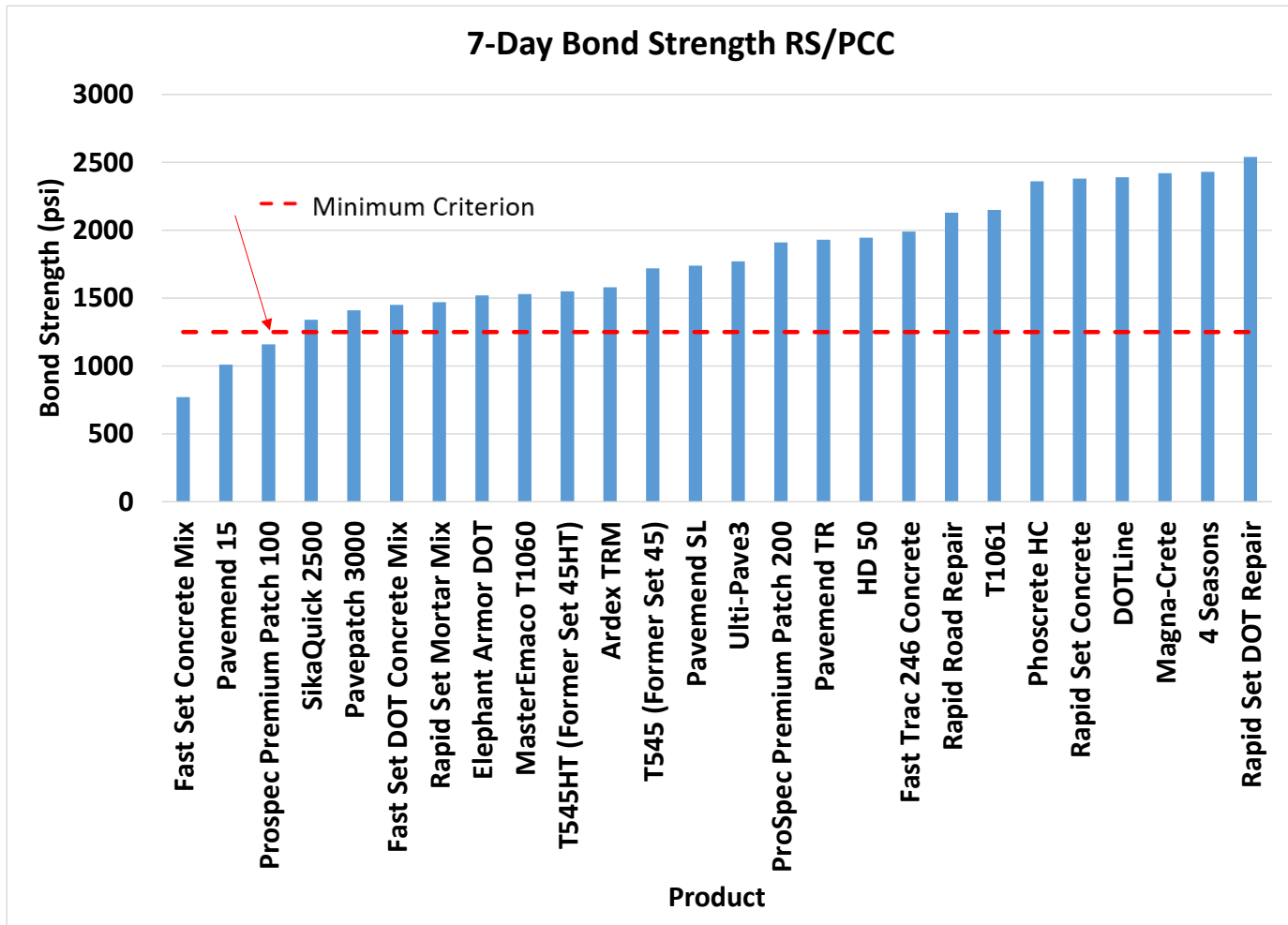

(d) Product comparison at 7-day bond strength RS/PCC. 


\subsection{Modulus of elasticity}

Comparisons of the modulus of elasticity results are in Table 10. Based on these results, the established limits of between 2 and $6 \mathrm{Mpsi}$ at the test ages of $2 \mathrm{hr}$ and 28 days appear appropriate; thus, no changes are recommended at this time.

Table 10. Summary of modulus of elasticity results.

\begin{tabular}{|c|c|c|c|c|}
\hline \multirow[b]{2}{*}{ Product Name } & \multirow[b]{2}{*}{ Manufacturer } & \multirow[b]{2}{*}{ Year Tested } & \multicolumn{2}{|c|}{$\begin{array}{l}\text { Modulus of Elasticity } \\
\text { (Mpsi) }\end{array}$} \\
\hline & & & $2 \mathrm{hrs}$ & 28 days \\
\hline Rapid Set DOT Repair Mix & CTS Cement Corp. & 2007 & 5.50 & - \\
\hline Pavemend EX-H & Cera Tech, Inc. & 2007 & 0.35 & - \\
\hline Pavemend SLQ & Cera Tech, Inc. & 2008 & 1.50 & - \\
\hline Ultimax Concrete Mix & Ultimax Cement & 2008 & 2.80 & - \\
\hline Great White & Cera Tech, Inc. & 2009 & 3.60 & - \\
\hline Mainline & Cera Tech, Inc. & 2009 & 2.35 & - \\
\hline Fast Set DOT Concrete Mix & Quickcrete Companies & 2010 & 1.95 & 3.75 \\
\hline Rapid Set Concrete Mix & CTS Cement Corp. & 2010 & 3.15 & - \\
\hline FasTrac & Western Material \& Design & 2010 & 3.5 & - \\
\hline DOTLine & Cera Tech, Inc. & 2013 & 2.95 & 5.35 \\
\hline Pavepatch 3000 & Dayton Superior Corp. & 2013 & 5.05 & 4.85 \\
\hline SikaQuick 2500 & Sika Corp. & 2013 & 4.30 & 5.40 \\
\hline MasterEmaco T1060 & BASF & 2013 & 4.95 & 6.65 \\
\hline Pavemend SL & Cera Tech, Inc. & 2013 & 3.60 & 6.20 \\
\hline Phoscrete 4 Seasons & Phoscrete Corp. & 2013 & 2.20 & 3.70 \\
\hline Ulti-Pave3 & Buzzi-Unicem USA, Inc. & 2014 & 2.50 & 4.75 \\
\hline Ardex TRM & Ardex Americas & 2014 & - & 3.25 \\
\hline Fast Set Concrete Mix & Quikcrete Companies & 2014 & 1.95 & 4.00 \\
\hline Rapid Road Repair & Quikcrete Companies & 2014 & 1.40 & 3.90 \\
\hline HD 50 & Dayton Superior Corp. & 2015 & 3.30 & 4.70 \\
\hline Prospec Premium Patch 100 & H.B. Fuller Construction & 2015 & 2.75 & 4.70 \\
\hline ProSpec Premium Patch 200 & H.B. Fuller Construction & 2015 & 2.95 & 4.40 \\
\hline Rapid Set Mortar Mix & CTS Cement Corp. & 2015 & 2.20 & 3.10 \\
\hline Magna-Crete & Henkel Americas & 2015 & 3.30 & 7.90 \\
\hline Pavemend 15 & Cera Tech, Inc. & 2015 & 0.95 & 2.35 \\
\hline Phoscrete HC & Phoscrete Corp. & 2016 & 3.40 & 4.27 \\
\hline Elephant Armor DOT & GST International & 2016 & 3.40 & 4.65 \\
\hline FasTrac 246 Concrete & Western Material \& Design & 2016 & 3.20 & 4.70 \\
\hline
\end{tabular}




\begin{tabular}{|c|c|c|c|c|}
\hline Pavemend TR & Cera Tech, Inc. & 2017 & 3.68 & 4.28 \\
\hline T545 (Formerly Set 45) & BASF & 2017 & 2.35 & 5.35 \\
\hline T545HT (Formerly Set 45HT) & BASF & 2017 & 2.72 & 5.32 \\
\hline Rapid Set Concrete & CTS Cement Corp. & 2017 & 3.34 & 4.08 \\
\hline T1061 & BASF & 2017 & 3.27 & 6.12 \\
\hline
\end{tabular}

\subsection{Time of setting}

Data comparison of the times of setting is shown in Table 11. Graphs of the initial and final setting based on the ASTM C191 (2013c) and ASTM C4O3 (2016f) methods are illustrated in Figures 17 and 18. Based on these results, modifications are recommended on both testing requirement methods and pass/fail criteria for the initial and final set times. The current protocol recommends testing by the Vicat method of ASTM C191. However, many of the products are either extended with pea gravel or have aggregates already in the proprietary mix. The current test method is ASTM C191, which is for a cement paste only. When conducting this test on products, the aggregates are wet sieved over a No. 4 sieve before being placed in the mold and having the set time monitored. Although not in the current protocols, the ASTM C403 (2016f) time of setting of concrete mixtures by penetration resistance has also been conducted on products tested between 2013 and 2017. For some products, the time of setting deviated from the Vicat versus the penetrometer testing. It is recommended that the time of setting be conducted by the ASTM C4O3 procedure without sieving the aggregates to more accurately represent the field concrete placement of the rapid-repair material.

The published protocol shows no requirements for the initial and final set times, but the current pass criteria for initial set is over $15 \mathrm{~min}$ and for final set between 25-35 min. However, many products fail on one or both of these parameters by having a high initial set time with no upper boundary provided, and/or failing the final set time by having a set time over $35 \mathrm{~min}$. It is recommended the initial set requirement be between 15 to $90 \mathrm{~min}$. and the final set time be less than $2 \mathrm{hr}$, provided it meets the strength requirements at $2 \mathrm{hr}$. 
Table 11. Summary of time of setting results.

\begin{tabular}{|c|c|c|c|c|c|c|}
\hline \multirow[b]{2}{*}{ Product Name } & \multirow[b]{2}{*}{ Manufacturer } & \multirow[b]{2}{*}{ Year Tested } & \multicolumn{2}{|c|}{ ASTM C191 } & \multicolumn{2}{|c|}{ ASTM C403 } \\
\hline & & & $\begin{array}{l}\text { Initial } \\
\text { (min) }\end{array}$ & $\begin{array}{l}\text { Final } \\
(\min )\end{array}$ & $\begin{array}{l}\text { Initial } \\
\text { (min) }\end{array}$ & $\begin{array}{l}\text { Final } \\
(\min )\end{array}$ \\
\hline MasterEmaco T545HT & BASF & 2007 & 25 & 35 & - & - \\
\hline Ultimax Concrete Mix & Ultimax Cement & 2008 & 30 & 75 & - & - \\
\hline Mainline & Cera Tech, Inc. & 2009 & 22 & - & - & - \\
\hline Fast Set DOT Concrete Mix & Quickcrete Companies & 2010 & 55 & 61 & - & - \\
\hline FasTrac & $\begin{array}{l}\text { Western Material \& } \\
\text { Design,LLC }\end{array}$ & 2010 & 44 & 50 & - & - \\
\hline Speedcrete 2028 & Euclid Chemical Co. & 2010 & 34 & 38.5 & - & - \\
\hline DOTLine & CeraTech, Inc. & 2013 & 33 & 44 & 38 & 40 \\
\hline Pavepatch 3000 & Dayton Superior Corp. & 2013 & 26 & 60 & 38 & 58 \\
\hline SikaQuick 2500 & Sika Corp. & 2013 & 21 & 44 & 21 & 46 \\
\hline MasterEmaco T1060 & BASF & 2013 & 25 & 30 & 43 & 47 \\
\hline Pavemend SL & Cera Tech, Inc. & 2013 & 20 & 40 & 24 & 35 \\
\hline Phoscrete 4 Seasons & Phoscrete Corp. & 2013 & 20 & 25 & 6 & 8 \\
\hline Ulti-Pave3 & Buzzi-Unicem USA, Inc. & 2014 & 39 & 46 & 25 & 45 \\
\hline Ardex TRM & Ardex Americas & 2014 & 80 & 120 & 120 & 140 \\
\hline Fast Set Concrete Mix & Quikcrete Companies & 2014 & 17 & 21 & 18 & 26 \\
\hline Rapid Road Repair & Quikcrete Companies & 2014 & 20 & 30 & 25 & 37 \\
\hline HD 50 & Dayton Superior Corp. & 2015 & 24 & 27 & 23 & 26 \\
\hline $\begin{array}{l}\text { Prospec Premium Patch } \\
100\end{array}$ & H.B. Fuller Construction & 2015 & 67 & 73 & 65 & 72 \\
\hline $\begin{array}{l}\text { ProSpec Premium Patch } \\
200\end{array}$ & H.B. Fuller Construction & 2015 & 20 & 25 & 20 & 24 \\
\hline Rapid Set Mortar Mix & CTS Cement Corp. & 2015 & 33 & 43 & 37 & 43 \\
\hline Magna-Crete & Henkel Americas & 2015 & 9 & 11 & 8 & 11 \\
\hline Pavemend 15 & Cera Tech, Inc. & 2015 & 9 & 15 & 15 & 30 \\
\hline Phoscrete HC & Phoscrete Corp. & 2016 & 3 & 5 & 4 & 5 \\
\hline Elephant Armor DOT & GST International & 2016 & 28 & 32 & 30 & 35 \\
\hline FasTrac 246 Concrete & $\begin{array}{l}\text { Western Material \& } \\
\text { Design, LLC }\end{array}$ & 2016 & 45 & 65 & 48 & 69 \\
\hline Pavemend TR & CeraTech, Inc. & 2017 & 12 & 18 & 15 & 20 \\
\hline T545 (Formerly Set 45) & BASF & 2017 & 15 & 17 & 15 & 20 \\
\hline $\begin{array}{c}\text { T545HT (Formerly Set } \\
45 \mathrm{HT} \text { ) }\end{array}$ & BASF & 2017 & 16 & 21 & 20 & 24 \\
\hline Rapid Set DOT Repair & CTS Cement Corp. & 2017 & 34 & 43 & 40 & 44 \\
\hline Rapid Set Concrete & CTS Cement Corp. & 2017 & 18 & 23 & 20 & 25 \\
\hline T1061 & BASF & 2017 & 111 & 124 & 72 & 88 \\
\hline
\end{tabular}


Figure 17. Summary of time of setting product comparison based on ASTM C191.

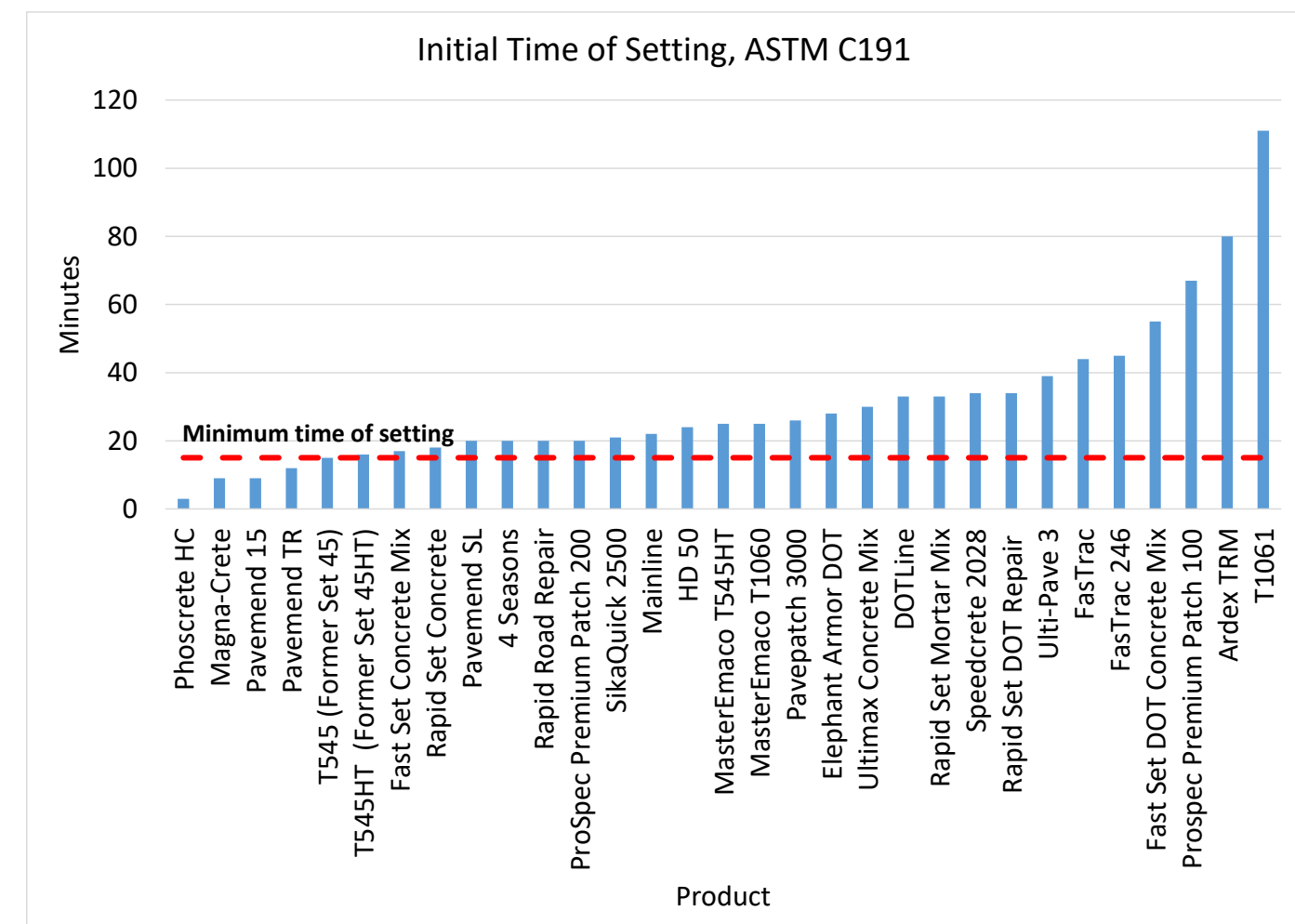

(a) Product comparison of initial time of setting based on ASTM C191.

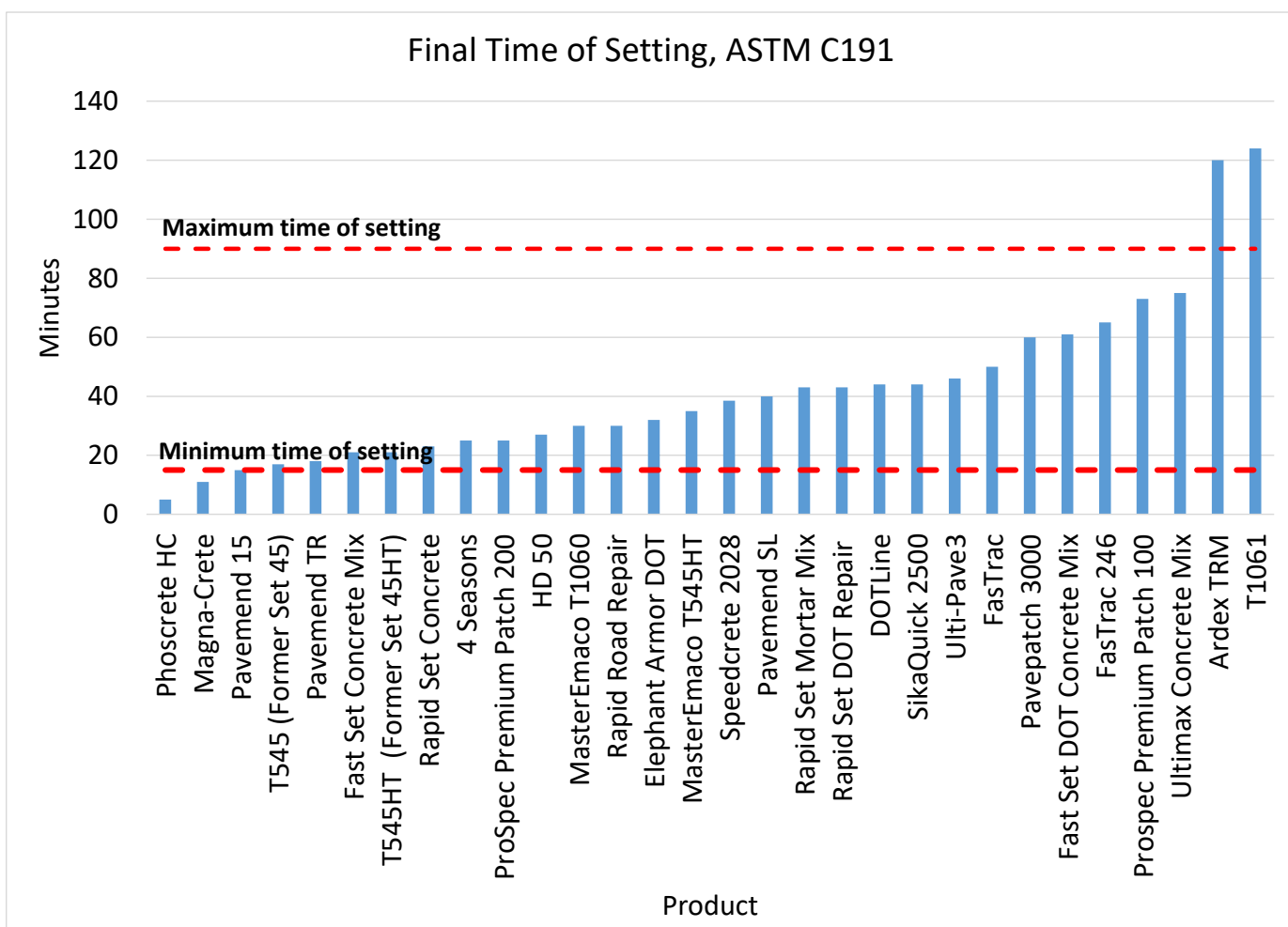

(b) Product comparison of final time of setting based on ASTM C191. 
Figure 18. Summary of time of setting product comparison based on ASTM C403.

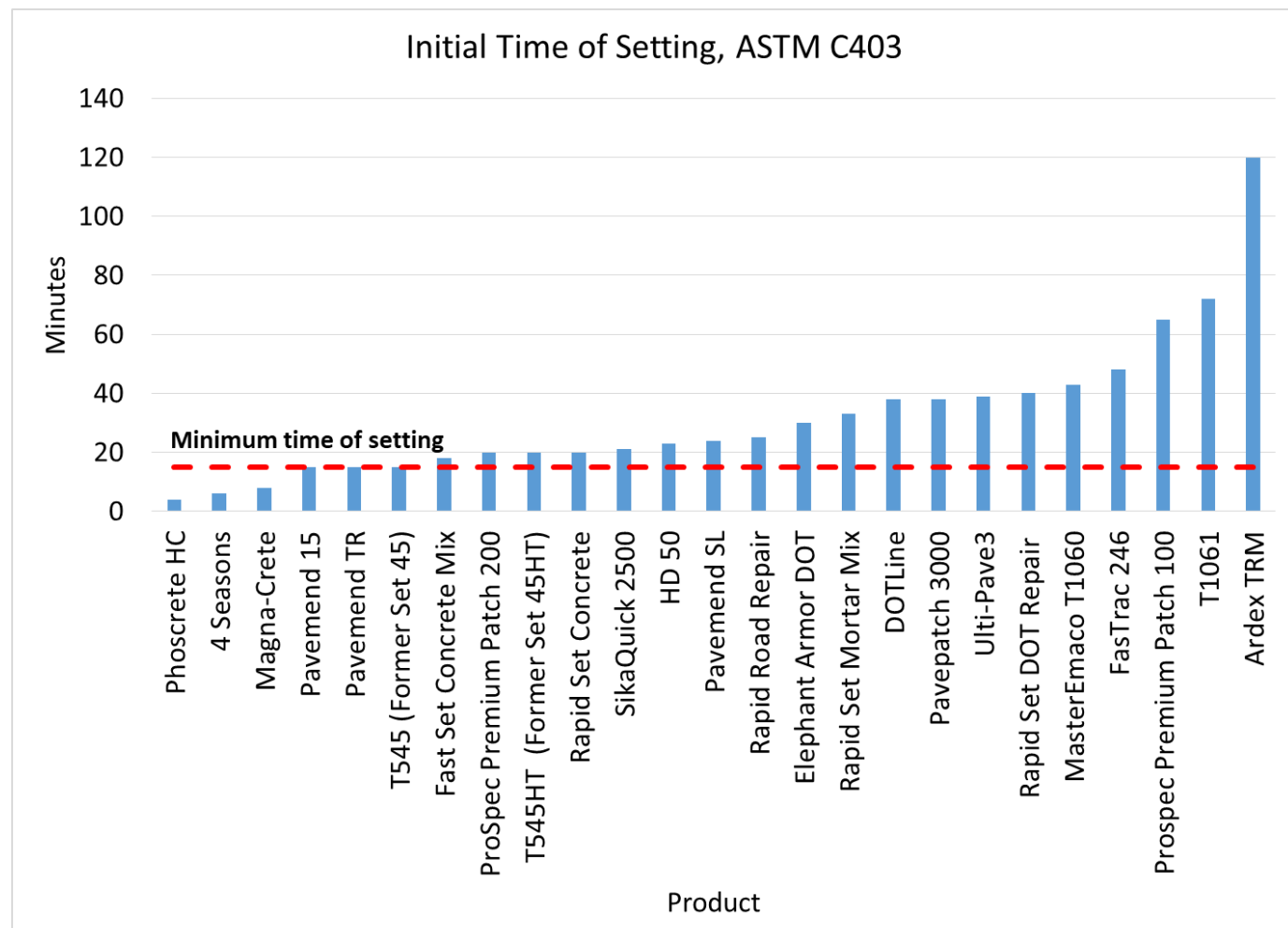

(a) Product comparison of initial time of setting based on ASTM C403.

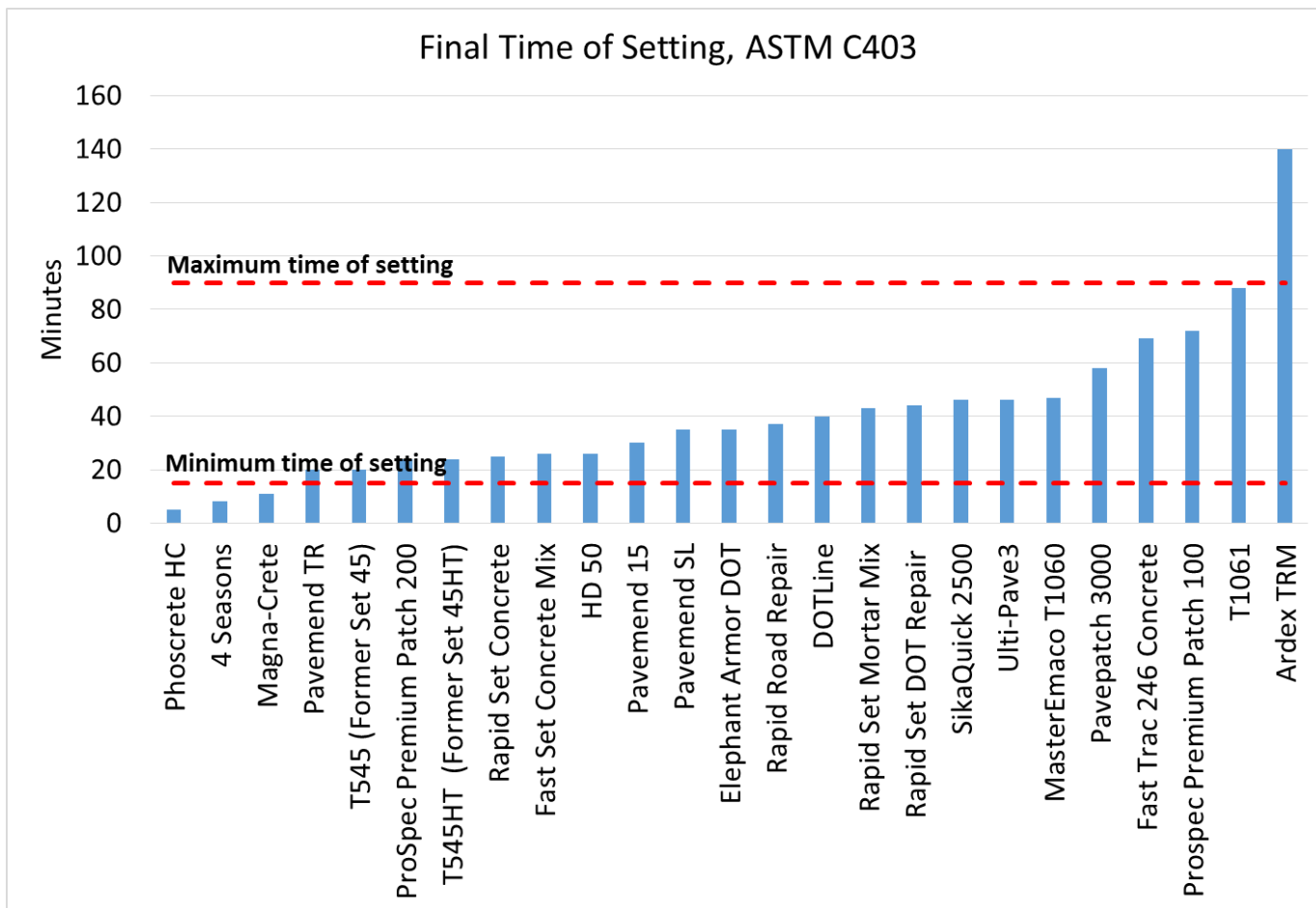

Product

(b) Product comparison of final time of setting based on ASTM C403. 


\subsection{Workability}

Comparisons of the workability are shown in Table 12. No slump requirement was established in the previous test protocol based on the ETL 08-02 (AFCEC 2008), and TR-11-13 (Priddy 2011) requires only that the slump be measured. The ASTM C928 (2013b) recommends a minimum slump of 3 in. for cementitious, rapid-setting materials. The same minimum criterion of 3 in. with no maximum slump or flow is suggested for the new test protocol. The standard slump from ASTM C143 (2015c) is the first test to perform within 5 min of adding the water to the material. If the concrete measures a slump greater than 9 in., the concrete may not be adequately cohesive for this test to have significance, as noted in the standard method. Therefore, a slump flow must then be measured on a new batch of material using procedures detailed in ASTM C1611 (2014b). A flowchart of the workability testing is shown in Figure 19.

Table 12. Summary of slump results.

\begin{tabular}{|c|c|c|c|}
\hline Product Name & Manufacturer & Year Tested & Slump (in.) \\
\hline Fast Set DOT Concrete Mix & Quickcrete Companies & 2010 & 4 \\
\hline DOTLine & Cera Tech, Inc. & 2013 & 5 \\
\hline Pavepatch 3000 & Dayton Superior Corp, & 2013 & 10 \\
\hline SikaQuick 2500 & Sika Corp, & 2013 & 10 \\
\hline MasterEmaco T1060 & BASF & 2013 & 5 \\
\hline Pavemend SL & Cera Tech, Inc. & 2013 & 2.75 \\
\hline Phoscrete 4 Seasons & Phoscrete Corp. & 2013 & 6 \\
\hline Ardex TRM & Ardex & 2013 & 9 \\
\hline Ulti-Pave3 & Buzzi-Unicem USA, Inc. & 2014 & 9 \\
\hline Fast Set Concrete Mix & Quikcrete Companies & 2014 & 3 \\
\hline Rapid Road Repair & Quikcrete Companies & 2014 & 3 \\
\hline HD 50 & Dayton Superior Corp, & 2015 & 11 \\
\hline Prospec Premium Patch 100 & H.B. Fuller Construction Products & 2015 & 2 \\
\hline ProSpec Premium Patch 200 & H.B. Fuller Construction Products & 2015 & 3 \\
\hline Rapid Set Mortar Mix & CTS Cement Corp. & 2015 & 4 \\
\hline Magna-Crete & Henkel Americas & 2015 & 6 \\
\hline Pavemend 15 & Cera Tech, Inc. & 2015 & 19 \\
\hline Phoscrete $\mathrm{HC}$ & Phoscrete Corp. & 2016 & 2 \\
\hline Elephant Armor DOT & GST International & 2016 & 7 \\
\hline FasTrac 246 Concrete & Western Material \& Design, LLC & 2016 & 8 \\
\hline Rapid Set DOT Repair & CTS Cement Corp. & 2017 & 12 \\
\hline
\end{tabular}




\begin{tabular}{|c|c|c|c|}
\hline Pavemend TR & Cera Tech, Inc. & 2017 & 11 \\
\hline T545 (Formerly Set 45) & BASF & 2017 & 7 \\
\hline T545HT (Formerly Set 45HT) & BASF & 2017 & 8 \\
\hline Rapid Set DOT Repair & CTS Cement Corp. & 2017 & 12 \\
\hline Rapid Set Concrete & CTS Cement Corp. & 2017 & 3 \\
\hline T1061 & BASF & 2017 & 2 \\
\hline
\end{tabular}

Figure 19. Flowchart of test requirements for workability.

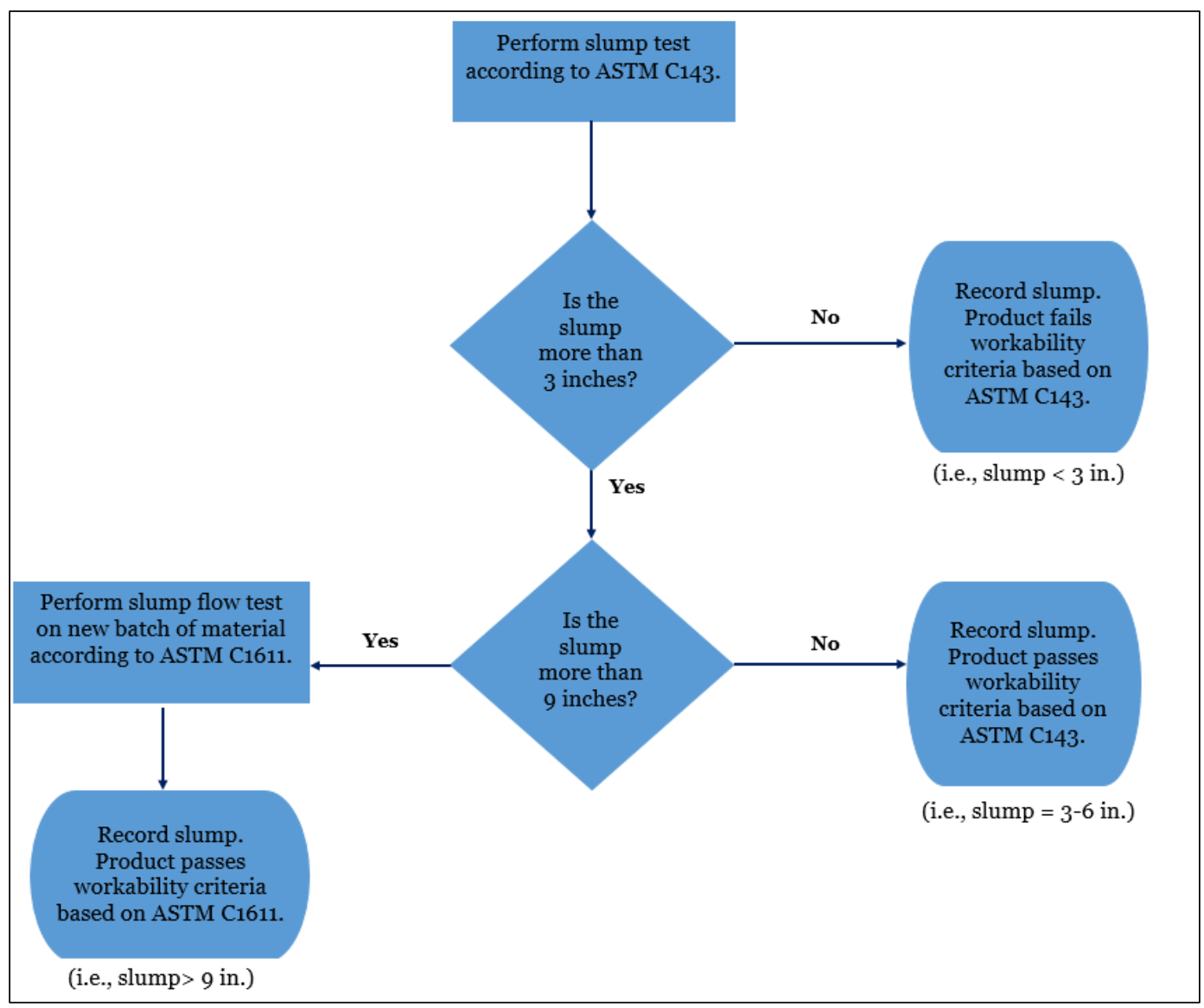

\subsection{Coefficient of thermal expansion}

The current CTE limit is a maximum value of $12 \times 10^{-6}$ (in./in. $/{ }^{\circ} \mathrm{F}$ ) with a test age of 7 days as established in ERDC TR-11-13 (Priddy 2011). Based on the CTE test data shown in in Table 13 and illustrated in Figure 20, all materials tested fall well below this requirement and are more comparable to the value established in ETL 08-O2 (AFCEC 2008) of $7 \times 10^{-6}$ 
(in./in. $/{ }^{\circ} \mathrm{F}$ ). It is recommended that this test limit be reduced to an upper limit of $7 \times 10^{-6}$ (in./in. $/{ }^{\circ} \mathrm{F}$ ).

The testing laboratory followed the procedure for linear shrinkage as suggested in ASTM C531 (2012a) with the frequency of measuring the mortar bars first by daily readings for 2 weeks at $73 \pm 4^{\circ} \mathrm{F}$. A heating and cooling cycle of readings was then carried out on the mortar bars with the following cycle until a constant length change was measured: readings were taken on mortar bars after being stored in an oven at $210^{\circ} \mathrm{F}$ for 3 days; then readings were taken after the bars had been stored in a desiccator overnight and mortar bars had cooled to $73^{\circ} \mathrm{F}$. The average time for a constant linear CTE to be achieved was an additional two weeks.

Table 13. Summary of CTE results.

\begin{tabular}{|c|c|c|c|}
\hline Product Name & Manufacturer & Year Tested & CTE results \\
\hline Pavemend SLQ & Cera Tech, Inc. & 2008 & 6.3 \\
\hline Pavemend TR & Cera Tech, Inc. & 2008 & 6.3 \\
\hline Great White & Cera Tech, Inc. & 2009 & 4.6 \\
\hline Mainline & Cera Tech, Inc. & 2009 & 3.2 \\
\hline Fast Set DOT Concrete Mix & Quickcrete Companies & 2010 & 5.3 \\
\hline Rapid Set Concrete Mix & CTS Cement Corp. & 2010 & 3.4 \\
\hline FasTrac & Western Material \& Design, LLC & 2010 & 2.5 \\
\hline DOTLine & Cera Tech, Inc. & 2013 & 5.5 \\
\hline Pavepatch 3000 & Dayton Superior Corp. & 2013 & 6.2 \\
\hline SikaQuick 2500 & Sika Corp. & 2013 & 5.0 \\
\hline MasterEmaco T1060 & BASF & 2013 & 5.1 \\
\hline Pavemend SL & Cera Tech, Inc. & 2013 & 4.4 \\
\hline Phoscrete 4 Seasons & Phoscrete Corp. & 2013 & 2.4 \\
\hline Ulti-Pave3 & Buzzi-Unicem USA, Inc. & 2014 & 5.2 \\
\hline Fast Set Concrete Mix & Quikcrete Companies & 2014 & 4.2 \\
\hline Rapid Road Repair & Quikcrete Companies & 2014 & 7.0 \\
\hline HD 50 & Dayton Superior Corp. & 2015 & 7.0 \\
\hline Magna-Crete & Henkel Americas & 2015 & 7.6 \\
\hline ProSpec Premium Patch 200 & H.B. Fuller Construction Products, Inc. & 2015 & 8.0 \\
\hline Rapid Set Mortar Mix & CTS Cement Corp. & 2015 & 7.0 \\
\hline Elephant Armor DOT & GST International & 2016 & 5.9 \\
\hline
\end{tabular}


Figure 20. Comparison graph of CTE results and criteria limits.

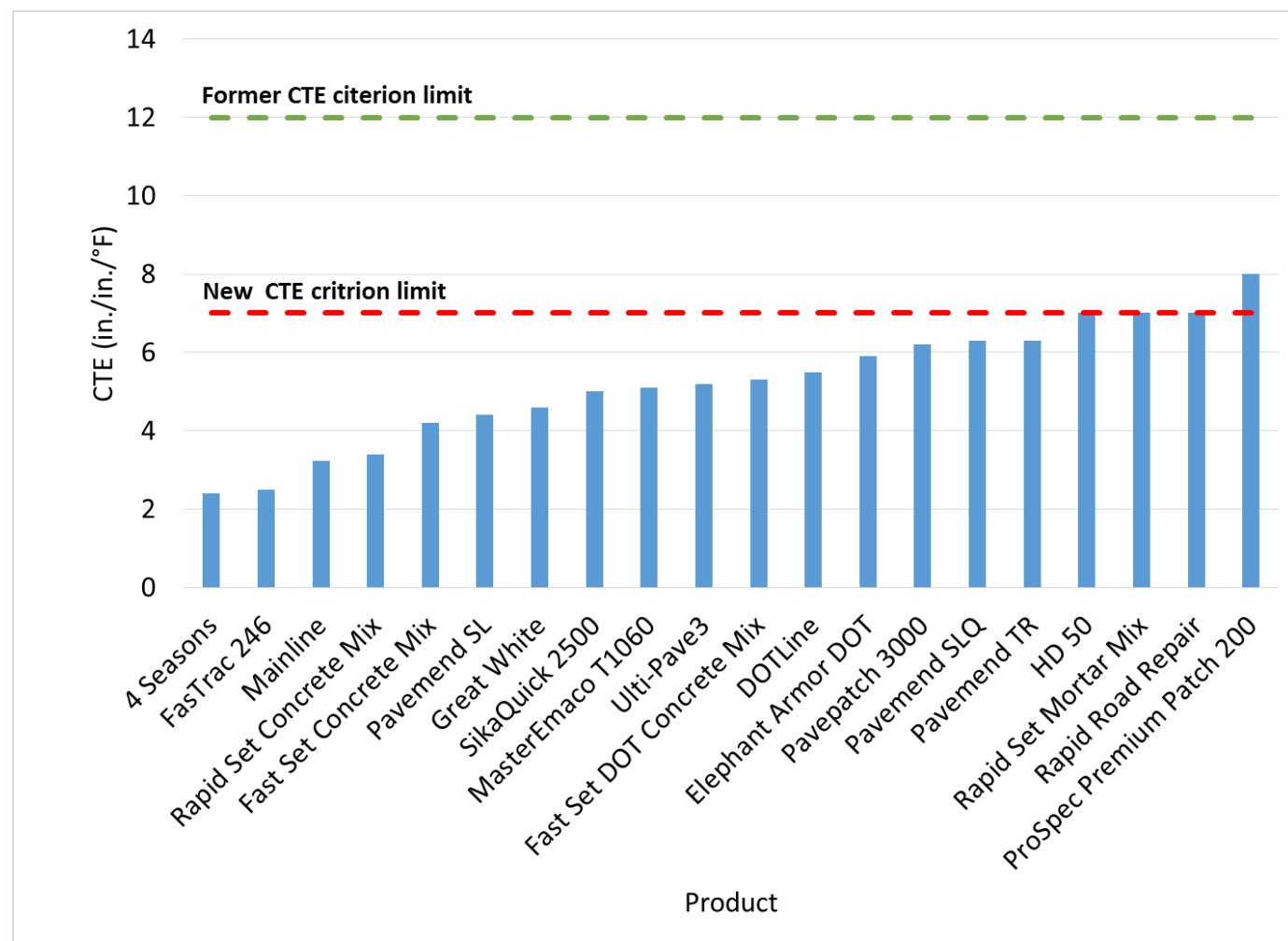

\subsection{Length change}

The former length change testing protocol required that the 28-day minimum allowable expansion not exceed 0.03 percent when cured in water and a minimum allowance of shrinkage not exceed 0.04 percent. Based on the test results in both air and water cure environments shown in Table 14, this limit appears appropriate; and no changes to the 28-day protocol are recommended.

However, ASTM C157 (2014a) recommends this test continue until 64 weeks to determine long-term performance. Research of ultimate drying shrinkage using this method from the REMR program recommended the critical limit as a maximum of 0.1 percent at 1 year (WES 1994). No testing was conducted with specimens cured in water to determine possible ultimate expansion criteria. It is recommended that length change readings and reporting continue until 64 weeks for both air- and watercure environments to establish an appropriate pass/fail criteria for ultimate expansion and contraction in the future. 
Table 14. Summary of length change results.

\begin{tabular}{|c|c|c|c|c|}
\hline \multirow[b]{2}{*}{ Product Name } & \multirow[b]{2}{*}{ Manufacturer } & \multirow[b]{2}{*}{ Year Tested } & \multicolumn{2}{|c|}{ 28-day length change (in.) } \\
\hline & & & Air Cure & Water Cure \\
\hline Pavemend SLQ & Cera Tech, Inc. & 2008 & 0.04 & - \\
\hline Great White & Cera Tech, Inc. & 2009 & 0.0203 & - \\
\hline Mainline & Cera Tech, Inc. & 2009 & -0.0313 & - \\
\hline Fast Set DOT Concrete Mix & Quickcrete Companies & 2010 & 0.01 & 0.03 \\
\hline Rapid Set Concrete Mix & CTS Cement Corp. & 2010 & 0.01 & 0 \\
\hline FasTrac & Western Material \& Design & 2010 & 0.04 & - \\
\hline DOTLine & Cera Tech, Inc. & 2013 & 0.032 & 0.028 \\
\hline Pavepatch 3000 & Dayton Superior Corp & 2013 & -0.037 & 0.012 \\
\hline SikaQuick 2500 & Sika Corp. & 2013 & -0.006 & 0.019 \\
\hline MasterEmaco T1060 & BASF & 2013 & -0.009 & 0.031 \\
\hline Pavemend SL & Cera Tech, Inc. & 2013 & 0.009 & 0.047 \\
\hline Phoscrete 4-Seasons & Phoscrete Corp. & 2013 & -0.065 & 0 \\
\hline Ulti-Pave3 & Buzzi-Unicem USA, Inc. & 2014 & -0.015 & 0.015 \\
\hline Fast Set Concrete Mix & Quikcrete Companies & 2014 & 0 & 0.01 \\
\hline Rapid Road Repair & Quikcrete Companies & 2014 & 0.03 & 0.08 \\
\hline HD 50 & Dayton Superior Corp & 2015 & -0.0055 & 0.017 \\
\hline Magna-Crete & Henkel Americas & 2015 & -0.028 & -0.010 \\
\hline ProSpec Premium Patch 200 & H.B. Fuller Construction & 2015 & -0.005 & 0.015 \\
\hline Rapid Set Mortar Mix & CTS Cement Corp. & 2015 & 0 & 0.02 \\
\hline Elephant Armor DOT & GST International & 2016 & 0.002 & 0.019 \\
\hline
\end{tabular}

\subsection{Shrinkage ring}

Comparisons of shrinkage ring results are shown in Table 15. The restrained shrinkage ring test equipment was updated in FY12-FY13 to run the standard specimen dimensions and procedures in accordance with ASTM C1581 (2016c). The previous rings had an incorrect thickness and diameter. With these changes, the test criteria may not be appropriate. The 14-day requirement of a microstrain value of less than 40 is the criterion of most concern. Some products failed this 14-day requirement but passed the 28-day requirement of no cracking. Based on these results, it is recommended to record the 14-day microstrain value but have no failure criterion and also to have the 28-day microstrain value recorded and fail the product if cracking occurs. The significance in recording and reporting the microstrain values at both 14 and 28 days is to possibly establish a quantitative pass/fail limit in the future. 
Table 15. Summary of shrinkage ring results.

\begin{tabular}{|c|c|c|c|c|}
\hline & & & 14 days & 28 days \\
\hline Product Name & Manufacturer & Year Tested & $\begin{array}{l}\text { Microstrain } \\
\text { Value }\end{array}$ & $\begin{array}{c}\text { Cracking } \\
(\mathrm{Y} / \mathrm{N})\end{array}$ \\
\hline Pavemend SLQ & Cera Tech, Inc. & 2008 & - & $\mathrm{N}$ \\
\hline Pavemend TR & Cera Tech, Inc. & 2008 & - & $\mathrm{N}$ \\
\hline Ultimax Concrete Mix & Ultimax Cement & 2008 & - & $\mathrm{N}$ \\
\hline Great White & Cera Tech, Inc. & 2009 & 40 & $\mathrm{~N}$ \\
\hline Mainline & Cera Tech, Inc. & 2009 & 51 & $\mathrm{~N}$ \\
\hline Fast Set DOT Concrete Mix & Quickcrete Companies & 2010 & 54 & $\mathrm{~N}$ \\
\hline Rapid Set Concrete Mix & CTS Cement Corp. & 2010 & - & $\mathrm{N}$ \\
\hline FasTrac & Western Material \& Design & 2010 & 31 & $\mathrm{~N}$ \\
\hline DOTLine & Cera Tech, Inc. & 2013 & 19 & $\mathrm{~N}$ \\
\hline Pavepatch 3000 & Dayton Superior Corp. & 2013 & 0 & $\mathrm{Y}$ \\
\hline MasterEmaco T1060 & BASF & 2013 & 0 & Y \\
\hline Pavemend SL & Cera Tech, Inc. & 2013 & 22 & N \\
\hline Phoscrete 4 Seasons & Phoscrete Corp. & 2013 & 50 & $\mathrm{~N}$ \\
\hline Ulti-Pave3 & Buzzi-Unicem USA, Inc. & 2014 & 49 & $\mathrm{~N}$ \\
\hline Fast Set Concrete Mix & Quikcrete Companies & 2014 & 27 & $\mathrm{~N}$ \\
\hline Rapid Road Repair & Quikcrete Companies & 2014 & 24 & N \\
\hline HD 50 & Dayton Superior Corp. & 2015 & 25.5 & $\mathrm{~N}$ \\
\hline ProSpec Premium Patch 200 & H.B. Fuller Construction & 2015 & 24 & $\mathrm{~N}$ \\
\hline Rapid Set Mortar Mix & CTS Cement Corp. & 2015 & 19 & $\mathrm{~N}$ \\
\hline Elephant Armor DOT & GST International & 2016 & 34 & $\mathrm{~N}$ \\
\hline
\end{tabular}

\subsection{Freeze-thaw resistance}

Comparisons of the freeze-thaw resistance results are shown in Table 16. The ASTM C666 (2015b) Method A appears to be an extreme test for the rapid-repair products. Even though no criterion was established for a pass/fail criterion in the existing testing protocol, none of the products tested reached 300 cycles before failure, as suggested in the standard test method. Based on these results, it is recommended that new testing procedures be developed and standardized to further assess the freezethaw test methods for pavements. 
Table 16. Summary of the freeze-thaw results.

\begin{tabular}{|c|c|c|c|c|}
\hline & & & \multicolumn{2}{|c|}{ Freeze-Thaw Results } \\
\cline { 3 - 5 } Product Name & Manufacturer & Year Tested & $\begin{array}{c}\text { Durability } \\
\text { Factor }\end{array}$ & $\begin{array}{c}\text { \# Cycles before } \\
\text { Failure }\end{array}$ \\
\hline Fast Set DOT Concrete Mix & Quickcrete Companies & 2010 & 41 & 44 \\
\hline DOTLine & Cera Tech, Inc. & 2013 & 27 & 132 \\
\hline Pavepatch 3000 & Dayton Superior Corp. & 2013 & 36 & 189 \\
\hline Phoscrete 4 Seasons & Phoscrete & 2013 & 64 & 200 \\
\hline MasterEmaco T1060 & BASF & 2013 & 27 & 85 \\
\hline SikaQuick 2500 & Sika & 2013 & 6 & 36 \\
\hline Pavemend SL & Cera Tech, Inc. & 2013 & 4 & 47 \\
\hline Fast Set Concrete Mix & Quikrete Companies & 2014 & 64 & 200 \\
\hline Ulti-Pave3 & Buzzi-Unicem & 2014 & 20 & 118 \\
\hline Rapid Road Repair & Quikcrete Companies & 2014 & 56 & 68 \\
\hline HD 50 & Dayton Superior Corp. & 2015 & 5 & 33 \\
\hline Elephant Armor DOT & GST International & 2016 & 9 & 56 \\
\hline H.B. Fuller Construction & 2015 & 5 & 33 \\
\hline
\end{tabular}




\section{Summary and Conclusions}

The objective of this project was to evaluate the performance criteria for the selection of cementitious rapid-repair materials for spall repairs. This was accomplished by assembling data by individual test and age from not only the 28 products tested from 2013 to 2017 but also historical triservice data. An analysis of the wide range of material properties of the laboratory testing results presented in this document led to the development of an updated testing protocol for cementitious rapid-repair products for airfield spall repairs. In order to achieve the best compatibility between the repair material and the original concrete surface, the recommendations for performance criteria are provided in the following section. However, it should be noted that laboratory tests are only index tests and do not necessarily predict performance. It is suggested that field tests be performed to correlate performance with the laboratory results to further validate the repair material.

\subsection{Laboratory lessons learned}

Based on the laboratory testing experience with the rapid-repair products, some general observations and lessons learned are summarized as follows.

- All technical data provided by the manufacturer of the product must be carefully read and strictly followed. This includes not only the mixture proportions, water recommendations, and mixing time but also the sequence of batching the components of the repair material (i.e., water, coarse aggregate, dry bagged material, etc.). Significant differences resulted in both fresh and hardened properties if, for example, the water was added first followed by mixing in the dry material versus the water added to the dry material then mixed.

- While there are some similarities between rapid-repair concrete and conventional concrete, no product should ever be approached the same. For example, Magnesium Phosphate Cement (MPC)-based products must be cured in a dry environment due to the potential of strength loss with a moist cure.

- Some materials have extremely tight working times of only a few minutes between the initial and final sets. Caution should be exercised with the quantity mixed, and personnel should be prepared for quick execution of the spall repair and cleanup of tools and equipment in the field. 
- Rapid-repair materials are highly exothermic, and the use of an infrared thermometer temperature gun is recommended not only for recording the initial and final temperatures but also for use during the entire mixing time. A sudden spike in the temperature is an indication that the material is approaching the initial set time and all operations need to be finalized quickly.

- In general, rapid-repair products are sensitive to moisture due to the material's large surface area and high fineness. In efforts to keep the products from hydrating and becoming unusable, products tested in the laboratory should be stored in sealed buckets with desiccant packets to create the most airtight environment possible.

- Some allergic symptoms may be experienced when handling some products. For example, strong ammonium fumes were experienced with the Magna-Crete product, which caused mild skin, eye, and respiratory irritation. For all products, the material safety data sheet (MSDS) should always be consulted for exposure controls and personal protection. Personal protection equipment including some combination of gloves, safety glasses, and dust or ventilation masks while working in an open air ventilation environment is recommended.

- Since all testing was conducted in a strictly controlled temperature environment of $72 \pm 4^{\circ} \mathrm{F}$, variations of high and low ranges of temperatures are recommended to evaluate the sensitivity of the product if the repairs are considered in a range outside the manufacturer's recommended installation temperature.

\subsection{Summary of testing protocol}

It is recommended that the updated testing protocol provided in Table 17 be used for the new selection criteria for certifying rapid-setting repair materials for spall repairs. The two-tier requirement method of testing is suggested from a cost and time requirement perspective due to the number of mechanical and volumetric property tests required. A comparison of the former and new test criteria is presented in Table 18. 
Table 17. Summary of updated test protocol for cementitious materials.

\begin{tabular}{|c|c|c|c|}
\hline \multicolumn{4}{|c|}{ Tier 1 Test Requirements } \\
\hline Test Property & Test Method & Test Age & Test Criteria \\
\hline \multirow{5}{*}{ Compressive Strength } & \multirow{5}{*}{ ASTM C39 } & $2 \mathrm{hr}$ & $\geq 2,500$ psi \\
\hline & & $3 \mathrm{hr}$ & $\geq 3,000$ psi \\
\hline & & 1 day & $\geq 4,000 \mathrm{psi}$ \\
\hline & & 7 days & $\geq 5,000 \mathrm{psi}$ \\
\hline & & 28 days & $\geq 5,000$ psi \\
\hline \multirow{3}{*}{ Flexural Strength } & \multirow{3}{*}{ ASTM C78 } & $2 \mathrm{hr}$ & $\geq 350$ psi \\
\hline & & 7 days & $\geq 500$ psi \\
\hline & & 28 days & $\geq 600$ psi \\
\hline \multirow{2}{*}{$\begin{array}{l}\text { Bond Strength } \\
\quad(\mathrm{RS} / \mathrm{RS})\end{array}$} & \multirow{4}{*}{ ASTM C882 } & 1 day & $\geq 1,000 \mathrm{psi}$ \\
\hline & & 7 days & $\geq 1,500 \mathrm{psi}$ \\
\hline \multirow{2}{*}{$\begin{array}{l}\text { Bond Strength } \\
\quad(\mathrm{PCC} / \mathrm{RS})\end{array}$} & & 1 day & $\geq 1,000 \mathrm{psi}$ \\
\hline & & 7 days & $\geq 1,250 \mathrm{psi}$ \\
\hline \multirow{2}{*}{ Modulus of Elasticity } & \multirow{2}{*}{ ASTM C469 } & $2 \mathrm{hrs}$ & $2 \leq \mathrm{x} \leq 6 \mathrm{Mpsi}$ \\
\hline & & 28 days & $2 \leq \mathrm{x} \leq 6 \mathrm{Mpsi}$ \\
\hline \multirow{2}{*}{$\begin{array}{c}\text { Set Time } \\
\text { Penetrometer Method }\end{array}$} & \multirow{2}{*}{ ASTM C403 } & Initial set & $\geq 15 \min$ \\
\hline & & Final set & $15-90 \mathrm{~min}$ \\
\hline Slump & ASTM C143 & $\begin{array}{l}\text { Within } 5 \text { min of } \\
\text { added water }\end{array}$ & $\begin{array}{c}3-9 \text { in. } \\
\text { if }>9 \text { in., perform slump flow }\end{array}$ \\
\hline Slump Flow & ASTM C1611 & $\begin{array}{l}\text { Within } 5 \text { min of } \\
\text { added water }\end{array}$ & $\geq 9$ in. \\
\hline \multicolumn{4}{|c|}{ Tier 2 Test Requirements } \\
\hline Test Property & Test Method & Test Age & Test Criteria \\
\hline \multirow{2}{*}{ Length Change } & \multirow{2}{*}{ ASTM C157 } & $\begin{array}{c}28 \text { days } \\
\text { Stored in air }\end{array}$ & \multirow{2}{*}{$\begin{array}{c}-0.04 \% \leq x \leq+0.03 \% \text { at } 28 \\
\text { days } \\
\text { Continue testing and report } \\
\text { length change until } 64 \text { weeks }\end{array}$} \\
\hline & & $\begin{array}{l}28 \text { days } \\
\text { Stored in water }\end{array}$ & \\
\hline Coefficient of Thermal Expansion & ASTM C531 & - & $\leq 7$ (in./in./ ${ }^{\circ} \mathrm{F} \times 10^{-6}$ ) \\
\hline \multirow{2}{*}{ Shrinkage Potential } & \multirow{2}{*}{ ASTM C1581 } & 14 days & $\begin{array}{l}\text { Record microstrain but no } \\
\text { pass/fail limits at this time }\end{array}$ \\
\hline & & 28 days & $\begin{array}{c}\text { Record microstrain and fail if } \\
\text { any ring cracked }\end{array}$ \\
\hline
\end{tabular}


Table 18. Comparison of former test criteria and new test criteria.

\begin{tabular}{|c|c|c|c|c|}
\hline Test Property & Test Method & Test Age & Former Criteria & New Criteria \\
\hline \multirow{5}{*}{$\begin{array}{l}\text { Compressive } \\
\text { Strength }\end{array}$} & \multirow{5}{*}{ ASTM C39 } & $2 \mathrm{hrs}$ & $\geq 3,000$ psi & $\geq 2,500 \mathrm{psi}$ \\
\hline & & $3 \mathrm{hr}$ & No requirement & $\geq 3,000$ psi \\
\hline & & 1 day & $\geq 5,000$ psi & $\geq 4,000$ psi \\
\hline & & 7 days & $\geq 5,000$ psi & No change \\
\hline & & 28 days & $\geq 5,000 \mathrm{psi}$ & No change \\
\hline \multirow{3}{*}{ Flexural Strength } & \multirow{3}{*}{ ASTM C78 } & $2 \mathrm{hr}$ & $\geq 350$ psi & No change \\
\hline & & 7 days & $\geq 600 \mathrm{psi}$ & $\geq 500$ psi \\
\hline & & 28 days & $\geq 600$ psi & No change \\
\hline \multirow{2}{*}{$\begin{array}{l}\text { Bond Strength } \\
\quad(\mathrm{RS} / \mathrm{RS})\end{array}$} & \multirow{4}{*}{ ASTM C882 } & 1 day & $\geq 1,000 \mathrm{psi}$ & No change \\
\hline & & 7 days & No requirement & $\geq 1,250 \mathrm{psi}$ \\
\hline \multirow{2}{*}{$\begin{array}{l}\text { Bond Strength } \\
\quad(\mathrm{PCC} / \mathrm{RS})\end{array}$} & & 1 day & $\geq 1000 \mathrm{psi}$ & No change \\
\hline & & 7 days & No requirement & $\geq 1,250 \mathrm{psi}$ \\
\hline \multirow{2}{*}{ Modulus of Elasticity } & \multirow{2}{*}{ ASTM C469 } & $2 \mathrm{hr}$ & $2 \leq \mathrm{x} \leq 6 \mathrm{Mpsi}$ & No change \\
\hline & & 28 days & $2 \leq \mathrm{x} \leq 6 \mathrm{Mpsi}$ & No change \\
\hline \multirow{2}{*}{$\begin{array}{l}\text { Time of Setting } \\
\text { Vicat Method }\end{array}$} & \multirow{2}{*}{ ASTM C191 } & Initial set & $\geq 15 \min$ & Remove \\
\hline & & Final set & $25-35 \min$ & Remove \\
\hline \multirow{2}{*}{$\begin{array}{l}\text { Set Time } \\
\text { Penetrometer } \\
\text { Method }\end{array}$} & \multirow{2}{*}{ ASTM C403 } & Initial set & No requirement & $\geq 15 \min$ \\
\hline & & Final set & No requirement & $15-90 \mathrm{~min}$ \\
\hline Slump & ASTM C143 & $\begin{array}{l}\text { Within } 5 \text { min of } \\
\text { added water }\end{array}$ & Record slump & $\begin{array}{c}3-9 \text { in. } \\
\text { if }>9 \text { in., perform } \\
\text { slump flow }\end{array}$ \\
\hline Slump Flow & ASTM C1611 & $\begin{array}{c}\text { Within } 5 \text { min of } \\
\text { added water }\end{array}$ & No requirement & $\geq 9$ in. \\
\hline \multirow{2}{*}{ Length Change } & \multirow{2}{*}{ ASTM C157 } & Stored in air & \multirow{2}{*}{$\begin{array}{c}-0.04 \% \leq x \leq+0.03 \% \\
\text { at } 28 \text { days }\end{array}$} & \multirow{2}{*}{ No change } \\
\hline & & Stored in water & & \\
\hline $\begin{array}{c}\text { Coefficient of } \\
\text { Thermal Expansion }\end{array}$ & ASTM C531 & - & $\begin{array}{c}\leq 12 \\
\left.\text { (in./in./ }{ }^{\circ} \mathrm{F} \times 10^{-6}\right)\end{array}$ & $\begin{array}{c}\leq 7 \\
\left.\text { (in./in. } /{ }^{\circ} \mathrm{F} \times 10^{-6}\right)\end{array}$ \\
\hline \multirow[t]{2}{*}{ Shrinkage Potential } & \multirow[t]{2}{*}{ ASTM C1581 } & 14 days & $\leq 40 \mu \varepsilon$ & $\begin{array}{c}\text { Record microstrain } \\
\text { but no pass/fail } \\
\text { limits }\end{array}$ \\
\hline & & 28 days & No cracking & $\begin{array}{l}\text { Record microstrain } \\
\text { and fail if cracking }\end{array}$ \\
\hline
\end{tabular}




\subsection{Summary of approved products}

The products shown in Table 19 are recommended approved products based on standards set forth in the updated test protocol. Note that the four products tested in 2017 (Rapid Set Concrete Mix, Rapid Set DOT Repair Mix, MasterEmaco T545HT, and MasterEmaco T545) were tested and approved for only the tier 1 properties. Tier 2 testing is scheduled for 2018.

Table 19. Recommended approved products based on new test protocol.

\begin{tabular}{|l|l|l|}
\hline \multicolumn{1}{|c|}{ Product Name } & \multicolumn{1}{|c|}{ Manufacturer } & Year Tested \\
\hline SikaQuick 2500 & Sika Corp. & 2013 \\
\hline Ulti-Pave3 & Buzzi-Unicem USA Inc. & 2014 \\
\hline ProSpec Premium Patch 200 & H.B. Fuller Construction Products Inc. & 2015 \\
\hline Rapid Set Mortar Mix & CTS Cement Corp. & 2015 \\
\hline HD 50 & Dayton Superior Corp. & 2015 \\
\hline FasTrac 246 Concrete & Western Material and Design, LLC & 2016 \\
\hline Rapid Set Concrete Mix & CTS Cement Corp. & 2017 \\
\hline Rapid Set D0T Repair Mix & CTS Cement Corp. & 2017 \\
\hline MasterEmaco T545HT & BASF & 2017 \\
\hline MasterEmaco T545 & BASF & 2017 \\
\hline
\end{tabular}

\subsection{Other testing recommendations}

Limited information is available in the area of durability and long-term performance of rapid-repair materials. The following are recommendations for future research to evaluate the durability of these materials.

- The ASTM C672 (2012b) scaling test was a recommended test in the previous test protocol but was not performed on any of the rapid-repair materials tested from 2013-2017. This test method is still recommended for products that may be used for repairs in harsh environments where chloride exposure or drying and wetting can take place.

- The ASTM C666 (ASTM 2015b) freeze-thaw test was a recommended test in the previous test protocol but was integrated into Tier 2 testing for several products. As reported in the results, all products fell below a 60 percent dynamic modulus at 300 cycles as suggested in the 
standard method. It is recommended that new test procedures be developed for freeze-thaw resistance methods better suited for rapidrepair materials.

- Further investigation is recommended to determine a suitable longterm limit criteria for rapid-repair materials based on long-term results from length change testing (i.e., conduct full 64-week test as per ASTM C157; 2014a).

- Limitations of the ASTM C1581 (2016c) shrinkage ring test include the inability to measure very early age shrinkage and the inability to measure the effects of expansion. It is recommended that new testing procedures be developed and standardized to assess the volumetric shrinkage and restrained stress development. 


\section{References}

Air Force Civil Engineering Center (AFCEC). 2008. Testing protocol for rigid spall repair materials. Engineering Technical Letter 08-02. Tyndall AFB, FL: Air Force Civil Engineering Center.

ASTM (American Society for Testing and Materials). 2012a. Standard test method for linear shrinkage and coefficient of thermal expansion of chemical resistant mortars, grouts, monolithic surfacings, and polymer concretes. Designation: C531-12. West Conshohocken, PA: ASTM International.

2012b. Standard test method for scaling resistance of concrete surfaces exposed to de-icing chemicals. Designation: C672-12. West Conshohocken, PA: ASTM International.

2013a. Standard test method for bond strength of epoxy-resin systems used with concrete by slant shear. Designation: C882-13. West Conshohocken, PA: ASTM International.

2013b. Standard test method for packaged, dry, rapid-hardening cementitious materials for concrete repair. Designation: C928-13. West Conshohocken, PA: ASTM International.

. 2013c. Standard test method for time of setting of hydraulic cement by vicat needle. Designation: C191-13. West Conshohocken, PA: ASTM International

2014a. Standard test method for length change of hardened hydraulic-cement mortar and concrete. Designation: C157-14. West Conshohocken, PA: ASTM International.

. 2014b. Standard test method for slump flow of self-consolidating concrete. Designation: C1611-14. West Conshohocken, PA: ASTM International.

.2014c. Standard test method for static modulus of elasticity and Poisson's ratio of concrete in compression. Designation: C469-14. West Conshohocken, PA: ASTM International.

2015a. Standard test method for compressive strength of cylindrical concrete specimens. Designation C39-15. West Conshohocken, PA: ASTM International.

2015b. Standard test method for resistance of concrete to rapid freezing and thawing. Designation: C666-15. West Conshohocken, PA: ASTM International.

2015c. Standard test method for slump of hydraulic cement concrete. Designation: C143-15. West Conshohocken, PA: ASTM International.

. 2016a. Standard test method for compressive strength of hydraulic cement mortars using 2-in. cube specimens. Designation: C109-16. West Conshohocken, PA: ASTM International.

.2016b. Standard test methods for concrete aggregates. Designation: C33-16. West Conshohocken, PA: ASTM International. 
. 2016c. Standard test method for determining age at cracking and induced tensile stress characteristics of mortar and concrete under restrained shrinkage. Designation: C1581-16. West Conshohocken, PA: ASTM International.

. 2016d. Standard test method for flexural strength of concrete (using simple beam with third-point loading. Designation: $778-16$. West Conshohocken, PA: ASTM International.

2016e. Standard test method for making and curing concrete test specimens in the laboratory. Designation: C192-16. West Conshohocken, PA: ASTM International.

. 2016f. Standard test method for time of setting of concrete mixtures by penetration resistance. Designation: $\mathrm{C} 403 / 403 \mathrm{M}-16$. West Conshohocken, PA: ASTM International.

Beer, G. P., D. W. Fowler, A. H. Meyer, and D. R. Paul. 1984. Laboratory tests on selected rapid-setting repair materials. Research Report CTR 311-2, Center for Transportation Research (CTR). Austin, TX: The University of Texas at Austin.

HQ Army, Navy, Air Force. 2018. O\&M manual: Asphalt and concrete pavement maintenance and repair. Unified Facilities Criteria (UFC) 3-270-01. Washington, DC: Headquarters Army, Navy and Air Force.

Priddy, L. P. 2011. Development of laboratory testing criteria for evaluating cementitious, rapid-setting pavement repair materials. ERDC/GSL TR-11-13. Vicksburg, MS: U.S. Army Engineer Research and Development Center.

U.S. Army Engineer Waterways Experiment Station (WES). 1992. Rapid-hardening cements and patching material. Repair, Evaluation, Maintenance, and Rehabilitation Research Program (REMR). Technical Note CS-MR-7.3. Vicksburg, MS: U.S. Army Engineer Waterways Experiment Station.

Vaysburd, A. M., P. H. Emmons, J. E. McDonald, R. W. Poston, and K. E. Kesner. 1999. Performance criteria for concrete repair materials, Phase II summary report. Technical Report REMR-CS-62. Vicksburg, MS: U.S. Army Engineer Waterways Experiment Station.

Wilson, T. P., K. L. Smith, and A. R. Romine. 1999. LTPP U.S. Army Engineer Research and Development Center pavement maintenance materials: PCC partial-depth spall repair experiment. Report No: FHWA-RD-99-153. Washington, DC: Federal Highway Administration, U.S. Department of Transportation. 


\section{Appendix A: Laboratory Testing Data Sheets}

\section{A.1 FY13 Rigid-Repair Material Evaluation Reports}

See Tables A1 through A6. 
Table A1. Pavement SL.

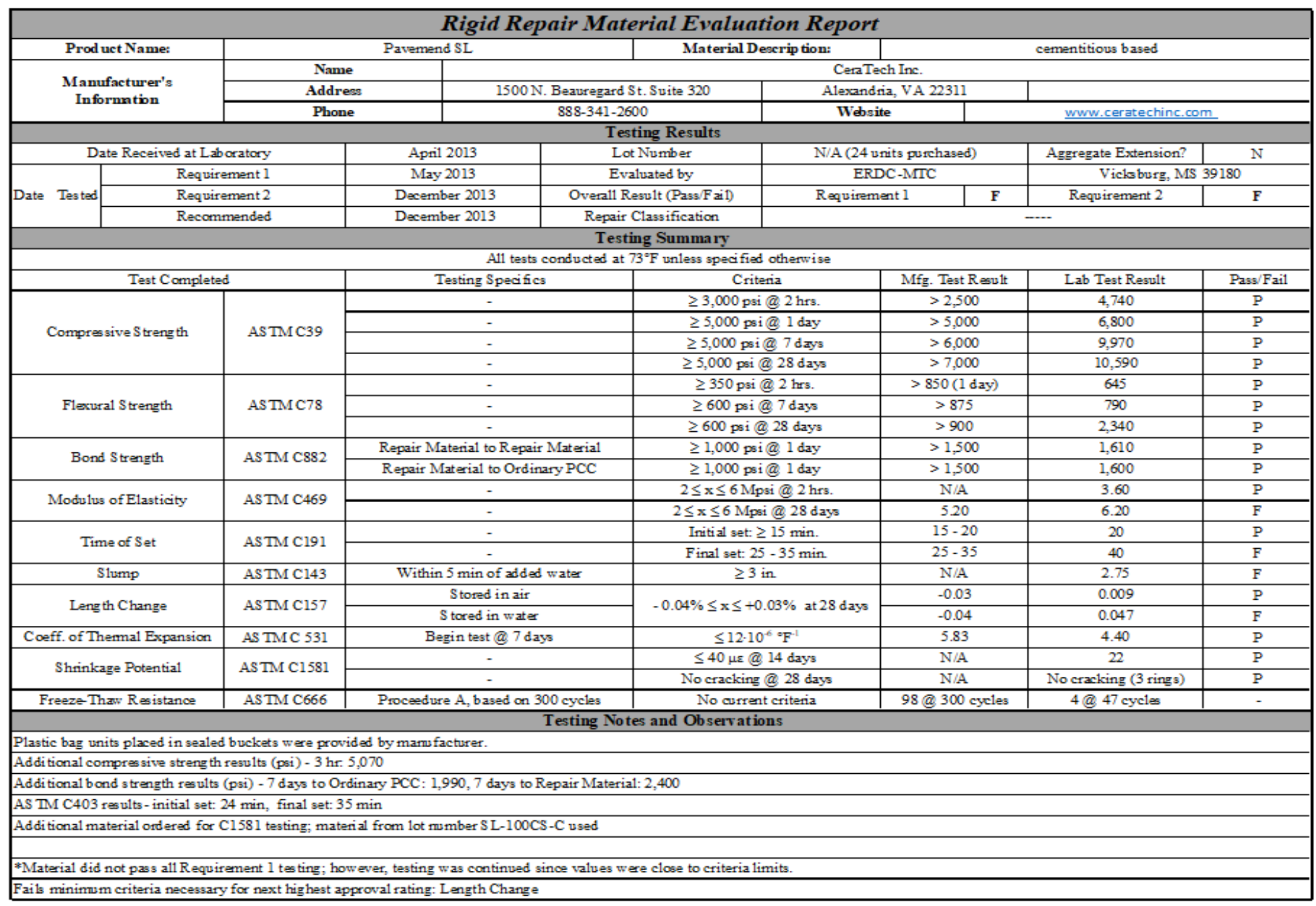


Table A2. DOT Line.

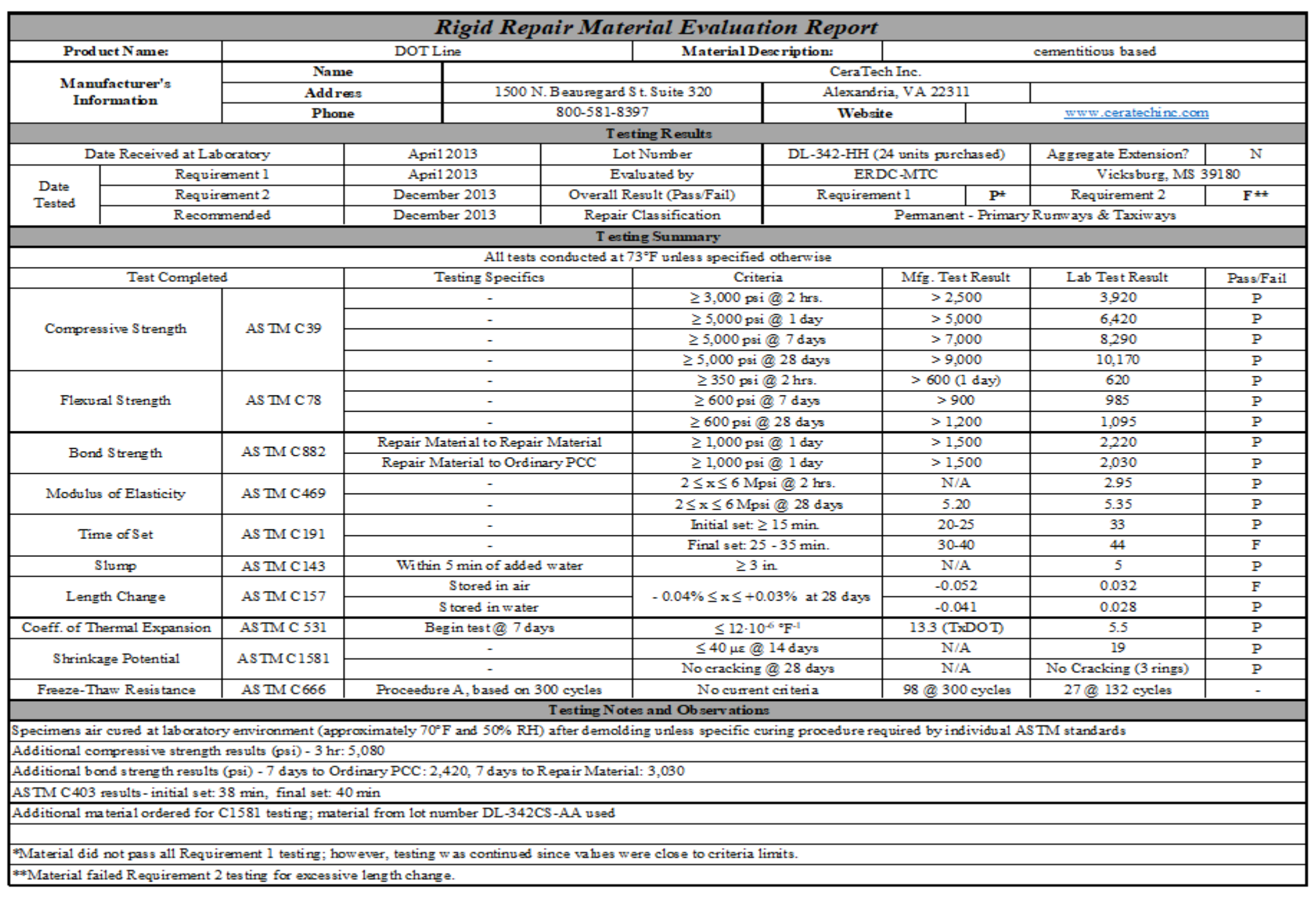


Table A3. SikaQuick 2500.

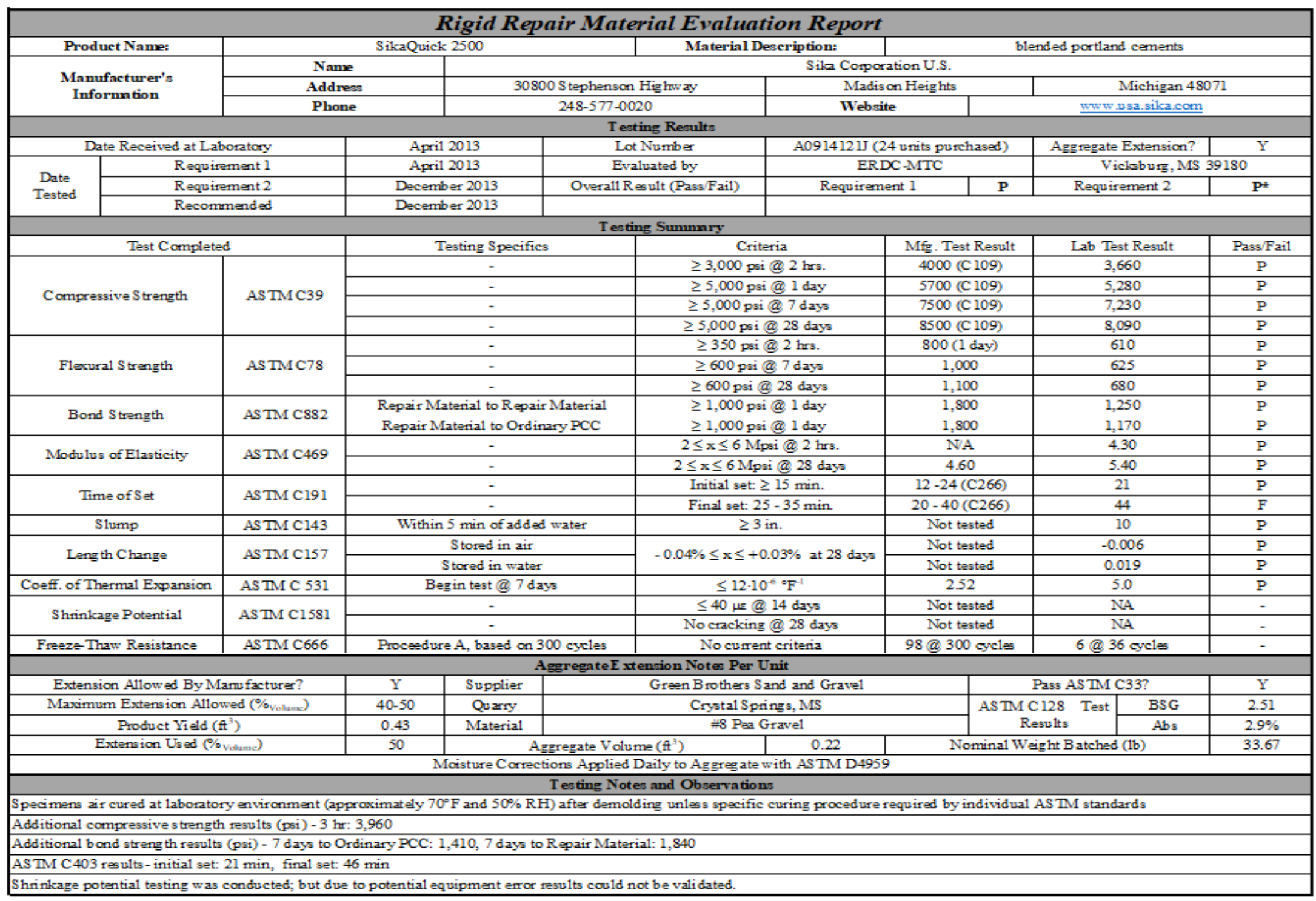


Table A4. 10-60 Repair Mortar.

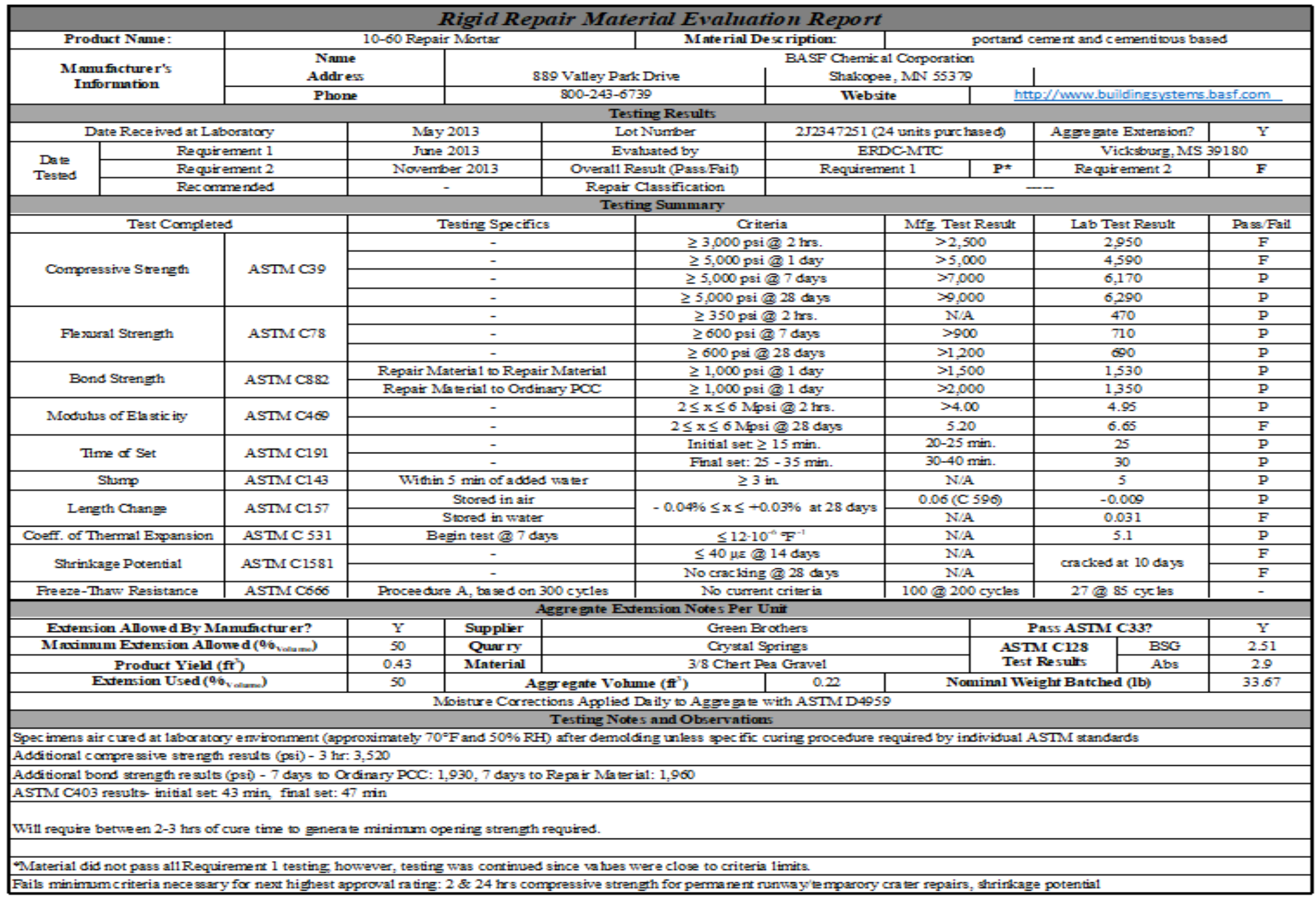


Table A5. Pavepatch 3000.

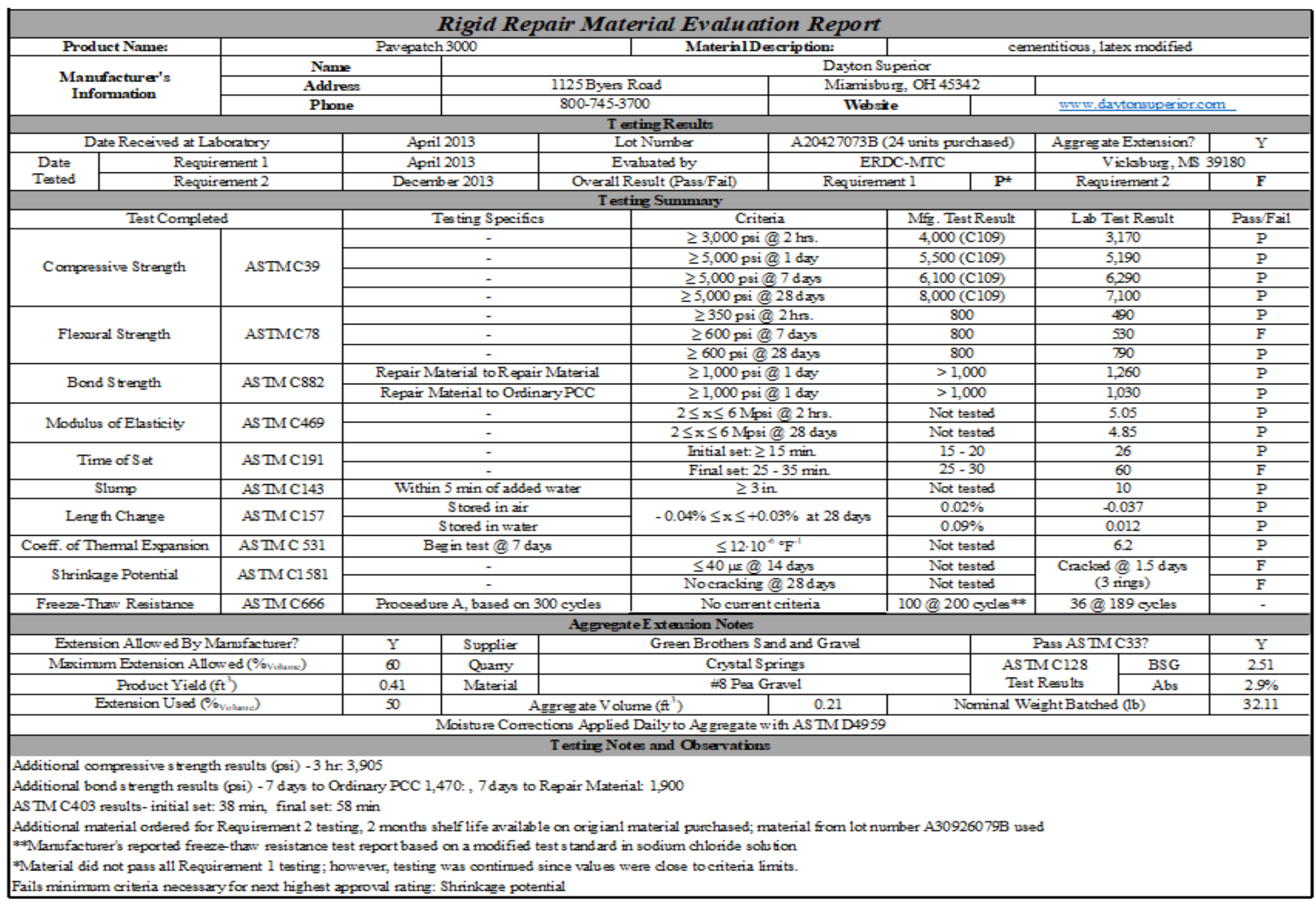


Table A6. Phoscrete 4 Seasons.

Rigid Repair Material Evaluation Report

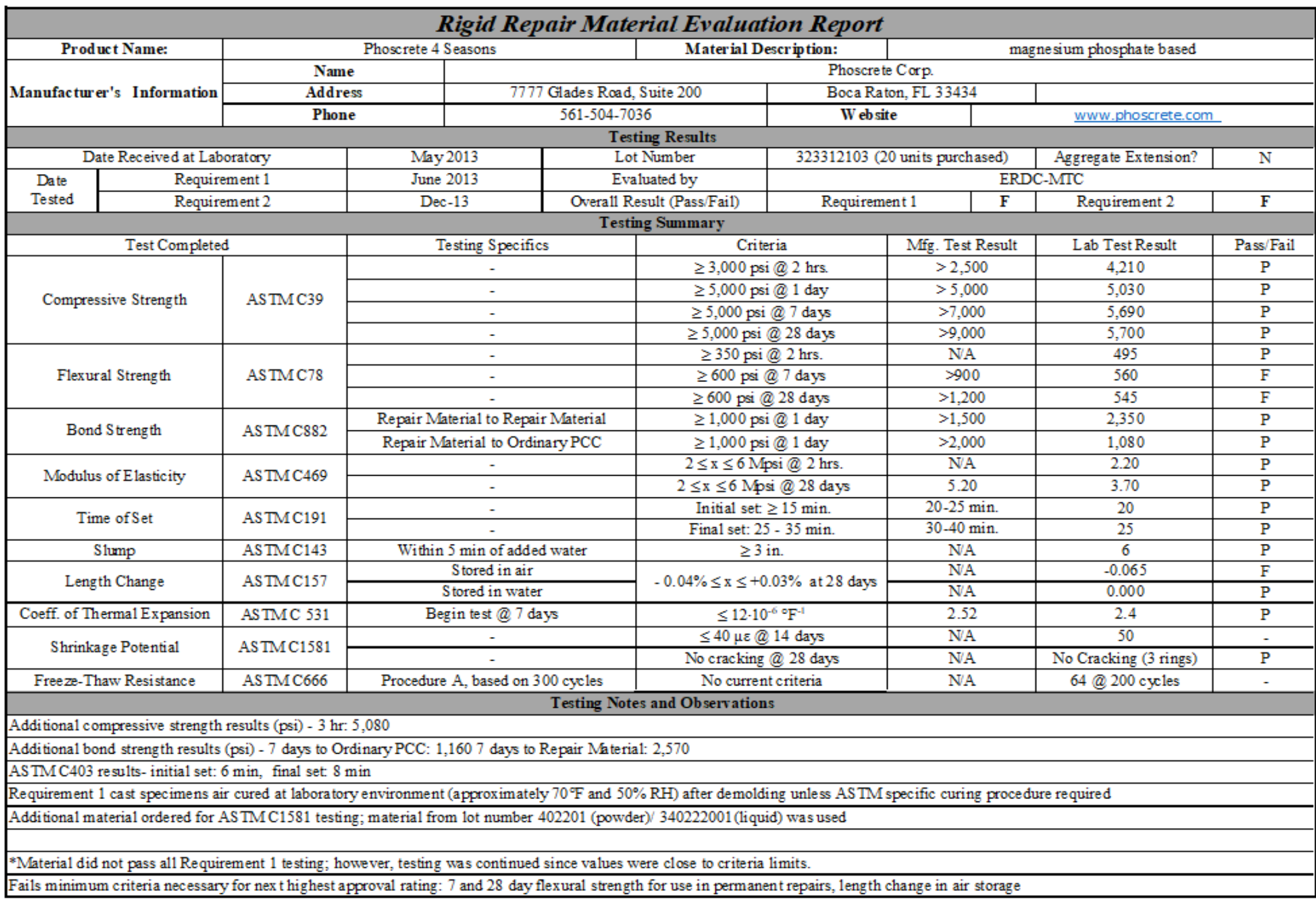




\section{A.2 FY14 Rigid-Repair Material Evaluation Reports}

See Tables A7 through A11. 
Table A7. Ulti-Pave3.

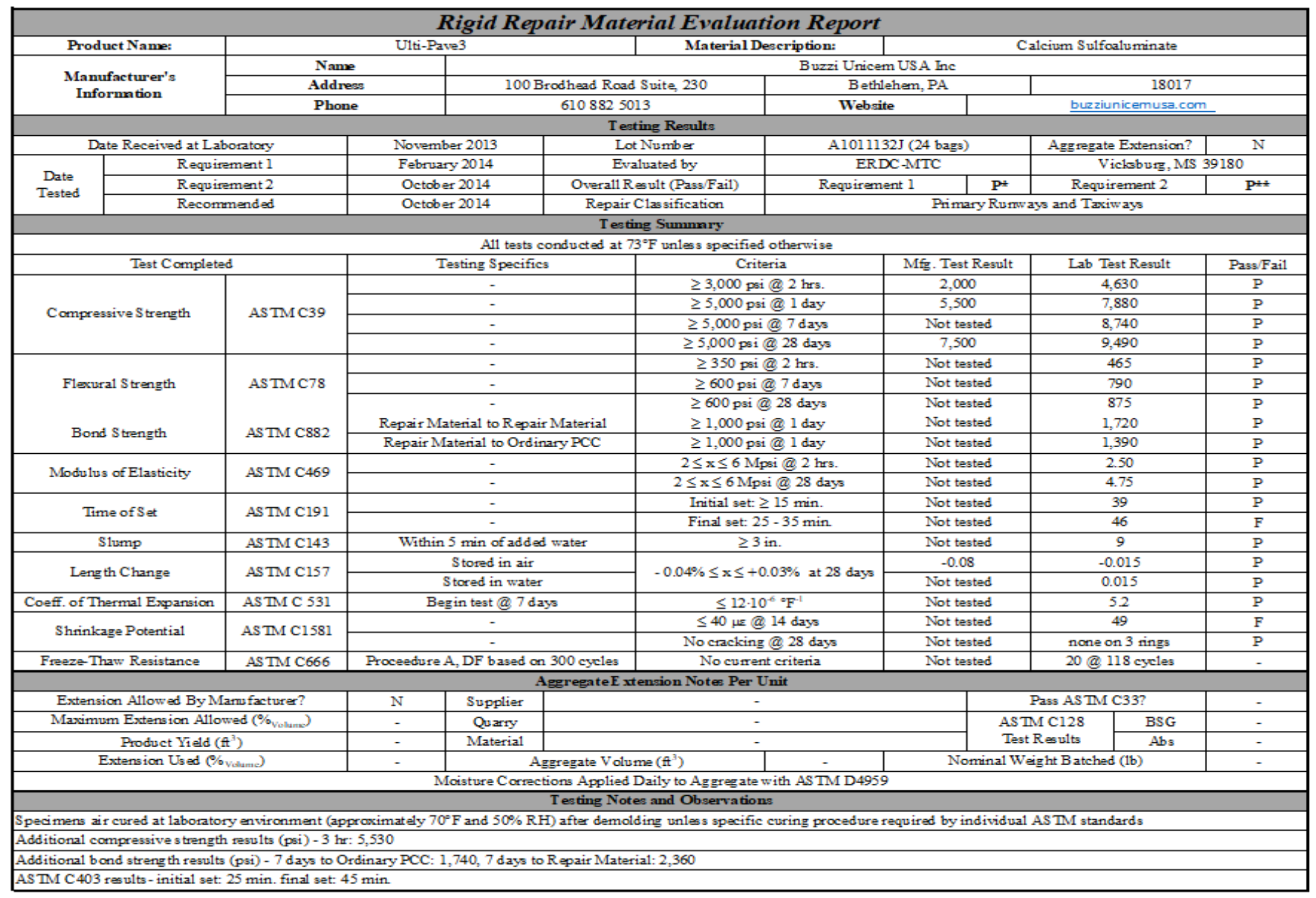


Table A8. Fast Set DOT Concrete Mix.

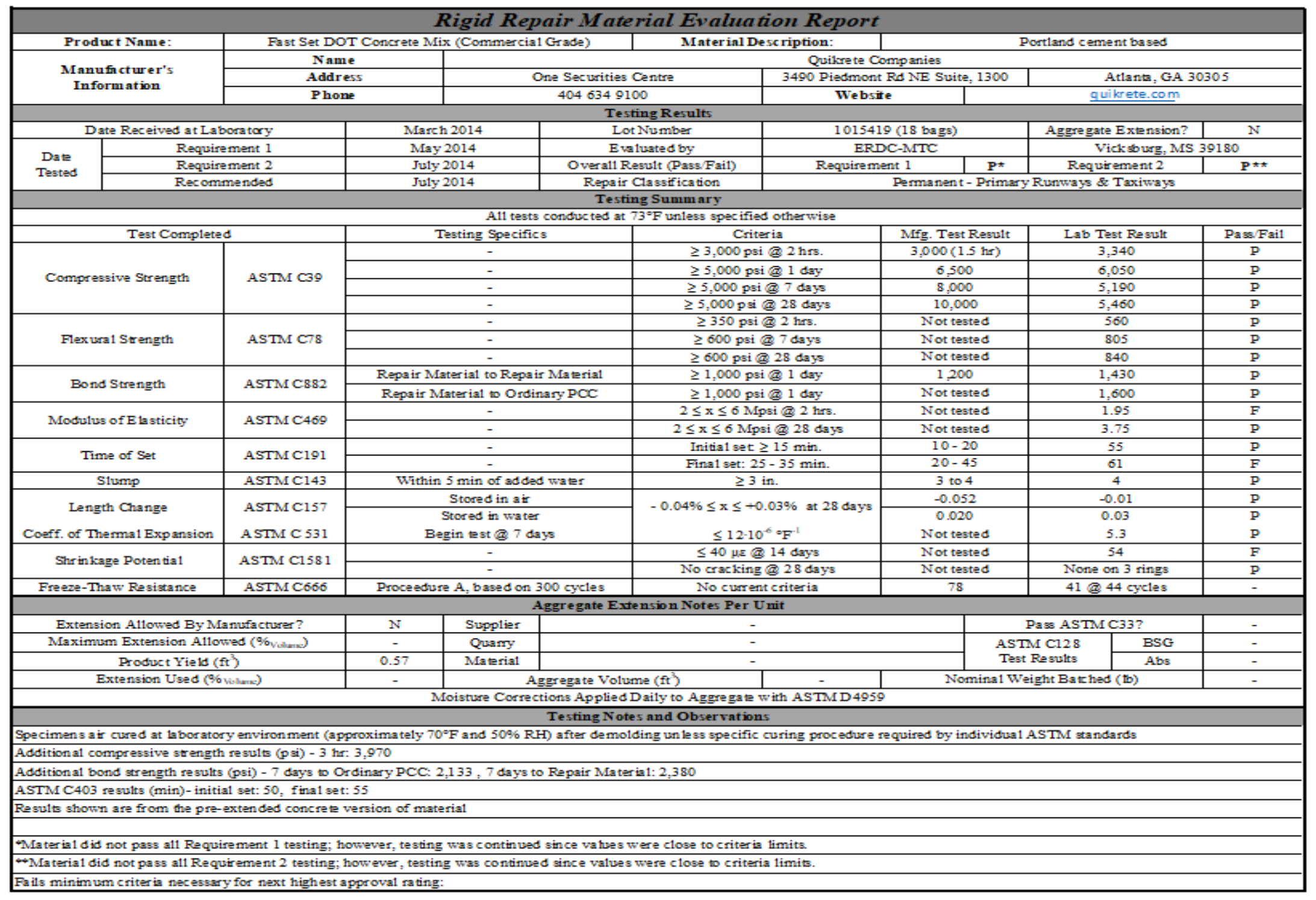


Table A9. Ardex TRM.

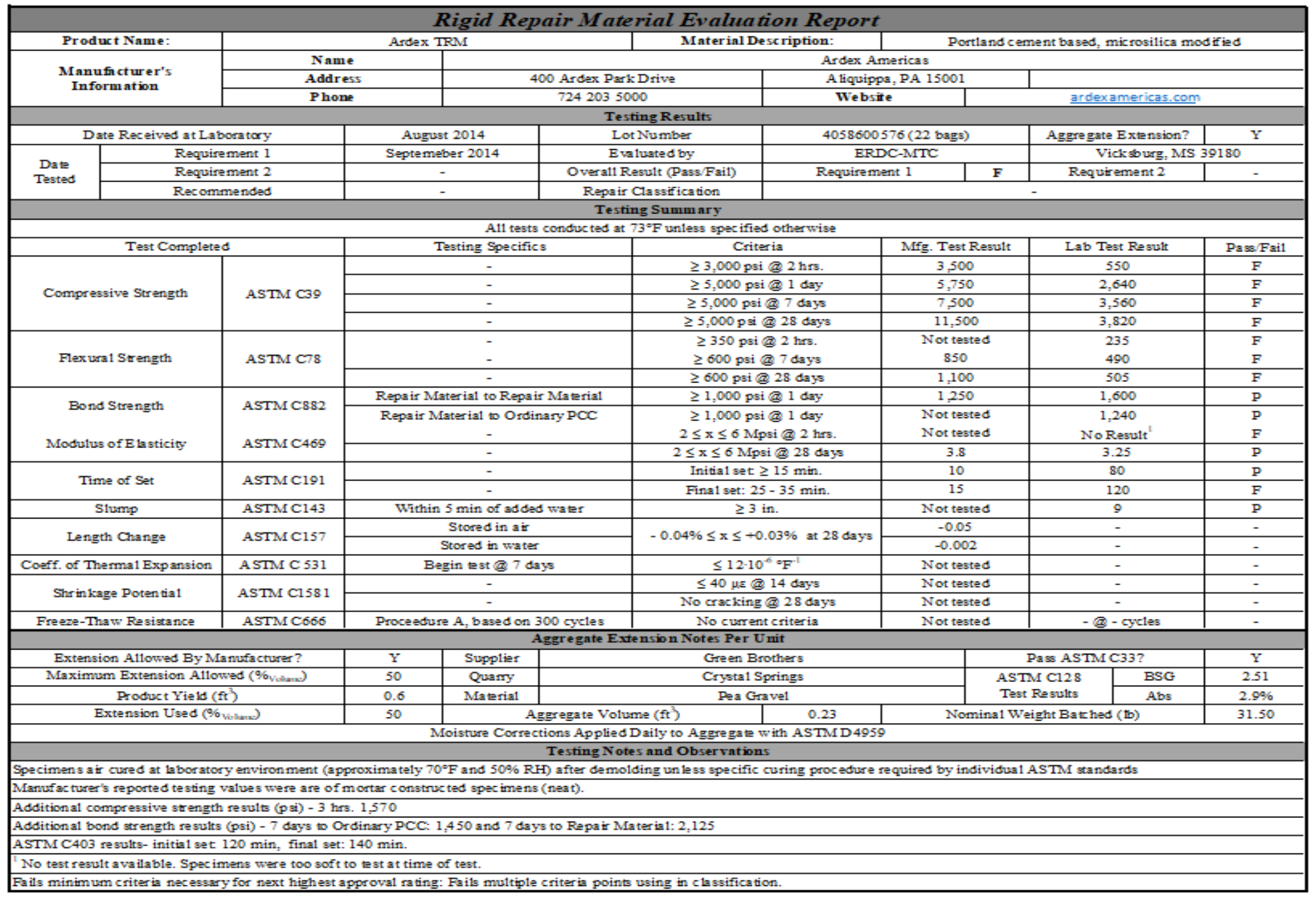


Table A10. Fast Set Concrete Mix.

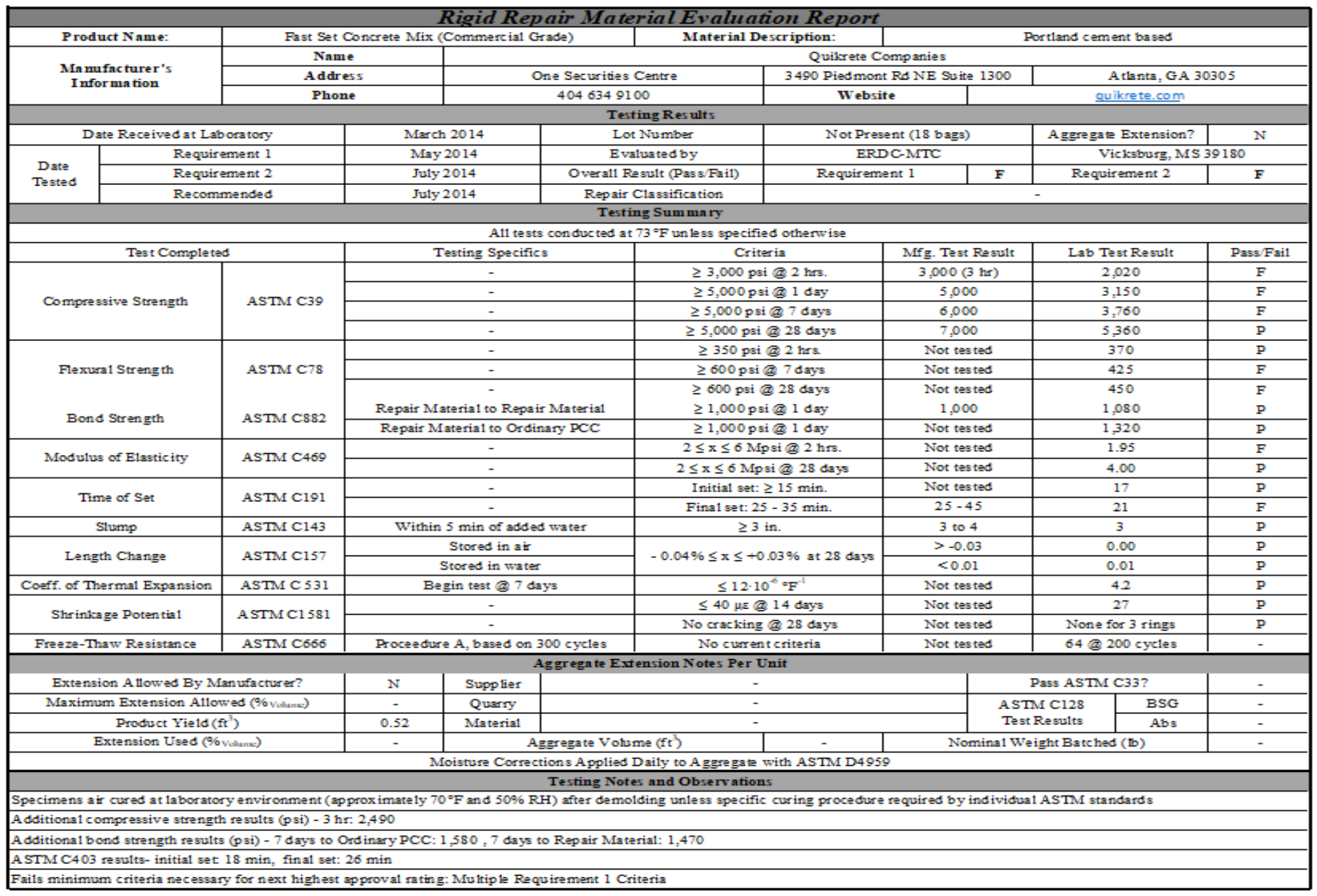


Table A11. Rapid Road Repair.

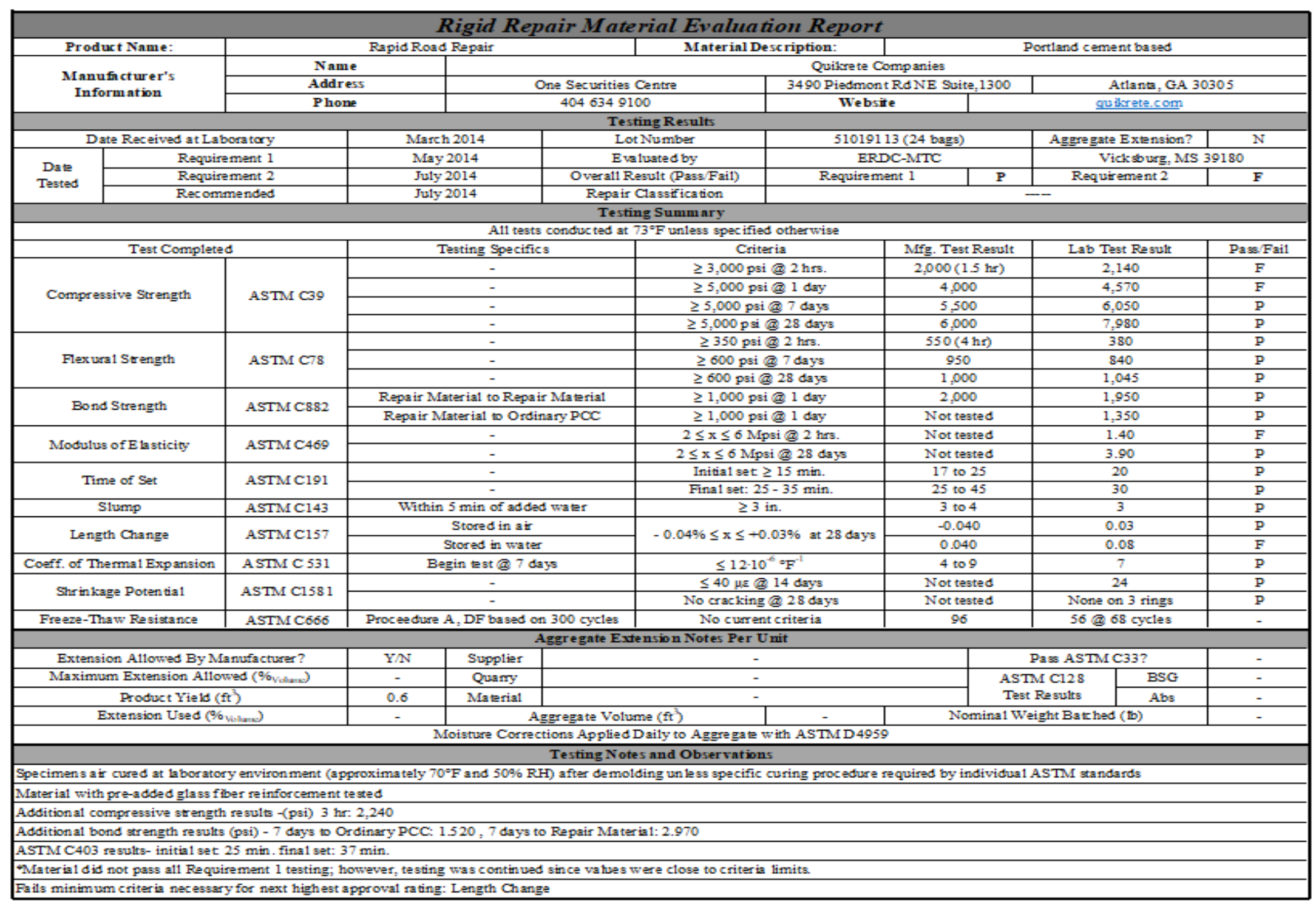




\section{A.3 FY15 Rigid-Repair Material Evaluation Reports}

See Tables A12 through A17. 
Table A12. HD 50.

\begin{tabular}{|c|c|c|c|c|c|c|c|c|c|}
\hline \multicolumn{10}{|c|}{ Rigid Repair Material Evaluation Report } \\
\hline \multirow{4}{*}{$\begin{array}{l}\text { Product Name: } \\
\text { Manufacturer's } \\
\text { Information }\end{array}$} & \multicolumn{4}{|c|}{$\mathrm{HD} 50$} & \multicolumn{2}{|c|}{ Material Description: } & \multicolumn{3}{|c|}{ Portland cement, latex modified, fiber reinforced } \\
\hline & & \multicolumn{7}{|c|}{ Dayton Superior Corp. } \\
\hline & \multirow{2}{*}{\multicolumn{2}{|c|}{$\begin{array}{l}\text { Address } \\
\text { Phone }\end{array}$}} & \multicolumn{3}{|c|}{1125 Byers Road } & \multicolumn{2}{|c|}{ Miamisburg, OH 45342} & \multirow{2}{*}{\multicolumn{2}{|c|}{ www.daytonsuperior.com }} \\
\hline & & & \multicolumn{3}{|c|}{8889779600} & \multicolumn{2}{|c|}{ Websiite } & & \\
\hline \multicolumn{2}{|c|}{ Date Received at Laboratory } & \multirow{2}{*}{\multicolumn{2}{|c|}{$\begin{array}{l}\text { January } 2014 \\
\text { March } 2015\end{array}$}} & \multicolumn{2}{|c|}{ Lot Number } & \multicolumn{2}{|c|}{ A4082005B } & Aggre gate Extension? & $\mathrm{Y}$ \\
\hline \multirow{2}{*}{\multicolumn{2}{|c|}{$\begin{array}{l}\text { Requirement } 1 \\
\text { Requirement } 2\end{array}$}} & & & & luated by & & ERDC & C-MTC & \\
\hline & & & & Overall & sult (Pass/Fail) & Requirem & ent 1 & Requirement 2 & FY16 \\
\hline Recom & mended & & & Repai & Classification & & & & \\
\hline & & & & Tes & Ig Summary & & & & \\
\hline & & & A11 test: & conducted a & $3^{\circ} \mathrm{F}$ unless speci & serwise & & & \\
\hline Test Complete & & & sting Specific & & & & Mfg. Test Result & Lab Test Result & Pase/Fail \\
\hline & & & - & & $\geq 3,000$ & 2 hrs. & $2000(\mathrm{C} 109 @ 1 \mathrm{hr})$ & 4,080 & P \\
\hline Compressive Strength & ASTM C39 & & - & & $\geq 5,000$ & 1 day & 6145 (C109) & 4,700 & F \\
\hline & & & - & & $\geq 5,000$ & days & $7000(\mathrm{C} 109)$ & 6,370 & P \\
\hline & & & - & & $\geq 5,000 \mathrm{p}$ & 8 days & 7990 (C109) & 6,980 & P \\
\hline & & & - & & $\geq 350 \mathrm{~g}$ & hrs. & Not tested & 625 & $\mathrm{P}$ \\
\hline Flexura1 Strength & ASTM C78 & & - & & $\geq 600 \mathrm{p}$ & days & Not tested & 710 & $\mathrm{P}$ \\
\hline & & & - & & $\geq 600 \mathrm{ps}$ & days & Not tested & 770 & $\mathbf{P}$ \\
\hline Bond Strength & ASTMMC882 & Repair & rial to Repa & Material & $\geq 1,000$ & 1 day & 2,000 & 1,820 & P \\
\hline Dofic sterignt & ASTMC8R2 & Repai: & terial to Ordi & $\operatorname{ary} \mathrm{PCC}$ & $\geq 1,000$ & 1 day & Not tested & 1,550 & $\mathrm{P}$ \\
\hline MOCULUS of Elasticity & ASTML +09 & & - & & $2 \leq x \leq 61$ & & Not tested & 4.70 & $\mathrm{P}$ \\
\hline Time of Ser & ASTMCC101 & & - & & Initia1 $\mathrm{se}$ & $\min$. & $15-20$ & 24 & $\mathrm{P}$ \\
\hline litive of set & ASTMCIFI & & - & & Final set: & $5 \mathrm{~min}$. & $25-30$ & 27 & $\mathrm{P}$ \\
\hline Slump & ASTM C143 & wit & $\min$ of $\operatorname{add}=$ & water & & & Not tested & 11 & $\mathrm{P}$ \\
\hline Length Change & ASTMC157 & & Stored in air & & $-0.04 \% \leq x \leq$ & $\%$ at 28 days & -0.11 & - & - \\
\hline & & & cored in wate & & $-0.0+70=\alpha=$ & 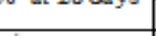 & 0.06 & - & - \\
\hline Coeff. of Therma1 Expansion & ASTM C 531 & & in est @ $7 \mathrm{~d}$ & & $\leq 12$ & & Not tested & - & - \\
\hline Shrinkage Potentia1 & ASTM C1581 & & - & & $\leq 40 \mu s$ & days & Not tested & - & - \\
\hline Shr tikage porendate & AOSTM CISO & & - & & No cracki & 28 days & Not tested & - & - \\
\hline Freeze-Thaw Resistance & ASTM C 666 & Proceedr & DF based o & 300 cycles & No cur & iteria & No Mass Loss & - & - \\
\hline & & & & ggre gate Es & nsion Notes Pe & & & & \\
\hline Extension Allowed By M & nufacturer? & $Y$ & Supplier & & Green & & & Pass ASTM C33? & $\mathrm{Y}$ \\
\hline Maximum Extension Allo & $\operatorname{led}(\%$ valumen $)$ & 60 & Quary & & Crysta & & AST & $\mathrm{MCl} 28$ & 2.51 \\
\hline Product Yield ( & & 0.42 & Material & & Pea & & Test & Results & $2.9 \%$ \\
\hline Extension Used ( $9 \%$ & (henta) & 50 & & gregate Vol & ne $\left(\mathrm{ft}^{3}\right)$ & 0.20 & Nomina1 We & ight Batched (tb) & 31.61 \\
\hline & & & isture Corre & tions Appliec & aily to Aggre ga & ASTM D 4959 & & & \\
\hline & & & & Testing No & s and Observat & & & & \\
\hline pecimens a ir cured at la borato & yenvironment (af & ximately & Fand $50 \% \mathrm{R}$ & 1) after demo & fing un less speci: & procedure & luired by individual. & ASTM standards & \\
\hline Additional compressive stengt? & results $(p s i)-3 \mathrm{~h}$ & 4,200 & & & & & & & \\
\hline Addition al bond strength results & $(p s i)-7$ days to 0 & tinary PCC & $90 \mathrm{psi} 7 \mathrm{da}$ & to Repair $\mathrm{M}$ & Eria1: $2,960 \mathrm{psi}$ & & & & \\
\hline ASTM C403 results- initial set & $23 \mathrm{~min}$. final set: & $\min$. & & & & & & & \\
\hline
\end{tabular}


Table A13. Pavemend 15.0

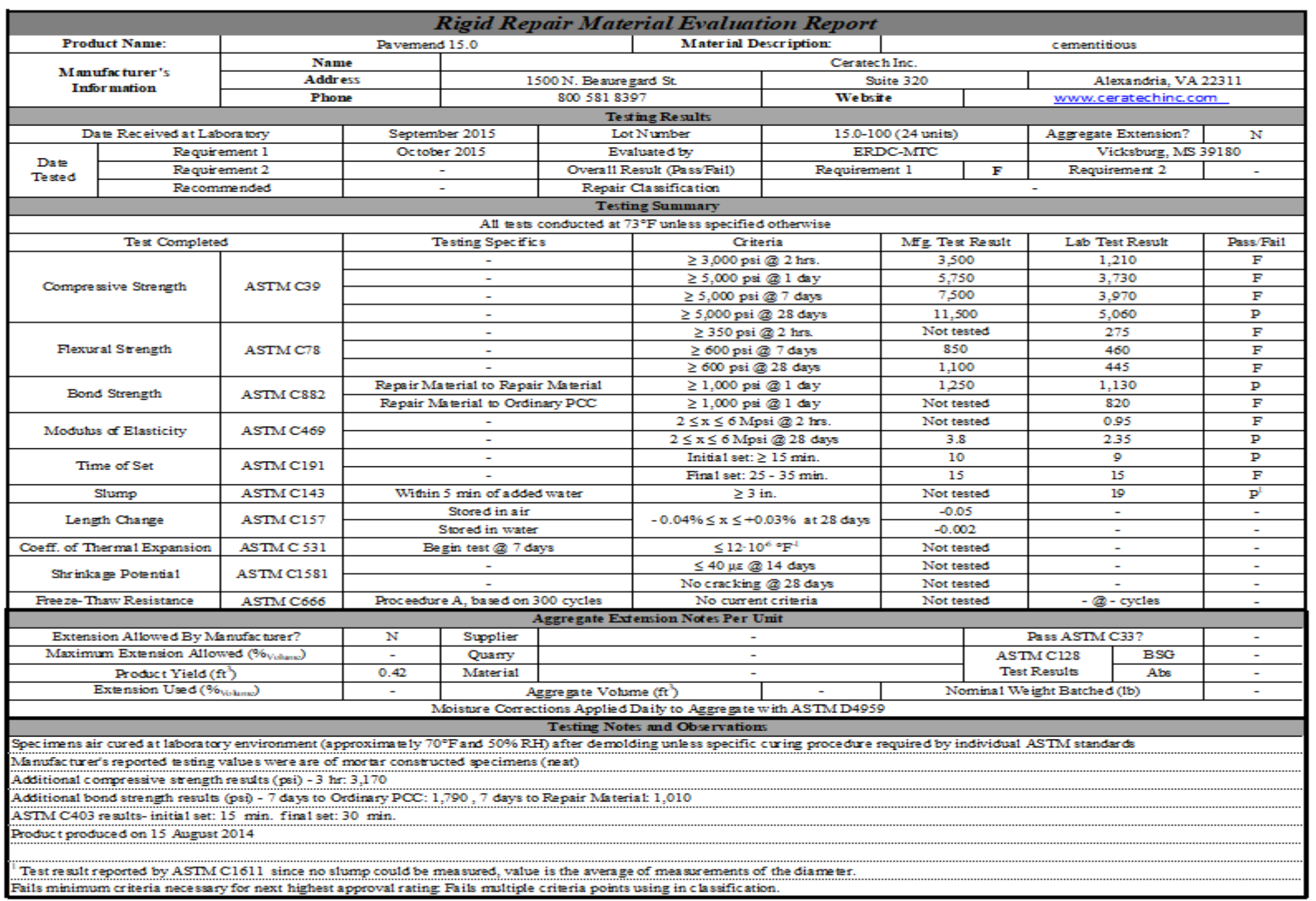


Table A14. Rapid Set Mortar Mix.

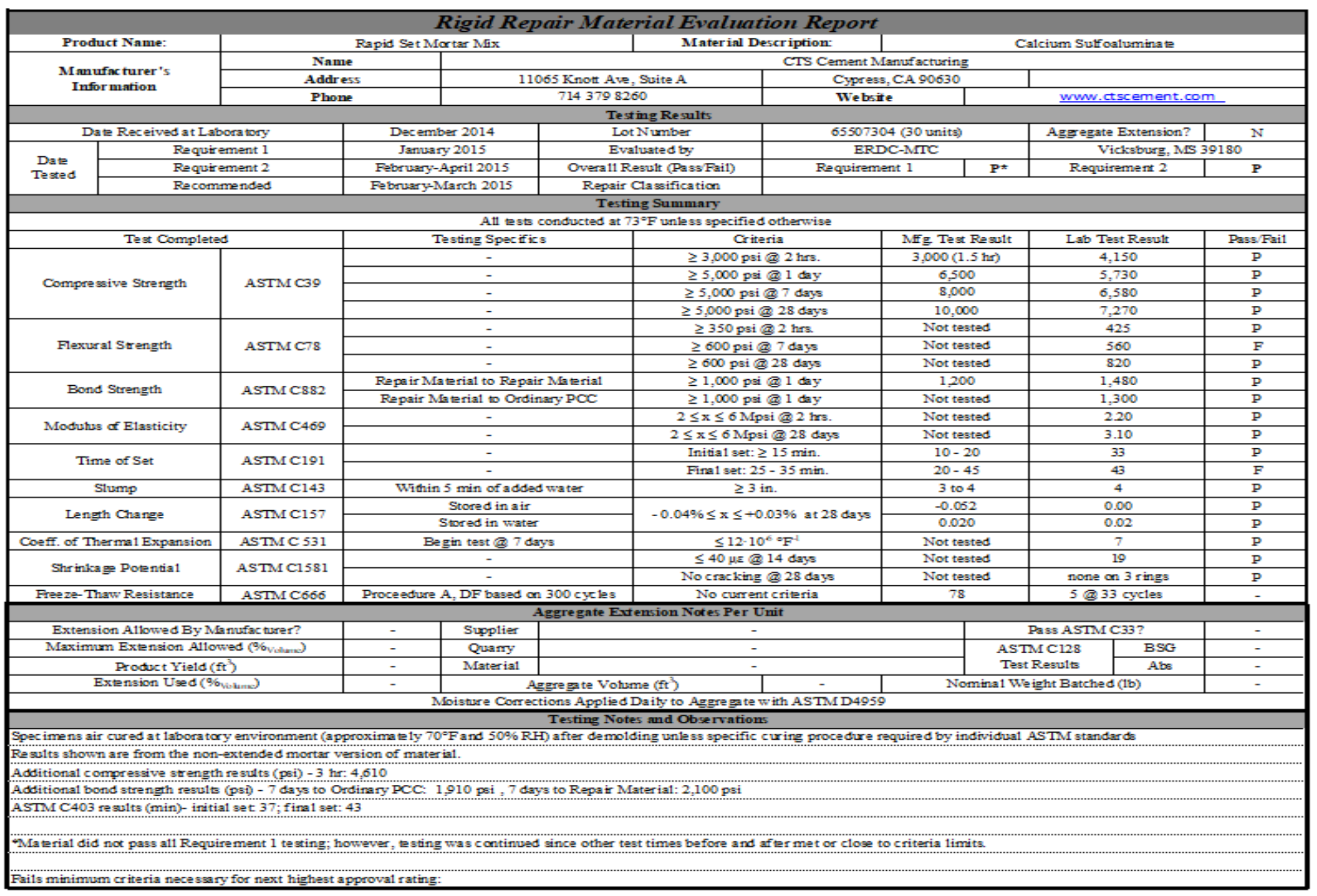


Table A15. Prospec Premium Patch 100.

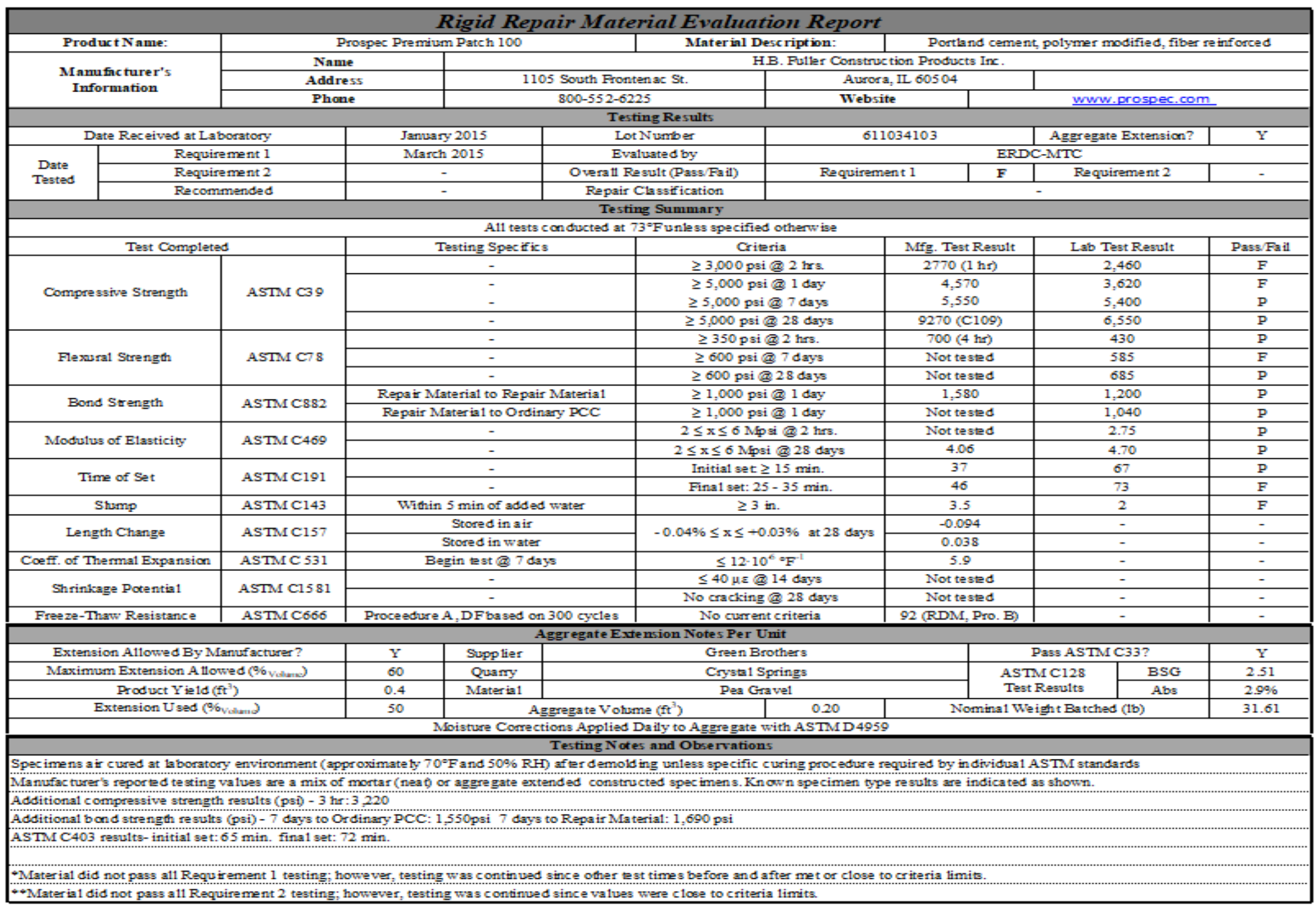


Table A16. Prospec Premium Patch 200.

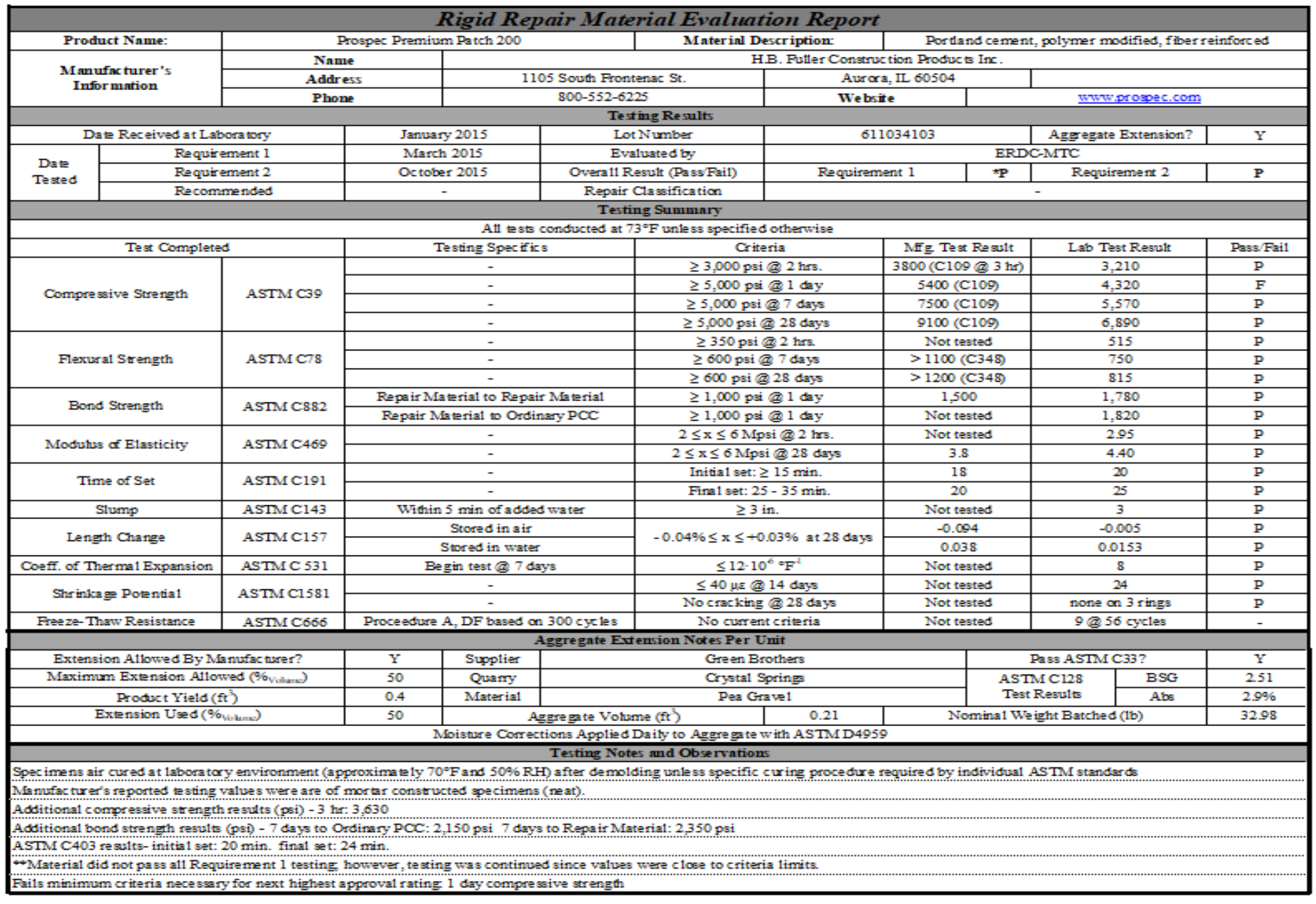


Table A17. Magna-Crete.

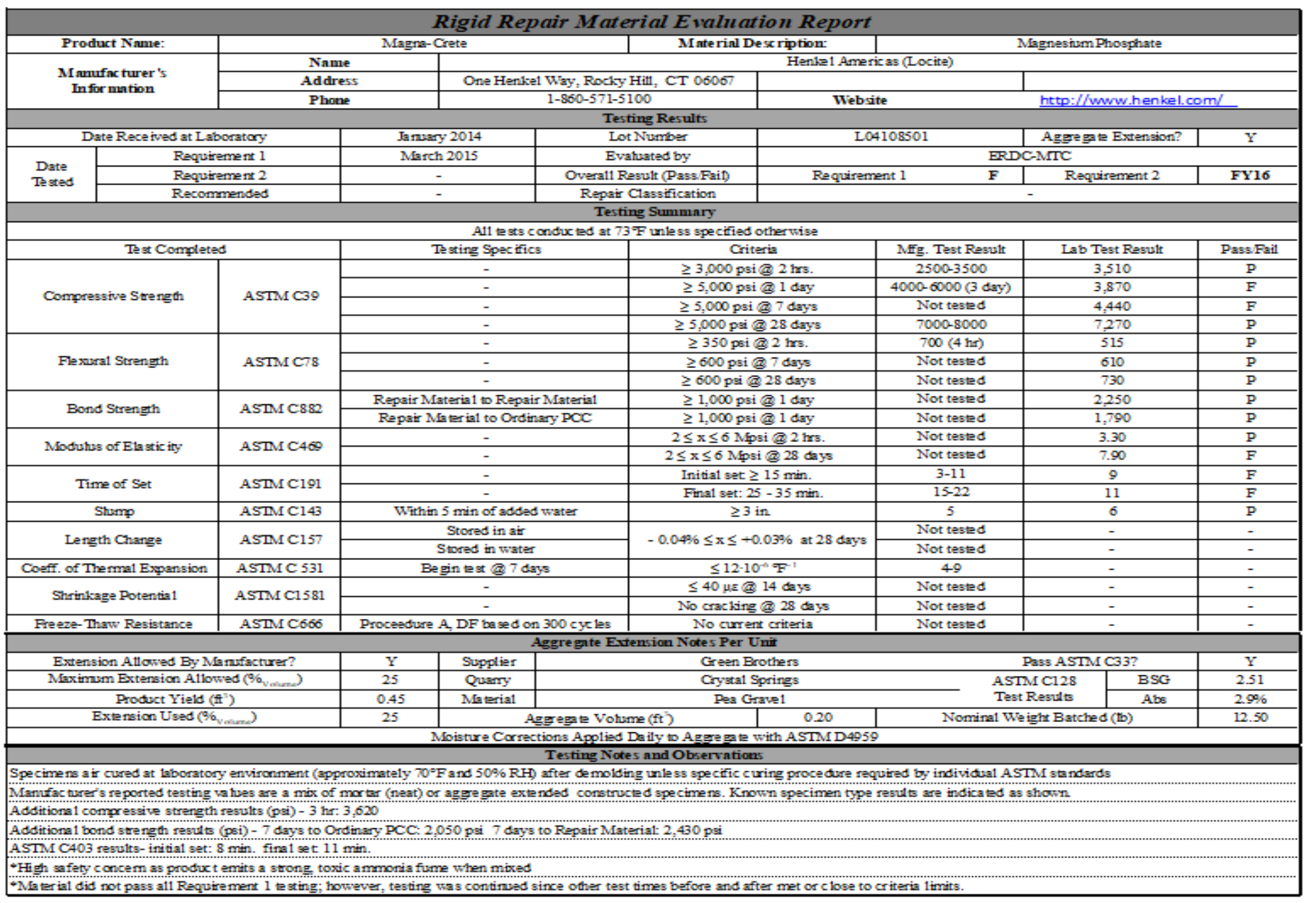




\section{A.4 FY16 Rigid-Repair Material Evaluation Reports}

See Tables A18 through A22. 
Table A18. Elephant Armor DOT.

Rigid Repair Material Evaluation Report

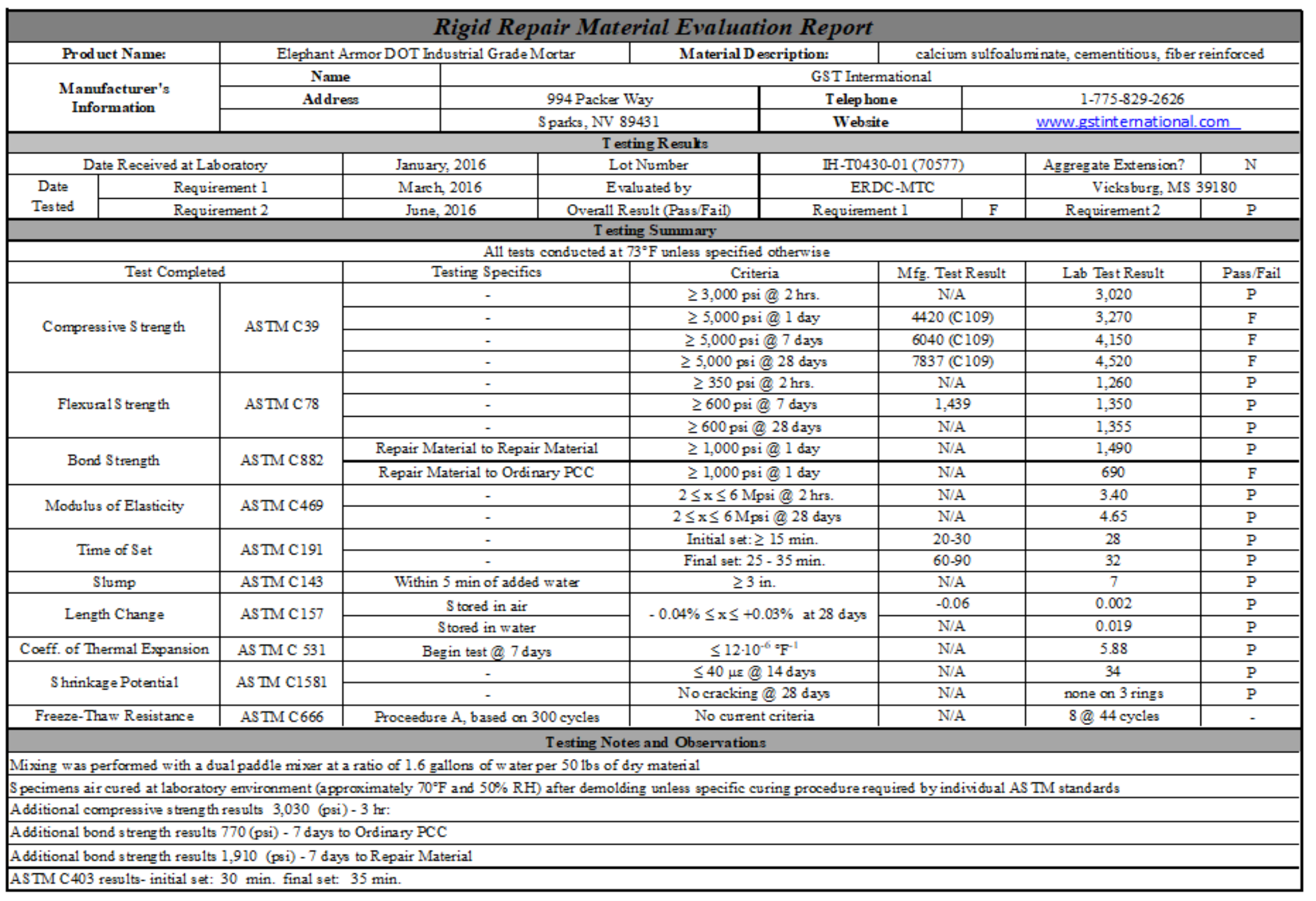


Table A19. Phoscrete HC.

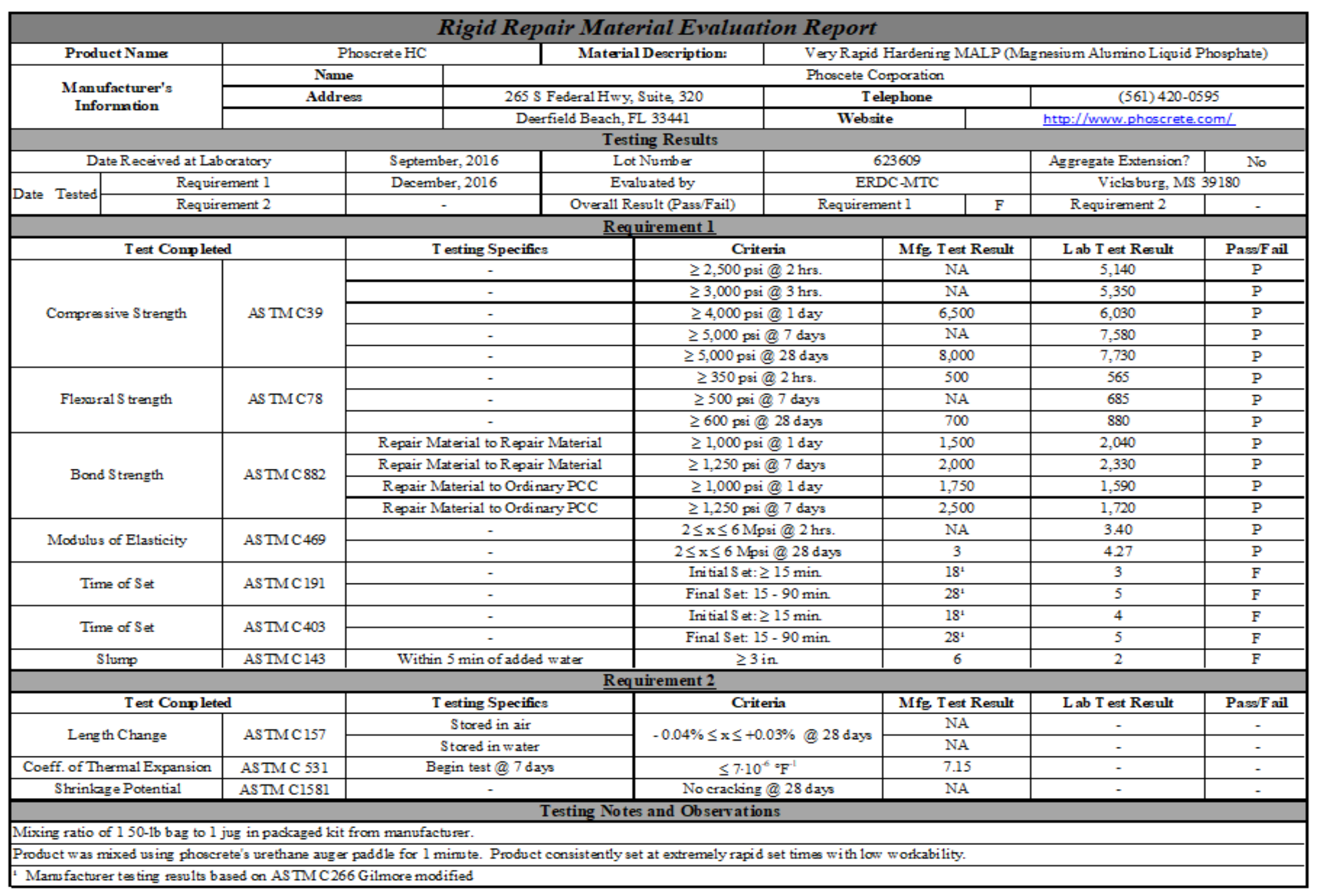


Table A20. FasTrac 246 Concrete.

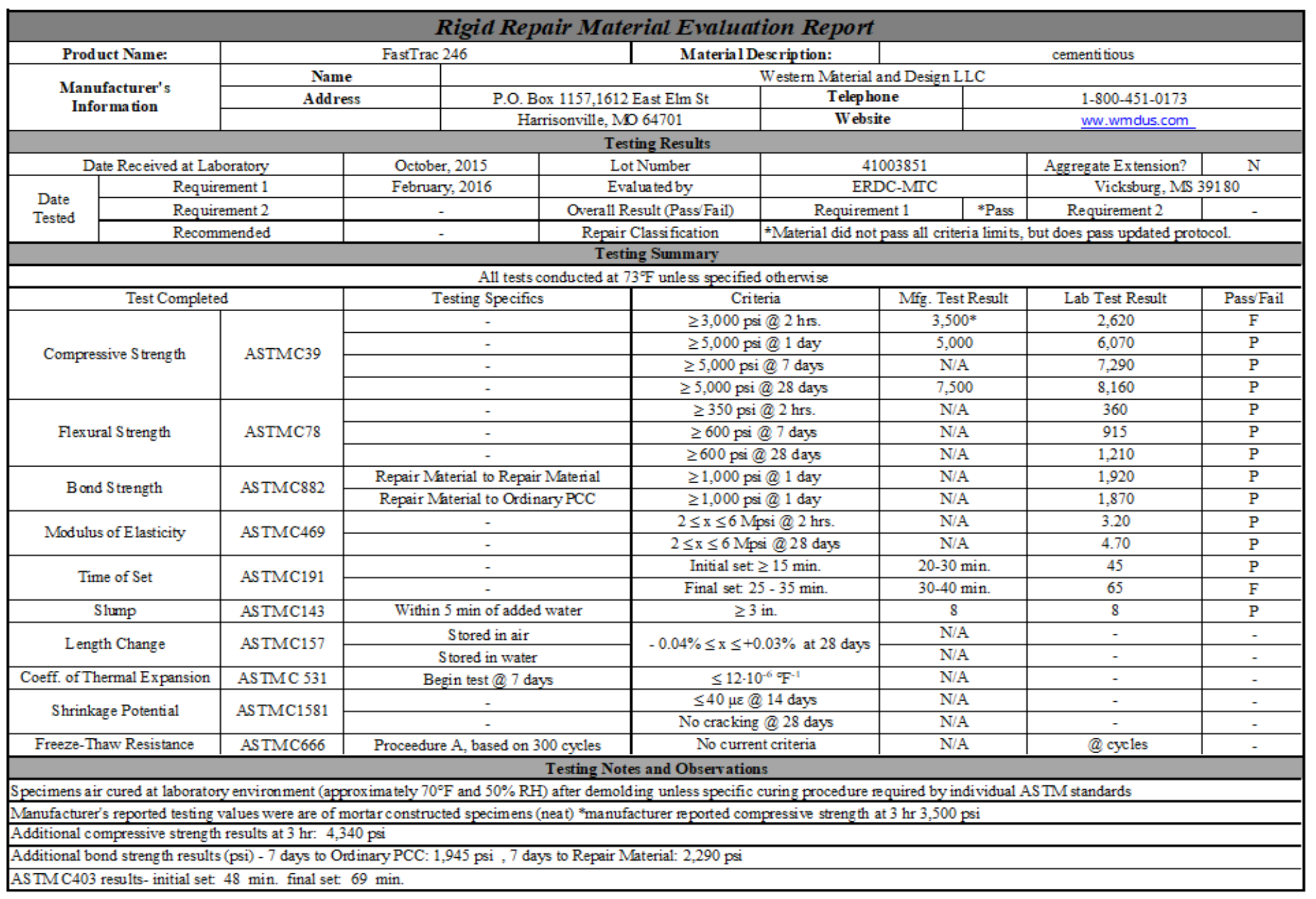


Table A21. Magna-Crete.

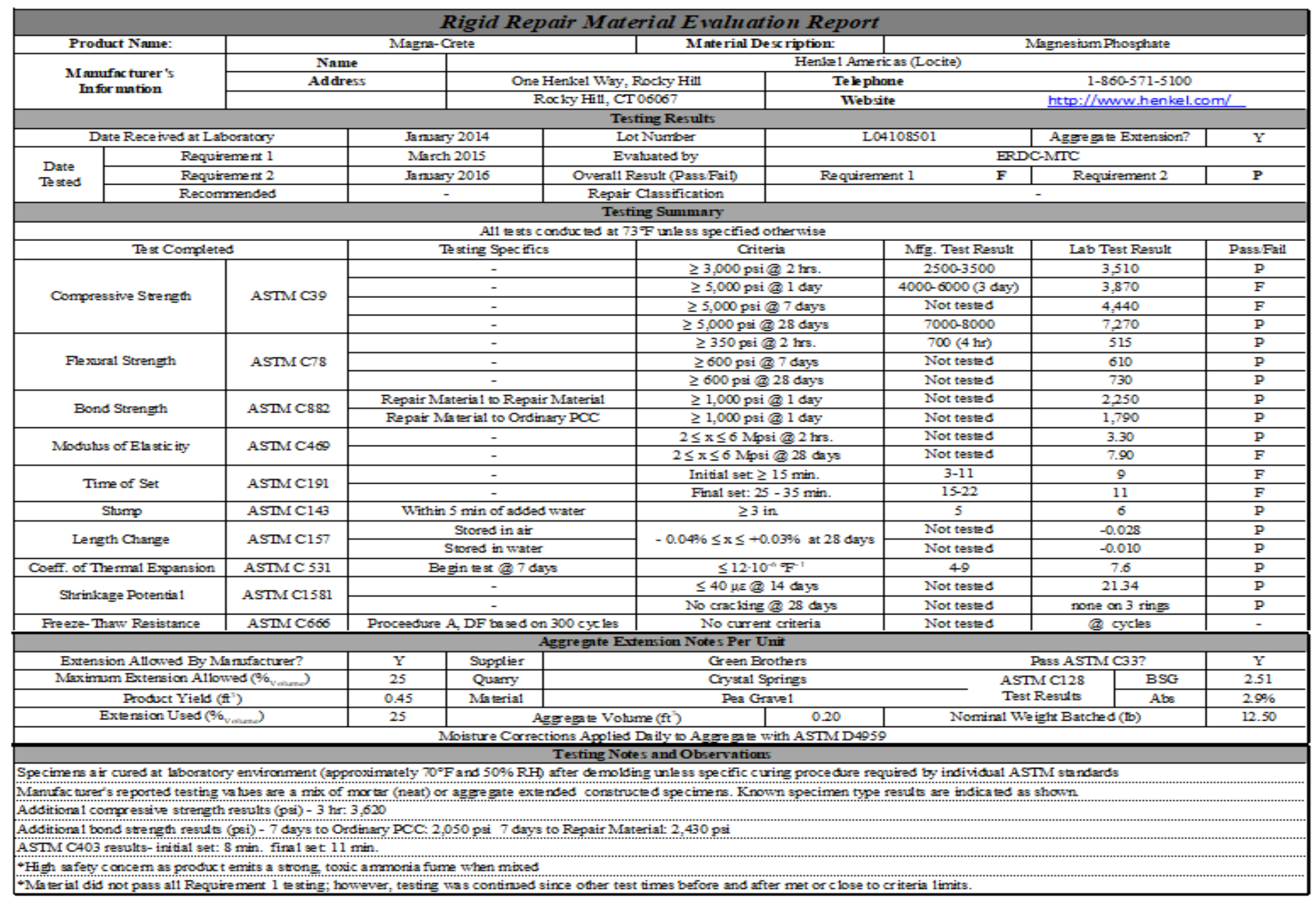


Table A22. HD 50.

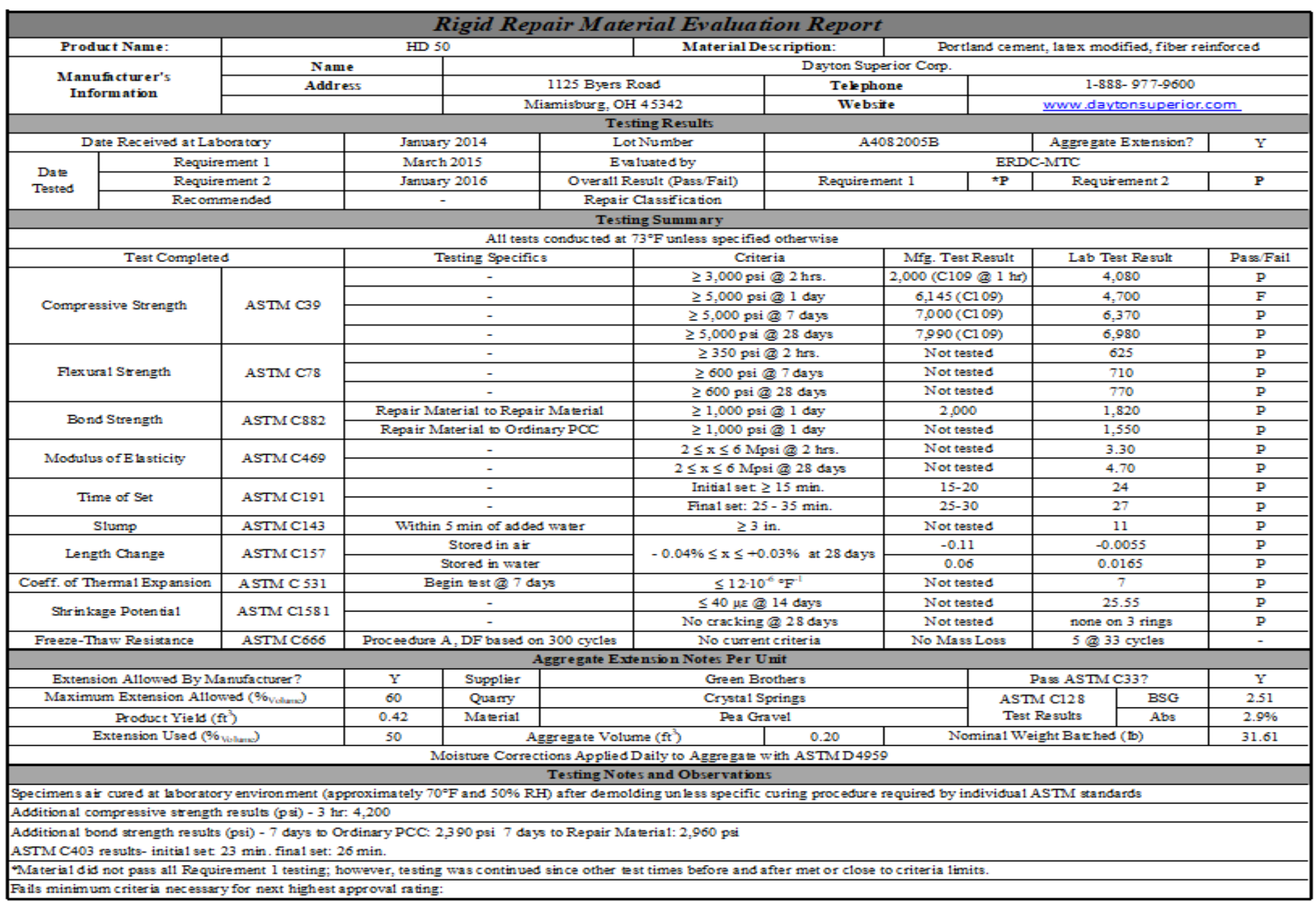




\section{A.5 FY17 Rigid-Repair Material Evaluation Reports}

See Tables A23 through A28. 
Table A23. Rapid Set DOT Repair Mix.

\section{Rigid Repair Material Evaluation Report}

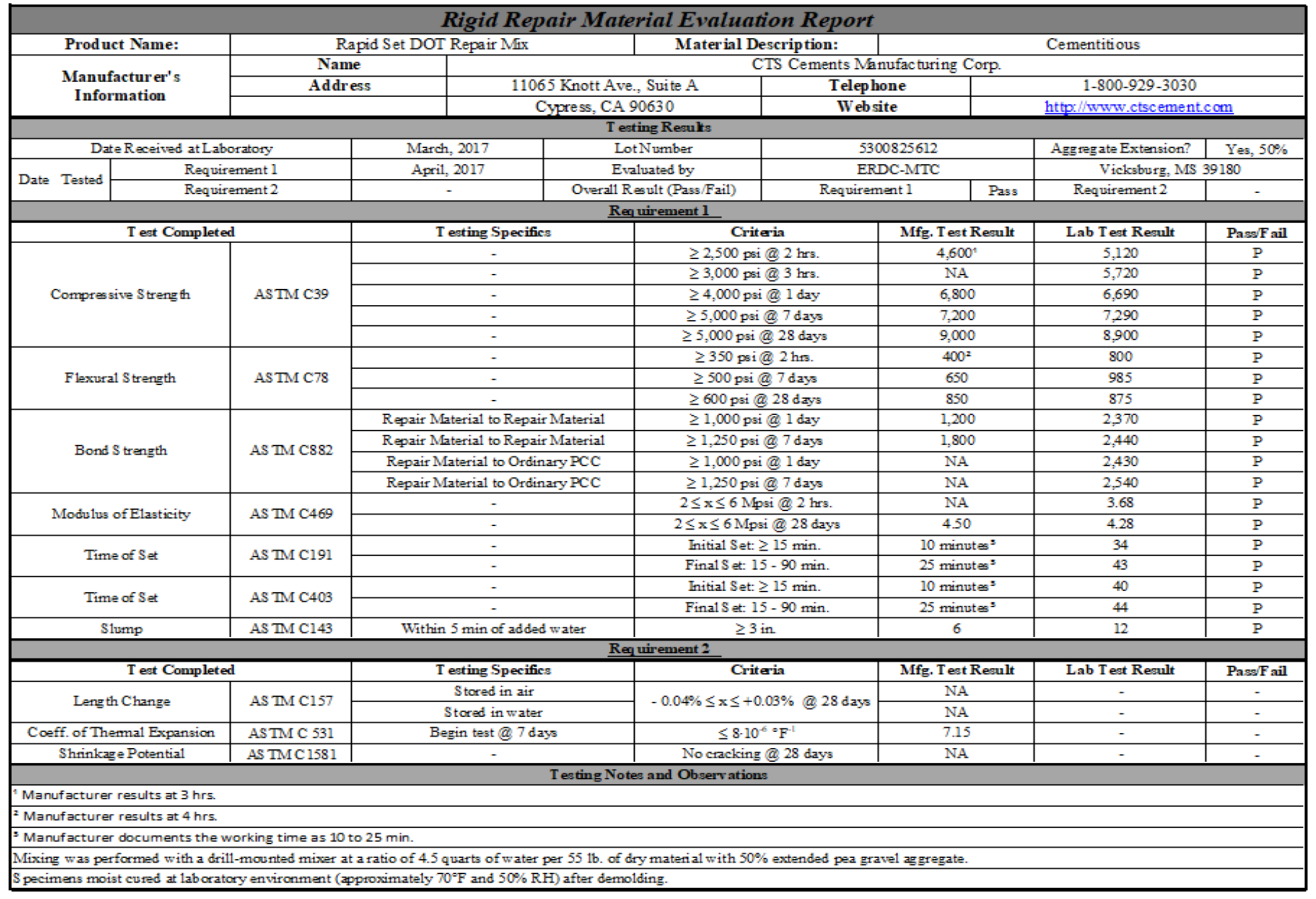


Table A24. Pavemend TR.

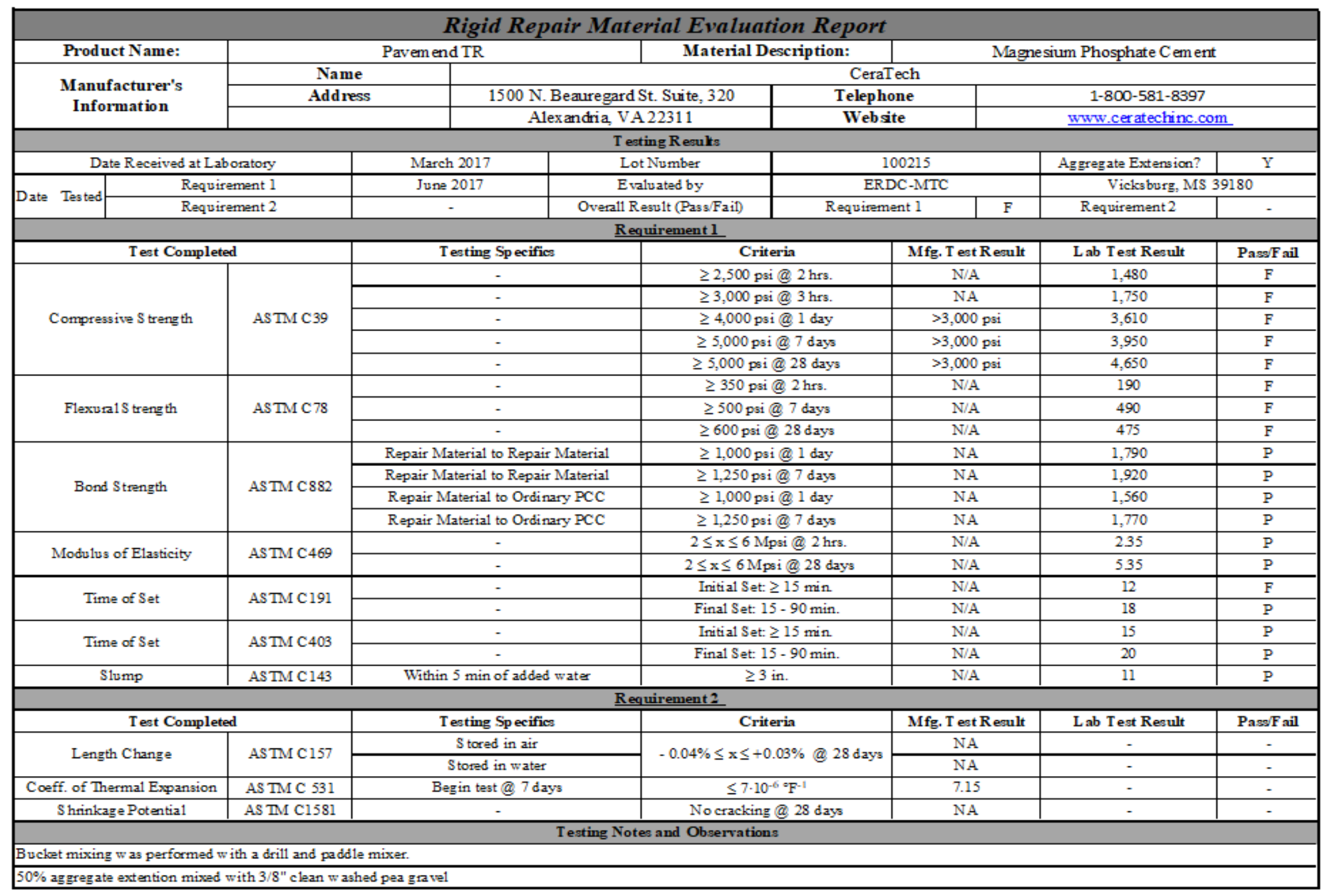


Table A25. T545 (Formerly Set 45).

Rigid Repair Material Evaluation Report

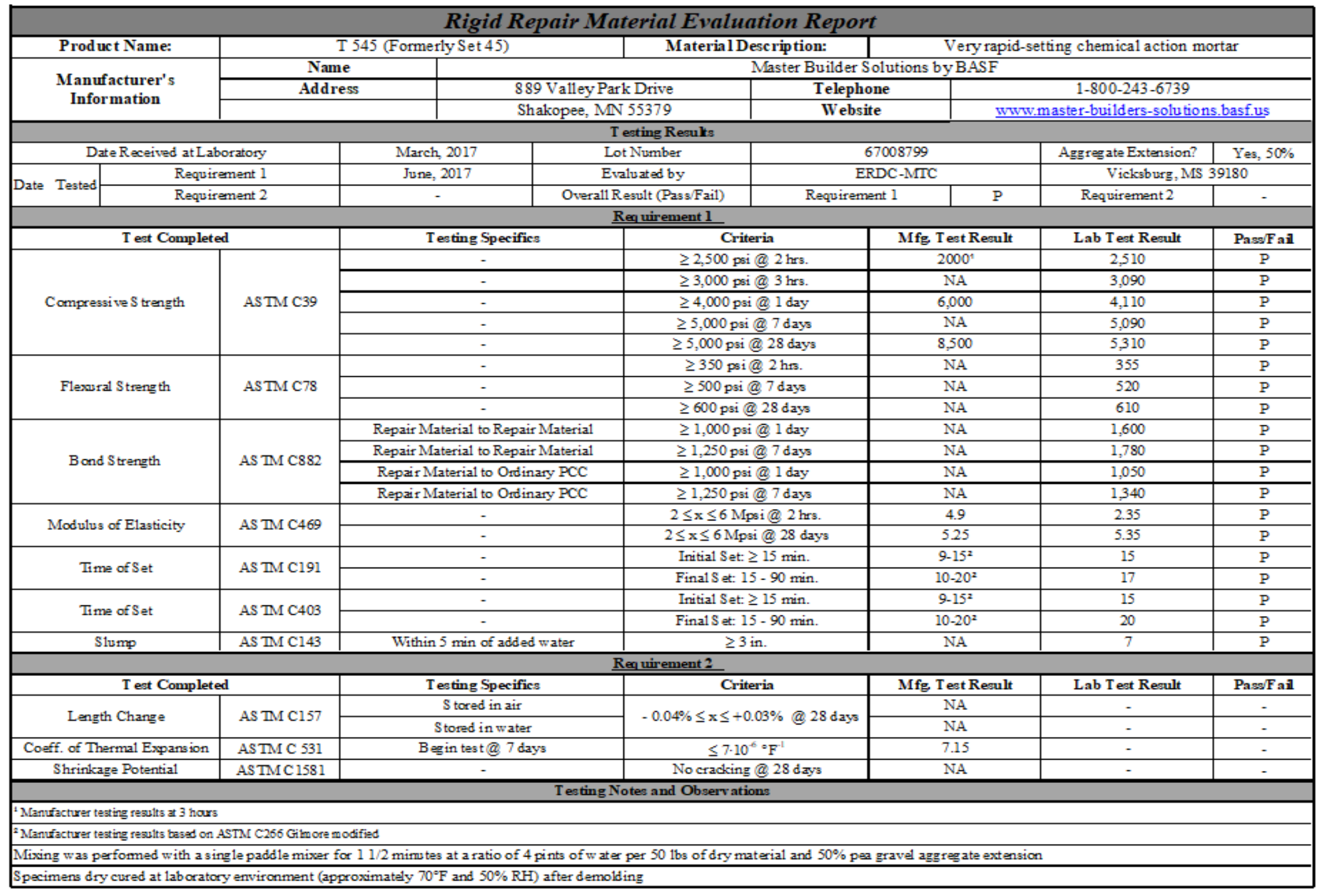


Table A26. T545T (Formerly Set 45HT).

Rigid Repair Material Evaluation Report

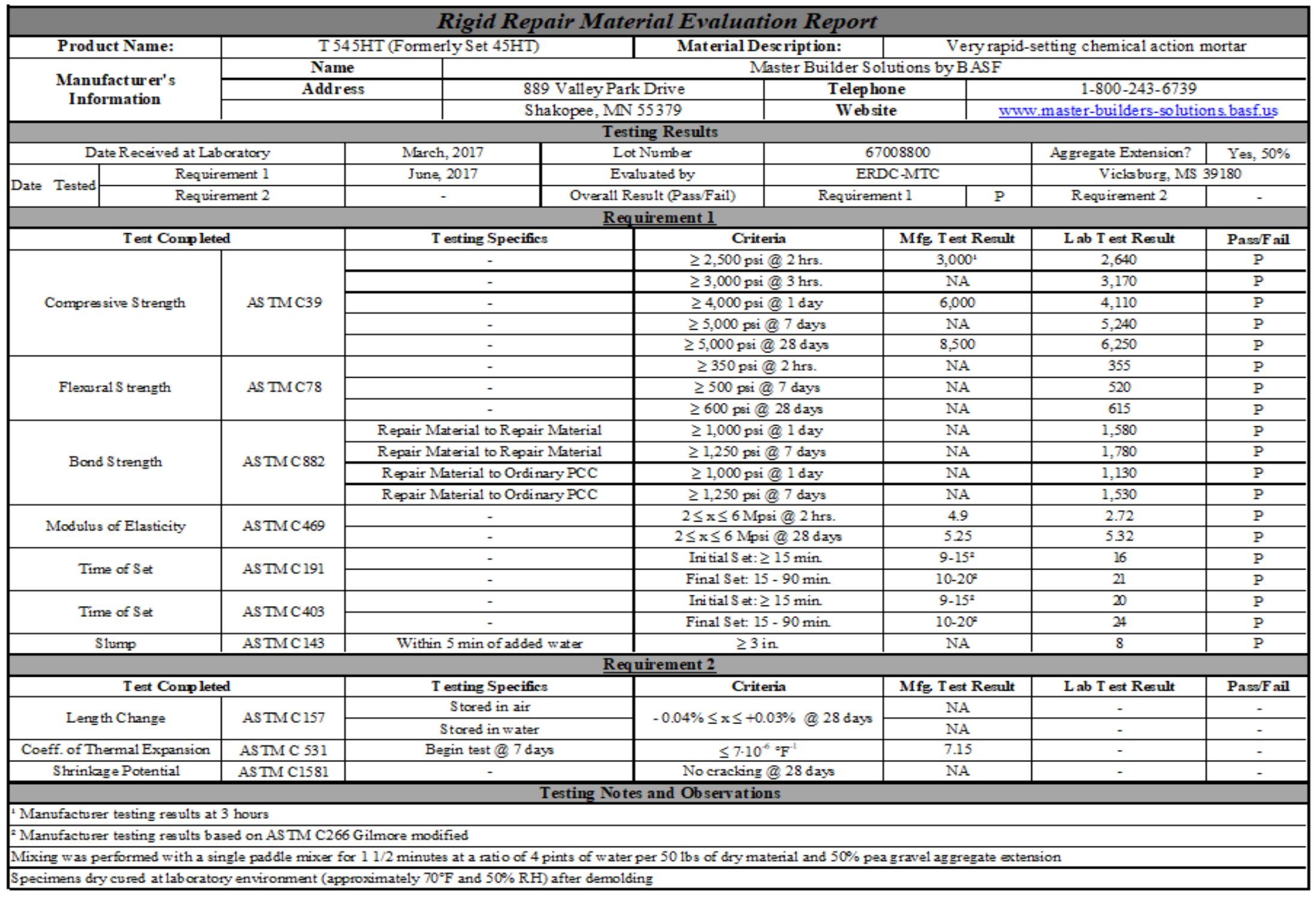

Specimens dry cured at laboratory environment (approximately $70^{\circ} \mathrm{F}$ and $50 \% \mathrm{RH}$ ) after demolding 
Table A27. Rapid Set Concrete Mix.

\section{Rigid Repair Material Evaluation Report}

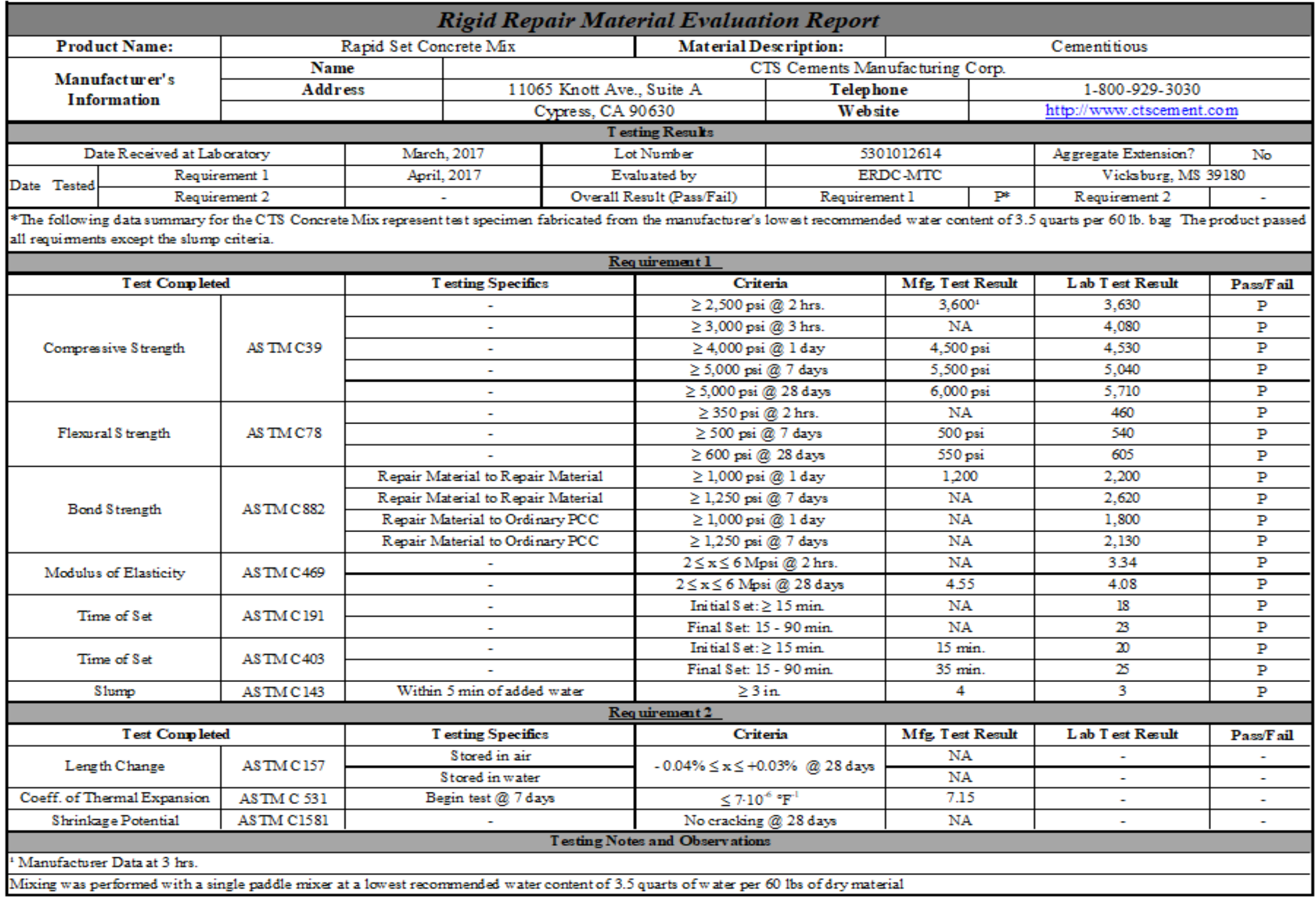

Whing was performed with a single padde nuxe at a lowestreconded water content of 3.5 quart of 
Table A28. T1061 (Formerly 10-61 Rapid Mix).

Rigid Repair Material Evaluation Report

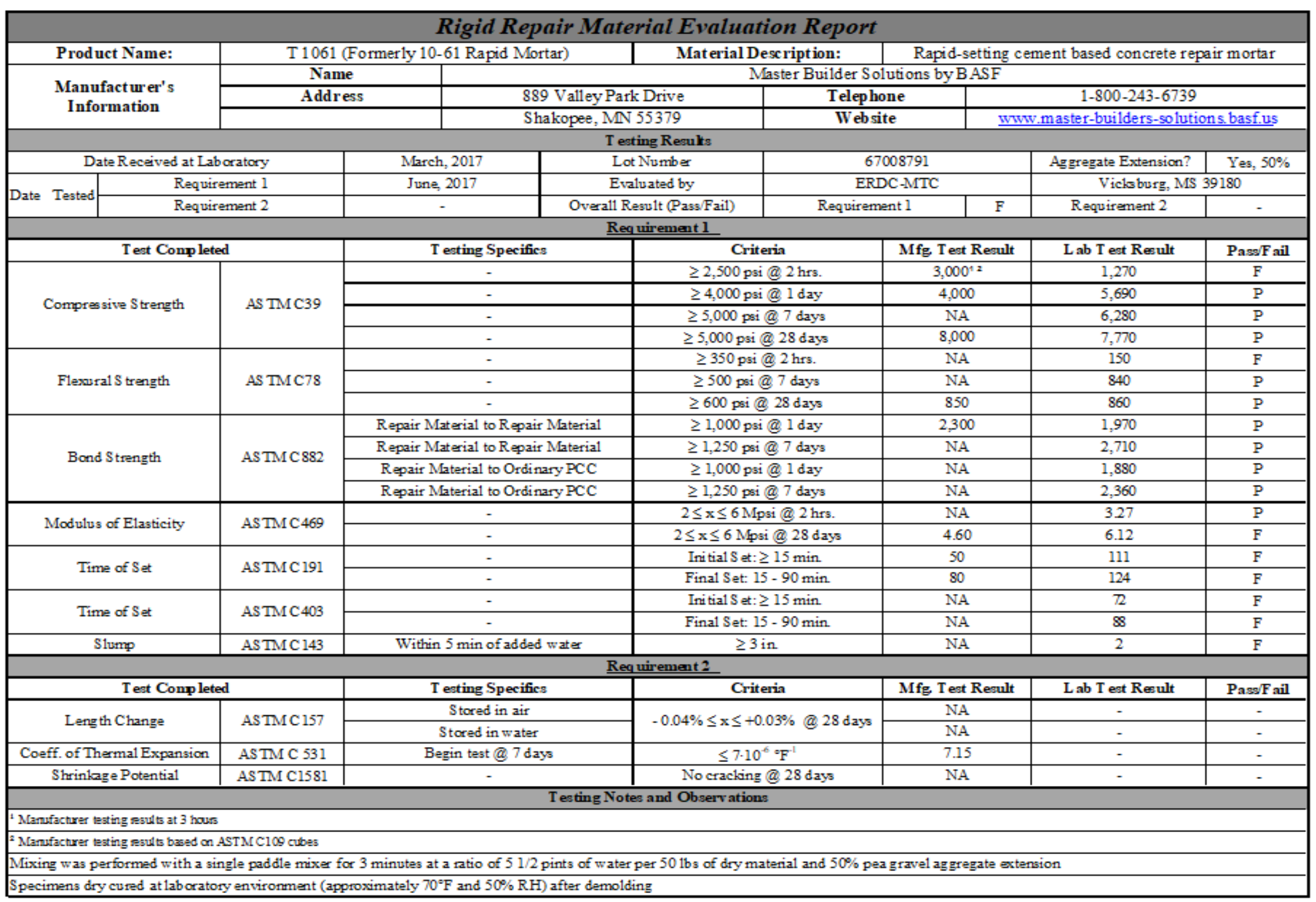




\section{Unit Conversion Factors}

\begin{tabular}{|c|c|c|}
\hline Multiply & By & To Obtain \\
\hline cubic feet & 0.02831685 & cubic meters \\
\hline cubic inches & $1.6387064 \mathrm{E}-05$ & cubic meters \\
\hline cubic yards & 0.7645549 & cubic meters \\
\hline degrees Fahrenheit & $(F-32) / 1.8$ & degrees Celsius \\
\hline feet & 0.3048 & meters \\
\hline gallons (U.S. liquid) & 3.785412 E-03 & cubic meters \\
\hline inches & 0.0254 & meters \\
\hline ounces (mass) & 0.02834952 & kilograms \\
\hline ounces (U.S. fluid) & $2.957353 \mathrm{E}-05$ & cubic meters \\
\hline pints (U.S. liquid) & 4.73176 E-04 & cubic meters \\
\hline pints (U.S. liquid) & 0.473176 & liters \\
\hline pounds (force) & 4.448222 & newtons \\
\hline pounds (force) per foot & 14.59390 & newtons per meter \\
\hline pounds (force) per inch & 175.1268 & newtons per meter \\
\hline pounds (force) per square foot & 47.88026 & pascals \\
\hline pounds (force) per square inch & 6.894757 & kilopascals \\
\hline pounds (mass) & 0.45359237 & kilograms \\
\hline pounds (mass) per cubic foot & 16.01846 & kilograms per cubic meter \\
\hline pounds (mass) per cubic inch & $2.757990 \mathrm{E}+04$ & kilograms per cubic meter \\
\hline pounds (mass) per square foot & 4.882428 & kilograms per square meter \\
\hline pounds (mass) per square yard & 0.542492 & kilograms per square meter \\
\hline quarts (U.S. liquid) & $9.463529 \mathrm{E}-04$ & cubic meters \\
\hline square feet & 0.09290304 & square meters \\
\hline square inches & 6.4516 E-04 & square meters \\
\hline
\end{tabular}




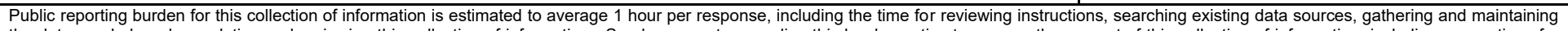

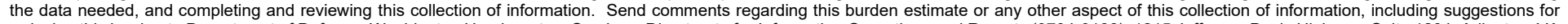

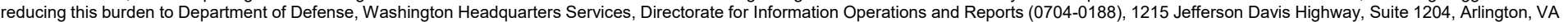

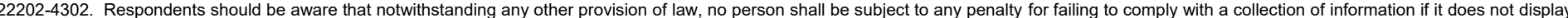
a currently valid OMB control number. PLEASE DO NOT RETURN YOUR FORM TO THE ABOVE ADDRESS.

\begin{tabular}{|l|l|}
\hline $\begin{array}{l}\text { 1. REPORT DATE (DD-MM-YYYY) } \\
\text { April } 2020\end{array}$ & $\begin{array}{l}\text { 2. REPORT TYPE } \\
\text { Final }\end{array}$ \\
\hline
\end{tabular}

\section{TITLE AND SUBTITLE}

Evaluation of Rapid-Setting Cementitious Materials and Testing Protocol for Airfield Spall Repair

3. DATES COVERED (From - To)

5a. CONTRACT NUMBER

5b. GRANT NUMBER

5c. PROGRAM ELEMENT NUMBER

6. AUTHOR(S)

5d. PROJECT NUMBER

Monica A. Ramsey, Jeb S. Tingle, and Dr. Craig A. Rutland

5e. TASK NUMBER

5f. WORK UNIT NUMBER

\section{PERFORMING ORGANIZATION NAME(S) AND ADDRESS(ES)}

Geotechnical and Structures Laboratory

U.S. Army Engineer Research and Development Center

3909 Halls Ferry Road

Vicksburg, MS 39180-6199

9. SPONSORING / MONITORING AGENCY NAME(S) AND ADDRESS(ES)

Headquarters, Air Force Civil Engineer Center

139 Barnes Avenue, Suite 1

Tyndall AFB, FL 32403-5319

\section{PERFORMING ORGANIZATION REPORT NUMBER}

ERDC/GSL TR-20-9

\section{DISTRIBUTION / AVAILABILITY STATEMENT}

Approved for public release; distribution is unlimited.

\section{SUPPLEMENTARY NOTES}

MIPR\# F4ATA46021JW02

\section{ABSTRACT}

The rapid-setting cementitious material certification program is part of a research effort to assist the U.S. Air Force Civil Engineering Center in the execution of independent testing on select commercially available proprietary products to repair partial-depth spalls in airfield concrete pavements. The purpose of this research was to determine whether the existing requirements for evaluating rapid-repair products for spall repairs were sufficient or further refinement and modifications were needed. This protocol is intended to aid airfield managers and repair teams in the selection of optimal spall repair materials by maintaining a database of approved tested products.

This report presents the test methods and results of 26 cementitious rapid-setting repair products tested at the U.S. Army Engineer Research and Development Center in Vicksburg, MS, during 2013 to 2017. An evaluation of these test methods and results, along with the historic database of products tested, led to the development of an updated testing protocol for assessing a material's suitability for airfield spall repairs. Based on the revised criteria, 10 products were identified as most compatible for partial-depth airfield pavement concrete spall repairs.

\begin{tabular}{|c|c|c|c|c|c|}
\hline \multicolumn{2}{|c|}{ 15. SUBJECT TERMS } & & Military bases \\
\hline \multicolumn{2}{|c|}{ Rapid-Setting Materials } & \multicolumn{3}{|c|}{ Testing Protocol-Concrete Pavements } & Cement composites-Testing \\
\hline \multicolumn{2}{|l|}{ Spall Repair } & \multicolumn{3}{|c|}{ Runways (Aeronautics)_-Maintenance and Repair } & Cement composites-Evaluation \\
\hline \multicolumn{3}{|c|}{ 16. SECURITY CLASSIFICATION OF: } & \multirow[t]{3}{*}{$\begin{array}{l}\text { 17. LIMITATION } \\
\text { OF ABSTRACT }\end{array}$} & $\begin{array}{l}\text { 18. NUMBER } \\
\text { OF PAGES }\end{array}$ & $\begin{array}{l}\text { 19a. NAME OF RESPONSIBLE } \\
\text { PERSON }\end{array}$ \\
\hline a. REPORT & b. ABSTRACT & c. THIS PAGE & & & 19b. TELEPHONE NUMBER (include \\
\hline & & & & 102 & \\
\hline
\end{tabular}

